\title{
Demand Response and Open Automated Demand Response Opportunities for Data Centers
}

\author{
Girish Ghatikar, Mary Ann Piette, Sydny Fujita, Aimee McKane, Junqiao Han Dudley, \\ and Anthony Radspieler \\ Lawrence Berkeley National Laboratory
}

\author{
K C Mares \\ Megawatt Consulting
}

Dave Shroyer

$S C G$

January 2010

\begin{abstract}
The work described in this report was coordinated by the Demand Response Research Center and funded by the California Energy Commission (Energy Commission), Public Interest Energy Research (PIER) Program, under Work for Others Contract No. 500-03-026, Pacific Gas and Electric Company (PG\&E) under Work for Others Contract No PGZ0803 and by the U.S. Department of Energy under Contract No. DE-AC02-05CH11231.
\end{abstract}




\section{Acknowledgements}

The work described in this report was coordinated by the Demand Response Research Center and funded by the California Energy Commission (Energy Commission), Public Interest Energy Research (PIER) Program, under Work for Others Contract No. 500-03026, Pacific Gas and Electric Company (PG\&E) under Work for Others Contract No PGZ0803 and by the U.S. Department of Energy under Contract No. DE-AC02$05 \mathrm{CH} 11231$.

The authors would like to thank Bill Tschudi for his data center energy-efficiency expertise and for assistance with this document and to thank Nan Wishner for her assistance in finalizing this document. The authors also want to acknowledge all others who assisted in review of this document, and for their ongoing support, including California Energy Commission Public Interest Energy Research (CEC/PIER) program's Ivin Rhyne, Chris Scruton, Anish Gautam, Paul Roggensack, and Mike Gravely, and Pacific Gas and Electric Company's (PG\&E) Albert Chiu.

\section{DISCLAIMER}

This document was prepared as an account of work sponsored by the United States Government. While this document is believed to contain correct information, neither the United States Government nor any agency thereof, nor The Regents of the University of California, nor any of their employees, makes any warranty, express or implied, or assumes any legal responsibility for the accuracy, completeness, or usefulness of any information, apparatus, product, or process disclosed, or represents that its use would not infringe privately owned rights. Reference herein to any specific commercial product, process, or service by its trade name, trademark, manufacturer, or otherwise, does not necessarily constitute or imply its endorsement, recommendation, or favoring by the United States Government or any agency thereof, or The Regents of the University of California. The views and opinions of authors expressed herein do not necessarily state or reflect those of the United States Government or any agency thereof or The Regents of the University of California.

Please cite this report as follows:

Ghatikar, Girish, M.A. Piette, S. Fujita, A. T. McKane, J.Q Han, A. Radspieler, K.C. Mares, D. Shroyer. 2010. Demand Response and Open Automated Demand Response Opportunities for Data Centers. California Energy Commission, PIER Program and Pacific Gas and Electric Company (PG\&E). 


\section{Table of Contents}

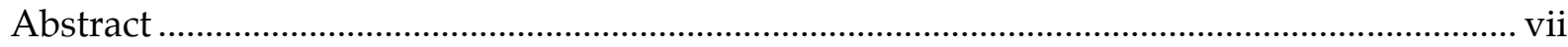

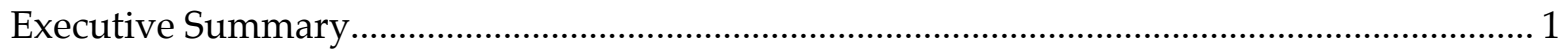

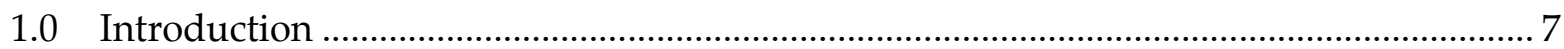

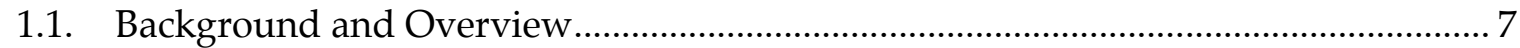

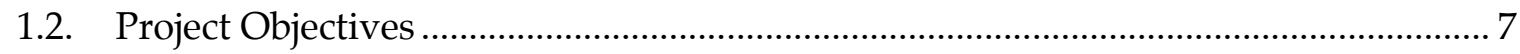

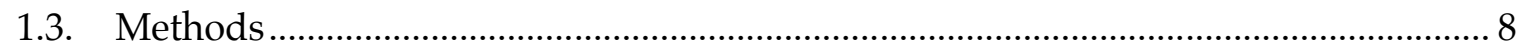

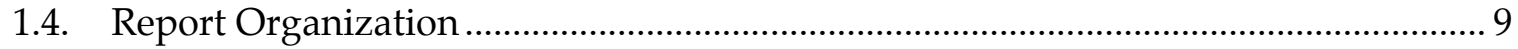

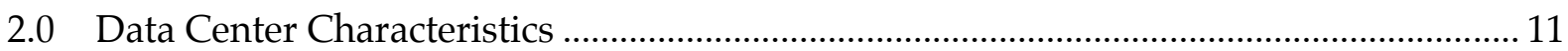

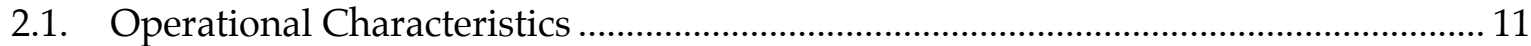

2.1.1. Current Guidelines and Standards .................................................................... 11

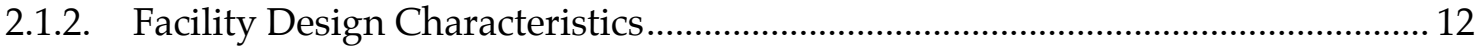

2.1.3. Energy-Use Profiles and Metrics ..................................................................... 14

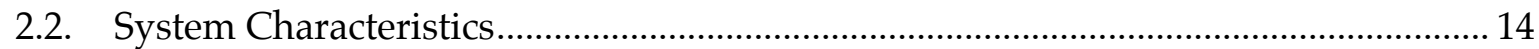

2.2.1. Servers, Storage, and Networking Devices...................................................... 14

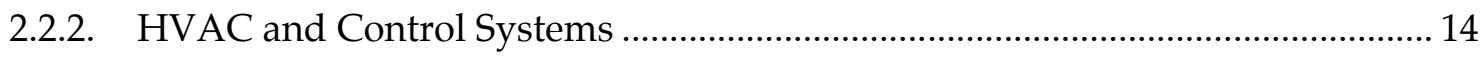

3.0 Energy Use and Load Characterization ......................................................................... 15

3.1. Data Center Energy Metrics ................................................................................. 16

3.1.1. Power Metrics for IT and Site Infrastructure ...................................................... 16

3.2. Data Center Energy Use and End Uses ............................................................. 17

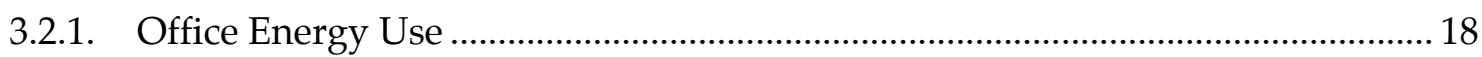

3.3. Data Center Load Characterization.......................................................................... 18

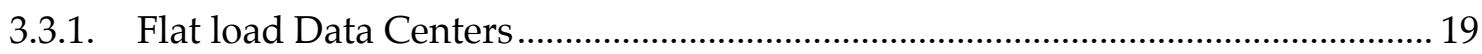

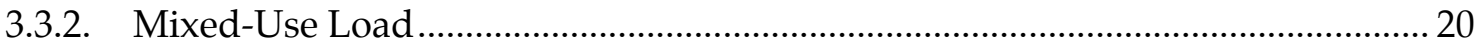

3.4. Summary of Data Center Load Characterization ....................................................... 21

3.5. Influences on Data Center Energy Use and Peak Demand ...................................... 21

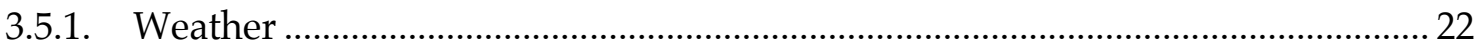

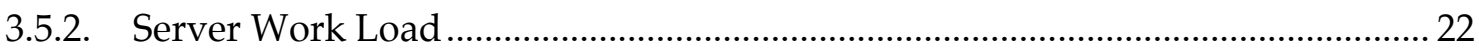

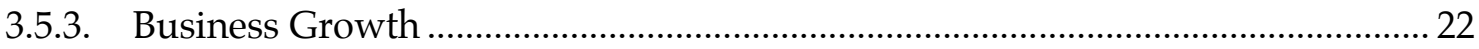

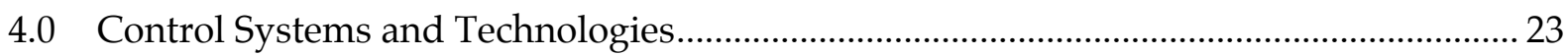

4.1. Efficiency Technology Implementation Scenarios ….................................................... 23

4.1.1. Improved Operation Scenario.............................................................................. 23

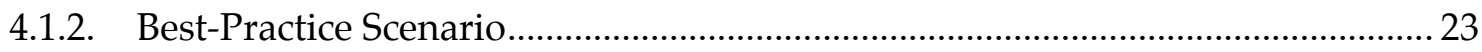

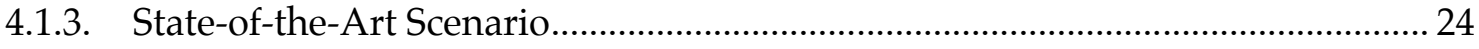

4.1.4. Potential Savings from Efficiency Measures....................................................... 24

4.2. Site Infrastructure Control System Technologies ......................................................... 24

4.2.1. Cooling, Power Delivery Systems, and Lighting Technologies.......................... 24

4.3. IT Infrastructure Virtualization Technologies ............................................................ 25

4.4. Synergy Between IT and Control Technologies ....................................................... 26 


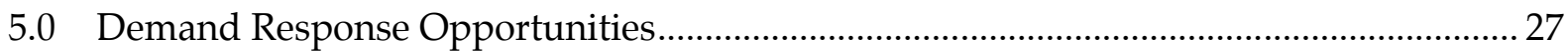

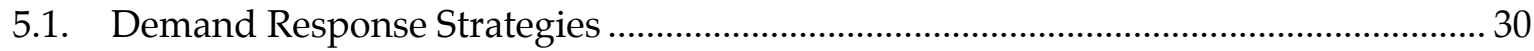

5.1.1. Demand Response Strategies for Site Infrastructure and Mixed Use ................. 30

5.1.2. Demand-Response Strategies for IT Infrastructure .......................................... 32

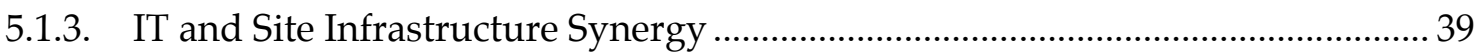

5.2. Challenges to Implementing Demand Response ...................................................... 39

5.2.1. Perceived Risk to Business and Operations ........................................................ 40

5.2.2. Performance Measurement and Verification........................................................ 41

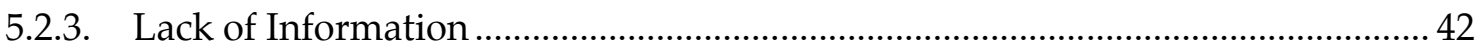

5.3. Summary of Demand Response Strategies .............................................................. 42

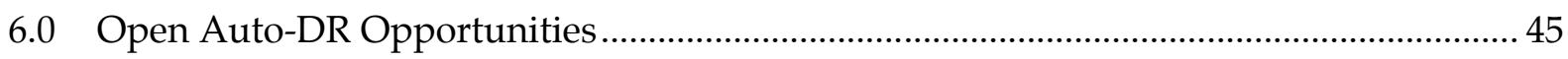

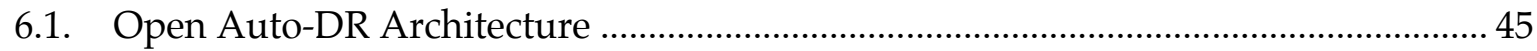

6.1.1. Open Auto-DR Integration with Control Systems............................................. 46

6.1.2. Open Auto-DR Integration with Virtualization Technologies.............................. 46

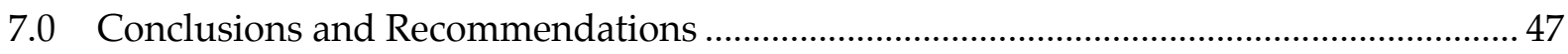

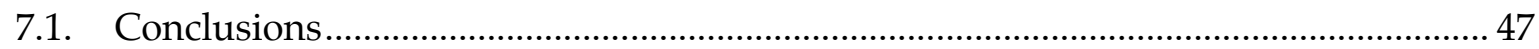

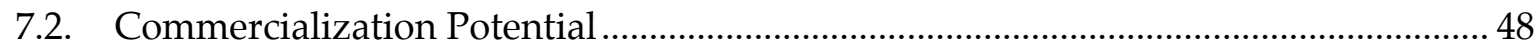

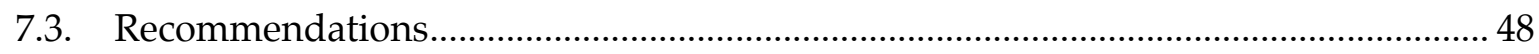

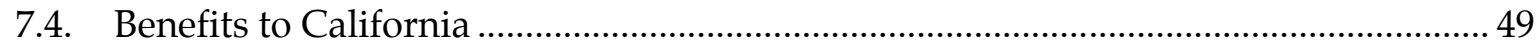

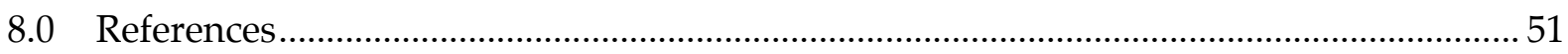

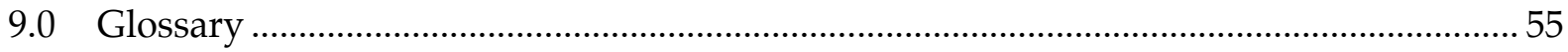

Appendix A. Recommendations and Guidelines, Data Center Classifications Appendix B. Data Center Components, Measurements, and Case Studies

Appendix C. EPA Energy Efficiency Scenarios and Data Center Designs and Technologies Appendix D. Analysis of DR Strategies Using Case Studies 


\section{List of Figures}

Figure 1. Typical Data Center Power Consumption and Distribution Architecture ........................ 15

Figure 2. Typical Data Center End-Use Energy Distribution: Cooling Energy End Uses ............... 17

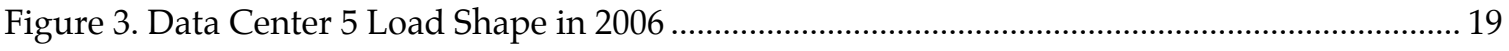

Figure 4. Data Center 5 Daily Load Shape in 2008 Summer and Winter ........................................... 20

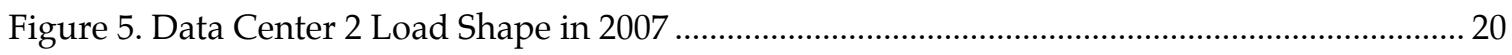

Figure 6. Data Center 2 Daily Load Shape in 2007 Summer and Winter ........................................... 21

Figure 7. Auto-DR Architecture Concept and Open Auto-DR Standards ........................................ 46

\section{List of Figures - Appendices}

Figure 8. ASHRAE 2008 Recommended Design Conditions at the Inlet to IT Equipment ..... APA-1

Figure 9. Typical Electrical Components in a Data Center and Office APB-1

Figure 10. PUE by Site Infrastructure End Uses in Relation to IT Equipment and Scenarios.. APB-2

Figure 11. Data Center 1 Load in 2008 APB-2

Figure 12. Data Center 1 Load on Summer and Winter Days 2008, with Standard Deviation APB-3

Figure 13. Some Variation in Data Center 1 Load during the week of August 3-9, 2008 .......... APB-3

Figure 14. Relatively Flat Data Center 1 Load on August 6, 2008 ............................................APB-4

Figure 15. Data Center 1 Load during 2008 Summer Days with Standard Deviation ...............APB-4

Figure 16. Data Center 1 Load during 2008 Winter Days with Standard Deviation ..................APB-5

Figure 17. Varying Mixed-use Data Center 2 Load during the Week of August 3-9, 2008....... APB-5

Figure 18. Mixed-use Data Center 2 Load on August 6, 2008 ..................................................... APB-6

Figure 19. Mixed-use Data Center 2 Summer Days Load in 2007 ................................................ APB-6

Figure 20. Mixed-use Data Center Winter Days Load in 2007 ……………................................. APB-7

Figure 21. Relatively Flat Data Center 5 Load in the week of August 3-9 of 2008 ...................... APB-7

Figure 22. Relatively Flat Data Center 5 Load on August 6, 2008 ............................................. APB-8

Figure 23. Steep Rise in Data Center 5 Load in 2007 ..................................................................PB-8

Figure 24. Decline in Data Center 5 Load in 2008 ...................................................................... APB-9

Figure 25. Data Center 5 Load for 2008 Summer Days ................................................................. APB-9

Figure 26. Data Center 5 Load for 2008 Winter Days ....................................................................APB-10 
Figure 27. Hot/Cold Aisle Layout APC-2

Figure 28. Hot/Cold Aisle with Aisle Lid and End Cap ...... APC-2

Figure 29. Server Consolidation Using Virtualization Technologies. APC-3

Figure 30. Storage Consolidation Using Virtualization Technologies APC-4

Figure 31. Network Consolidation Using Virtualization Technologies APC-4

Figure 32. Aggregated Load Results from NetApp's May 15 and 16, 2008 Localized Event.. APD-2

Figure 33. Aggregated Load Results from NetApp's Test DR Event on July 9, 2008. APD-3

Figure 34. May 2008 Data Indicative of Weather Sensitivity for NetApp APD-3

Figure 35. Typical UPS Bypass Configuration and Conversion Components. APD-6

\section{List of Tables}

Table 1. Eight Data Center Load Shapes in Relation to Average Daily Load Factor (DLF) ............ 18

Table 2. Summary of Data Center Demand-Response Strategies, ${ }^{*}$ Advantages and Cautions ...... 28

Table 3. Server consolidation using virtualization ............................................................................. 33

Table 4. Storage consolidation using virtualization ............................................................................ 34

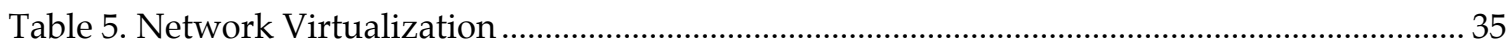

Table 6. Shifting or Queuing IT and back-up job processing ………………...................................... 36

Table 7. Built-in equipment power management................................................................................. 37

Table 8. Temporary work load migration ………………...................................................................... 38

\section{List of Tables - Appendices}

Table 9. ENERGY STAR Computer Server Power Supply and Power Factor Specifications . APA-2

Table 10. ENERGY STAR Idle Server Power Consumption Limits APA-2

Table 11. Data Center Types, Typical Sizes, and IT Equipment Characteristics APA-2

Table 12. EPA Scenarios and IT and Site Infrastructure Efficiency Measures..... APC-1

Table 13. Summary of NetApp DR Case Study for End-Use Strategies..... APD-1

Table 14. NetApp DR Results Summary Table for Localized and Auto-DR Event (kW) APD-4

Table 15. NetApp demand response Results Summary Table for Localized and Auto-demand response Event $(\%)$.. APD-4

Table 16. Demand Response and Open Auto-DR Opportunities and Strategies Summary ... APD-8 


\begin{abstract}
This study examines data center characteristics, loads, control systems, and technologies to identify demand response (DR) and automated DR (Open Auto-DR) opportunities and challenges. The study was performed in collaboration with technology experts, industrial partners, and data center facility managers and existing research on commercial and industrial DR was collected and analyzed. The results suggest that data centers, with significant and rapidly growing energy use, have significant DR potential. Because data centers are highly automated, they are excellent candidates for Open AutoDR. "Non-mission-critical" data centers are the most likely candidates for early adoption of DR. Data center site infrastructure DR strategies have been well studied for other commercial buildings; however, DR strategies for information technology (IT) infrastructure have not been studied extensively. The largest opportunity for DR or load reduction in data centers is in the use of virtualization to reduce IT equipment energy use, which correspondingly reduces facility cooling loads. DR strategies could also be deployed for data center lighting, and heating, ventilation, and air conditioning. Additional studies and demonstrations are needed to quantify benefits to data centers of participating in DR and to address concerns about DR's possible impact on data center performance or quality of service and equipment life span.
\end{abstract}

Keywords: Demand response, data center industry, buildings, electricity use, automation, communications, control systems, open standards. 


\section{Executive Summary}

\section{Introduction}

In 2006, the Industrial Demand Response Team, which is part of the Demand Response Research Center (DRRC) at Lawrence Berkeley National Laboratory (LBNL), began researching and evaluating demand response (DR) opportunities in industrial facilities.

In collaboration with a team of researchers, technology and controls experts, industrial partners, and data center facility managers, the DRRC investigated the application of DR research in the data center sector.

For purposes of this study, data centers are defined as collections of servers, storage, and network devices in a specific space(s) dedicated primarily to this equipment. Mixed-use data centers also have commercial office spaces used for business and operational needs. Data center facilities are divided into two elements: information technology (IT) infrastructure, which is typically composed of servers, storage, and networking equipment; and site infrastructure, which includes supporting systems to IT, such as power delivery and cooling systems and lighting controls.

This scoping study builds on ongoing DRRC research, development, demonstration, and deployment activities related to Open Automated Demand Response, also known as Open Auto-DR or OpenADR. Open Auto-DR is a set of continuous and open communication signals and systems provided over the internet to allow facilities to automate their DR with "no human in the loop." The utility programs are often known as Auto-DR.

\section{Purpose and Project Objectives}

The purpose of this study is to investigate data center characteristics, practices, loads, control systems, and technologies to identify DR and Open Auto-DR opportunities and challenges in data centers. The study is intended to facilitate discussion and further research related to advancing DR in data centers within California and elsewhere.

This study evaluates the technical and institutional capabilities and opportunities as well as challenges and issues related to DR in data centers. Specific project objectives were to:

- Identify different types of existing data centers and data center technologies.

- Determine technologies and strategies that could be used for DR and/or Open Auto-DR.

- Identify emerging technologies (e.g., virtualization, load migration, cloud computing, storage, etc.) that could be used for DR and/or Open Auto-DR.

- Verify data center load patterns and the potential magnitude of load shed or shift that could be achieved with little or no impact on data center business or operations.

- Assess the readiness of technologies that could be used with the existing Open Auto-DR infrastructure in California utilities.

- Identify concepts and opportunities for providing Open Auto-DR-enabled products to facilitate full automation of data center DR strategies. 
- Identify next steps and field study requirements as well as barriers, if any, for data center participation in DR or Open Auto-DR.

This work was funded by the PG\&E Emerging Technologies Program with co-funding from the California Energy Commission Public Interest Energy Research (PIER) Program.

\section{Conclusions and Key Findings}

The results suggest that data centers, on the basis of their operational characteristics and energy use, have significant potential for DR. Because data centers are highly automated, they are excellent candidates for Open Auto-DR. Specific types of data centers - i.e., those with "nonmission-critical" assignments such as those associated with research and laboratories - are the most likely candidates for early adoption of DR. Site infrastructure DR strategies have been well studied; however, DR strategies for IT infrastructure in data centers have not been studied extensively. The largest opportunity for DR and load reduction in data centers is in the use of virtualization to reduce IT equipment energy use, which correspondingly reduces facility (site) HVAC loads. Other areas where DR strategies could be deployed in data centers are HVAC and lighting. Additional studies and demonstrations are needed to quantify benefits to data centers of participating in DR and to address concerns about DR's possible impact on data center performance/quality of service and equipment life span.

Key Finding: Demand Response is underexploited in data centers; application of key DR strategies could reduce California's peak demand. There is an immediate DR potential in HVAC system and lighting loads (Site infrastructure).

- A modest peak reduction of 5 to 10 percent in mixed-use data centers through participation in existing California utility DR programs, focused on lighting and HVAC within both data center and office areas would result in significant total peak load reduction. In the PG\&E territory alone, this reduction would be equivalent to 25 to 50 MW. If field tests demonstrate their feasibility, other end-use strategies, such as ones for data center IT equipment, could double this peak-load reduction potential.

Key Finding: Synergy between IT and site infrastructure strategies will likely have maximum impact; shedding IT infrastructure loads also reduces site infrastructure cooling loads

- Synergy between IT and site infrastructures would likely lead to faster response, improved planning, and managing of end-use loads for DR events.

- Analysis of the performance of a small number of mixed-use data centers shows significant DR and energy-savings potential from temporary reductions in site infrastructure HVAC loads (for example, by raising temperature setpoints); demonstrations of DR strategies to reduce IT loads also show significant potential. Reducing IT loads correspondingly reduces site infrastructure cooling loads and power distribution losses.

Key Finding: The largest potential load reduction in data centers could come from use of virtualization on the IT infrastructure side.

- Virtualization technologies will enable on-demand, dynamic management of IT equipment (servers, storage, and network) for efficient energy use. Virtualization, when 
integrated with data center policies, DR strategies, and, potentially, the Open Auto-DR infrastructure, can reduce peak loads without any impact on data center operations.

Key Finding: Existing energy-efficiency and load-management technologies and practices could enable data centers to successfully participate in DR and Open Auto-DR events.

- Data centers are highly automated facilities and thus are promising candidates for implementation of Open Auto-DR and virtualization technologies; the latter have matured so that 12 percent to 15 percent server consolidation rates could be achieved on a regular basis with no disruption to data center operations. Although many data centers are less likely to use virtualization technologies to achieve higher consolidation rates for longer durations, using virtualization for short periods for DR is possible.

- The average server processor utilization rates are as low as $10 \%$ to $20 \%$ with high energy consumption. Virtualization technologies can dynamically increase utilization rates on selective servers up to $50 \%$ for few hours and consolidate redundant servers to save significant energy.

Key Finding: Data center end-use load reductions from DR strategies could migrate to standard daily operating practices and energy savings.

- Data centers are good candidates to try DR control strategies for temporary periods and likely allowing the lessons learned to lead to energy efficiency practices. For example, as described in Appendix D, in 2006, a mixed-use data center began participating in a DR program that increased temperature setpoints; in 2008, based on its DR experience, this data center permanently increased the upper limit of its supply-air temperature. Expansion of efficient practices beyond short-duration DR events would likely lead to greater energy and peak load savings, as well as economic savings for data centers.

Key Finding: For the purposes of DR, the data center type matters, not the size. Unless reliable and longer back-up energy capabilities exist, "mission-critical" data centers are less likely to participate in DR than data centers with consistent high availability needs, for example, research and laboratory data centers.

- Production data centers that are "mission critical" must meet stringent reliability and availability requirements to support business and client needs and thus are unlikely to participate in DR programs, at least at the outset. Laboratory and research and development (R\&D) data centers are, typically, not mission critical and thus are the most likely candidates for early adoption of DR strategies.

Key Finding: Most data centers have separate energy performance metrics for site and IT infrastructure. However, DR performance metrics must be established at the whole building power (WBP) level to determine how much total energy a building saves during a DR event.

- Data centers typically measure energy efficiency performance separately for IT and site infrastructures even when data exist for whole building power use. However, the utility or independent system operator (ISO) needs information at the whole-building power level to establish and determine energy reduction during a DR event, in order to quantify data center DR performance, corresponding incentives, and settlement. 
Key Finding: Studies and demonstrations supporting DR strategies in data centers are lacking, which leads to uncertainty on the part of data center facilities managers about the risks and benefits of participating in DR.

- Perceived risks of temporary load reductions in data centers include compromised service quality and reduced lifetime of sensitive IT equipment. Demonstration and assessment studies are needed to evaluate the actual risk to data center operations.

\section{Recommendations and Next Steps}

The results from this study indicate the need for field tests and comprehensive analysis of DR strategies for data centers. Key elements for the next phases of research in this area are:

- Field tests, data collection, and demonstration of all or subset of DR or Open Auto-DR strategies for data centers to determine effective strategies, and evaluation of the wholefacility load reduction potential against existing baselines.

- Evaluation of data center data management approaches, monitoring systems, connectivity requirements, and control system designs that will lead to a better understanding of the sequence of operations needed for in-depth DR strategy analysis.

- Education and outreach aimed at high-tech companies and organizations, such as the Green Grid, to advance DR as a higher technical priority.

- Identification of emerging data center technologies, vendors, and control strategies to reduce peak electrical load(s) for both data center IT equipment and HVAC loads.

- Identification of DR-ready, scalable, vendor-neutral, energy-efficiency technologies that can integrate with existing utility Open Auto-DR infrastructure.

- Evaluation of measurement metrics for combined IT and site infrastructure performance during DR events, to permit calculation of load shed, settlement, and economic value.

- With increasing grid integration with intermittent energy resources (such as wind/solar), determine the flexibility of data center loads to respond with different DR program dispatches.

\section{Benefits to California}

The data center industry is heavily concentrated in California, and data center energy use contributes significantly more to California's peak electricity load than the national average of 1.5 percent to 2 percent. EPA study findings suggest that, in the PG\&E service territory alone, data centers represent an estimated $500 \mathrm{MW}$ of peak load (approximately $2.5 \%$ of total) and growing fast. This energy use is increasing rapidly both within and outside of California (EPA 2007). ${ }^{1}$ Concentration of data centers in certain areas of the state will strain electricity distribution and supply systems if current trends continue. This DRRC study is the first

\footnotetext{
${ }^{1}$ The EPA estimates that in 2006, the energy use of the nation's servers and data centers was more than double that was used in 2000. Nationally, data center electricity use was estimated to be 61 billion kilowatt-hours ( $\mathrm{kWh}$ ) in 2006 (1.5 percent of total U.S. electricity consumption) for a total electricity cost of about $\$ 4.5$ billion. PG\&E represents about one-third of California electricity sales.
} 
comprehensive exploration of data center DR opportunities. Although the emphasis is on impacts of data center DR in California, the study findings and recommendations apply to other regions as well. Data center energy consumption is not only a domestic challenge but a growing global concern. 


\subsection{Introduction}

Demand Response (DR) is a set of actions taken to reduce electrical loads when contingencies, such as power grid emergencies or congestion, threaten the electricity supply-demand balance and/or market conditions cause the cost of electricity to increase. DR programs and tariffs are designed to improve grid reliability and decrease electricity use during peak demand periods, which reduces total system costs (Lekov et al. 2009, PG\&E 2008, and Flex Your Power 2008).

\subsection{Background and Overview}

During the past two years the Industrial DR Team of the Demand Response Research Center (DRRC) at Lawrence Berkeley National Laboratory (LBNL), has been evaluating DR opportunities in industrial facilities (McKane et al. 2008). This initial research included collecting and analyzing data on recommended DR strategies included in utility integrated audits and the applicability of these strategies in open automated DR (Open Auto-DR). The team supported a number of California electric utilities and their contractors in identifying potential automated industrial DR participants and provided technical assistance in evaluating DR sites. The team conducted in-depth analyses of industrial sectors that appeared to have Auto-DR potential and analyzed their DR technical capacity. In 2008, LBNL's DR and Open Auto-DR research team selected data center facilities as a focus because of their high and increasing energy use:

- Data center energy use is expanding rapidly in California and nationally. In the Pacific Gas \& Electric (PG\&E) territory alone, data centers are estimated to consume 500 megawatts (MW) of peak electricity annually (EPA 2007).

- According to a 2007 U.S. Environmental Protection Agency (EPA) report, national energy consumption by servers and data centers doubled from 2000 to 2006 and, if current trends continue, will nearly double again from the 2006 level of 61 billion kilowatt-hours (kWh) to more than $100 \mathrm{kWh}$ in 2011, with an estimated annual electricity cost of $\$ 7.4$ billion. An estimated $20 \%$ of this energy use in the Pacific region alone (EPA 2007).

- The EPA identifies the San Francisco Bay and Los Angeles areas in California, which have the largest concentration of existing data centers in the United States as "areas of concern" and "critical" for electricity transmission congestion.

- In Silicon Valley (southern S.F. Bay region), the impact of increasing data center energy use is anticipated to be particularly significant because of the high concentration of data centers in that region.

\subsection{Project Objectives}

This scoping study evaluates the technical and institutional capabilities and opportunities as well as challenges and unique issues related to DR in data centers. Specific project objectives were to:

- Identify different types of existing data centers and data center technologies.

- Determine technologies and strategies that could be used for DR and/or Open Auto-DR. 
- Identify emerging technologies (for example, virtualization, load migration, cloud computing, and storage) that could be used for DR and/or Open Auto-DR.

- Verify data center load patterns and the potential magnitude of load shed or shift that could be achieved with little or no impact on data center business or operations.

- Assess the readiness of technologies that could be used with the existing Open Auto-DR infrastructure in California utilities.

- Identify concepts and opportunities for providing Open Auto-DR-enabled products to facilitate full automation of data center DR strategies.

- Identify next steps and field study requirements as well as barriers, if any, for data center participation in DR or Open Auto-DR.

The study draws on more than six years of previous research and ongoing data center and hightech buildings-related energy-efficiency projects at LBNL (LBNL 2009). Past work has included: benchmarking of data centers, development of best practices and assessment tools for the U.S. Department of Energy (DOE) (for example, DC-PRO), case studies and demonstrations of energy efficiency, development of a certified practitioner program and a joint American Society of Heating, Refrigerating, and Air-conditioning Engineers (ASHRAE)-DOE awareness training curriculum, and studies of uninterruptible power supply and DR power efficiency.

This current scoping study is of potential interest to:

- Utilities and independent system operators (ISOs) (or DR service providers) wishing to identify new DR potential in the data center industry and to create targeted industrial DR programs.

- Data center operators wishing to reduce energy costs, explore DR value and strategies, and incorporate energy-efficiency or demand-side management measures beyond those already planned or implemented.

- Federal and state policy makers and regulators wishing to identify new DR opportunities and review technology availability and maturity as a basis for implementing recommendations for building codes and new construction.

- Members of the public wishing to know about utility and data center industry efforts to provide for energy and grid security and reliability.

- Product vendors and companies wishing to identify new business opportunities in the energy value chain.

This work was funded by the PG\&E Emerging Technologies Program with co-funding from the Public Interest Energy Research (PIER) Program at the California Energy Commission.

\subsection{Methods}

This initial scoping study in the data center DR research project has the objectives of characterizing data center loads and evaluating DR opportunities for data centers. This study is intended to develop a framework and roadmap for longer-term research. The methods used in this scoping study included:

1. Collect and analyze existing research on commercial and industrial DR to characterize data center operations, technologies, and energy use profiles. 
2. Based on the data center operation, technologies, and energy use profiles developed in step 1, evaluate and characterize data center load shapes and issues associated with data center participation in DR.

3. Based on the load shapes and findings from steps 1 and 2, identify data center DR opportunities and challenges, key strategies and technologies that could reduce electricity use in data centers.

4. Based on initial findings, develop DR and Open Auto-DR technical implementation scenarios for data centers and attempt a preliminary quantification of the value and benefit of DR for data centers and the automation capabilities for data center IT and site infrastructure.

\subsection{Report Organization}

Following this Introduction, the remainder of this report is organized as follows:

Section 2 describes basic data center industry characteristics and energy use fundamentals.

Section 3 summarizes representative data center energy use and load characterization using measured data.

Section 4 details existing and developing data center DR controls and technologies.

Section 5 outlines potential DR strategies for data centers.

Section 6 describes Open Auto-DR systems and opportunities for Auto-DR in data centers.

Section 7 presents conclusions and recommendations.

Sections 8 and 9 list references, followed by glossary of key terminologies used in this report and appendices that contain further analysis and details.

Appendix A includes recommendataions and guidelines as well as data center classifications.

Appendix B describes data center components, measurements, and case studies.

Appendix C describes EPA enery efficiency scenarios and data center design and technologies.

Appendix D details the analysis of DR strategies using case studies. 


\subsection{Data Center Characteristics}

Understanding the key operational characteristics of a data center is essential for understanding data center energy use and DR opportunities. A data center's characteristics will determine what DR strategies are feasible and whether DR could be automated.

A 2006 press release by the technology research firm Gartner, Inc. projected that, by 2008, data centers would be growing so fast that half would not have enough energy to support operational requirements because of the increasing deployment of high-density (high-energyuse) information technology (IT) equipment (Gartner 2006).

This study considers data centers as industrial facilities housing a collection of IT equipment servers and storage and network devices - in a dedicated space. We refer to the IT portion of a data center collectively as the "IT infrastructure." A data center's IT infrastructure is served by the facility's power, cooling, and lighting systems, which we refer to collectively as the"site infrastructure." The term "mixed-use data centers" refers to data centers that have large office spaces. In the remainder of this report, we address operational characteristics and DR opportunities for IT infrastructure and site infrastructure as well as "synergistic" energy efficiency and DR opportunities for both IT and site infrastructure.

\subsection{Operational Characteristics}

Data center facility design and energy use have unique characteristics that result from the data center's primary functions: housing and serving IT equipment. Data center energy performance metrics reflect typical data center facility management, in which IT operations and site operations are overseen by separate departments that often function relatively independently.

Nearly all data centers operate year-round. Cooling systems condition the IT equipment space at all times to meet the specified temperature and humidity tolerance ranges of IT equipment. A small number of Research and Development $(R \& D)$ data centers have less strict performance requirements and thus are exceptions to this year-round intense operational schedule.

Almost all larger data centers have uninterruptible power supply (UPS) and generator support back-up to maintain power to racks of servers. Servers will usually have annual uptime range of $99.99 \%$ to $99.9999 \%$, which translates to a few hours of outage per year averaged over many years. Planned outages require significant preparation and approval. Unplanned outages require significant operational resources to monitor, report, and manage.

\subsubsection{Current Guidelines and Standards}

To maintain optimal environmental conditions for IT equipment, data center managers tend to look to ASHRAE and U.S. Environmental Protection Agency (EPA) guidelines and standards.

\section{ASHRAE Environmental Conditions Guidelines}

Data center cooling systems attempt to meet ASHRAE TC 9.9 temperature and humidity specifications although some maintain lower temperatures than specified in this standard for operational reasons, or because of concerns about equipment failure risk (ASHRAE Technical Committee 2009), or poor air management practices in data center zone air management systems due to lack of information on temperature "hotspots" or areas of hot temperature. Such 
practices results in lower temperatures for the entire the facility even though only a few areas need extra cooling.

ASHRAE's 2004 “Thermal Guidelines for Data Processing Environments” cites an allowable temperature and humidity range of $59^{\circ} \mathrm{F}$ to $90^{\circ} \mathrm{F}$ and a recommended operating range of $68^{\circ} \mathrm{F}$ to $77^{\circ} \mathrm{F}$ server inlet temperature (ASHRAE 2004). In a 2008 update, ASHRAE expanded the recommended ranges to $64.4^{\circ} \mathrm{F}$ to $80.6^{\circ} \mathrm{F}$ and $40 \%$ to $60 \%$ relative humidity (ASHRAE 2008). Appendix A (ASHRAE 2008 TC 9.9 Recommendations) presents the updated 2008 guidelines for temperature and humidity for relevant data center classes.

\section{EPA ENERGY STAR Guidelines}

EPA is currently developing an ENERGY STAR rating for both stand-alone and mixed-use data centers (EPA ENERGY STAR 2009). The rating is intended to be a whole-building efficiency indicator, capturing the interactions of building systems, weather, and operational changes over time. Additionally, EPA is developing a new product specification for enterprise servers. The ENERGY STAR rating includes specifications for server power supply efficiency and power consumption when idle (Energy Star 2009). Because these ratings are still being developed, their effect on data center DR opportunities is yet to be determined. Appendix A (EPA ENERGY STAR Recommendations) describes ENERGY STAR efficiency requirements for servers in detail.

\subsubsection{Facility Design Characteristics}

The subsections below describe data center facility characteristics: size, clientele served, availability / reliability requirements, IT and site infrastructure management interactions, power needs, and office spaces. Appendix A (Data Center Design Types, Size, and Equipment Characteristics) describes data center design types in detail.

\section{Data Center Sizing}

Data centers can include a few hardware devices to more than 100,000. A data center's electrical load can range from about 1,000 watts (W) to $100 \mathrm{MW}$. Because small data centers have fewer financial and other motivations to participate in pilot DR programs than large data centers have, this study focuses on data centers with total load exceeding $500 \mathrm{~kW}$. These sites likely have more than 1,000 hardware devices, and, in California, will likely be on a time-of-use commercial or industrial electricity tariff. Most will have control and/or monitoring systems in place.

\section{Data Center Availability or Tiers}

Data centers are designed to meet availability (reliability) standards. Most data centers fall into the two high-availability classes defined by the Uptime Institute, a research organization: Tier III (99.982\% availability) and Tier IV (99.995\% availability). Tier specifications address the number and nature of power and cooling distribution and redundant components a data center must have as well as the ability to repair faults without interrupting IT load.

\section{Data Center Types}

The large corporate and similar-scale data centers that are the focus of this report fall into two general categories: internal and external. 
1. Internal data centers are dedicated to the needs of the organization that operates them and typically serve one of two main functions: production or R\&D. Production data centers directly serve business needs and their operation usually relates directly to business revenue. These data centers typically have more stringent operational and availability requirements than laboratory and R\&D data centers.

2. External data centers provide services to companies that have outsourced some or all of their IT function. Service offerings vary; some external data centers provide and manage all IT equipment, but most provide only a facility and related services such as power and cooling. Even though their service offerings vary, external data centers generally have similar availability requirements.

\section{Stand-alone IT and Facilities Management}

IT management has primary control over IT equipment operations and therefore energy use but is not responsible for utility bills and may not even be informed of the cooling energy costs associated with their equipment because these costs are, in most data centers, the jurisdiction of the facilities (i.e., site infrastructure) management (EPA 2007). Demand for continuously available, higher computing power shapes current IT operating practices, leading to increasing energy consumption. An indication of this growing demand is that shipments of highpowered, high-energy-consumption blade servers are currently increasing at the rate of $20 \%$ to $30 \%$ compounded annually (EPA 2007). Increasing IT infrastructure energy consumption combined with lack of interaction between IT management and those who pay the energy costs of these increases helps drive the trend toward ever higher data center energy use (Silicon Valley Leadership Group and Accenture 2008). This disconnect between IT and facilities management also leads to separate automation of IT and site infrastructure loads and back-up power, separate energy efficiency efforts, and so on.

\section{Data Center Power Sources}

Data centers rely on the power grid for high-quality and extremely reliable energy to avoid serious business disruption or data loss and commonly employ back-up generators to protect against power loss. Data center back-up generators are usually configured to start following a utility outage or voltage fluctuation of two to four seconds in duration or a power loss of greater than $10 \%$. Data centers also commonly rely on UPS and storage. Some data centers that are part of large campuses or office complexes have renewable energy (photovoltaic, fuel cell, thermal storage) and cogeneration (natural-gas-fired reciprocating engines or turbines) capabilities integrated with conventional systems. Section 3.0, Energy Use and Load Characterization, describes power sources in more detail.

\section{Data Center Office Spaces}

Most large data centers have minimal office space, (5\% to $10 \%$ of the total building space,) in these cases, the office space consumes less than $1 \%$ of the total power load. Office areas house security and support staff primarily during normal work hours: Monday through Friday 8 a.m. - 5 p.m. Office spaces in mixed-use data centers are larger and can account for $10 \%$ to $20 \%$ of total data center load.

In some cases, office lighting shares electrical panels with IT equipment areas although most data centers separate IT equipment into its own panel that is backed up by the data center 
generator system rather than by UPS. The UPS serves some plug loads that support critical systems (security, office networks, building management).

\subsubsection{Energy-Use Profiles and Metrics}

All data centers operate 24 hours a day, seven days a week, year round with little variation in load. Daily and seasonal fluctuations in ambient conditions affect heating, ventilation, and air conditioning (HVAC) system energy use. IT load tends to fluctuate minimally and grow gradually to meet business needs. Section 3.0, Energy Use and Load Characterization, analyzes data center loads, presents a framework to compare energy use profiles, and describes metrics used to measure data center energy use and efficiency.

\subsection{System Characteristics}

A data center's energy use and ability to participate effectively in DR depend heavily on the mission of the facility, its IT equipment, and the power, cooling, and other systems serving both IT and site infrastructure. This subsection describes server, storage, and networking equipment operation and the HVAC and control systems that support IT operations.

\subsubsection{Servers, Storage, and Networking Devices}

Data centers are almost always networked. As a rule of thumb, networking devices account for about $30 \%$ of the data centers' energy use; the rest of the IT equipment energy is consumed by servers used for IT processes and storage. Data center storage energy use is increasing because of service level agreement (SLA) requirements, ${ }^{2}$ regulatory requirements, and the growing need for data availability and data-rich content storage (videos, multimedia). Data storage energy needs range from 37\% to $40 \%$ of IT-related energy use (Copan Systems 2008). Storage requirements are increasingly being expanded beyond the confines of the data center facility, by means of Storage Area Networks (SANs). As a rule of thumb, each of these groups of devices servers, storage devices and networks - accounts for one-third of IT energy use in a data center.

\subsubsection{HVAC and Control Systems}

Data center HVAC systems vary in size, configuration, redundancy, and age. Most data centers either have air-cooled computer-room air-conditioning (CRAC) units adjacent to racks, with condensing coils on the building roof or the ground nearby, or water-cooled CRAC or computer room air handling (CRAH) units, with water supplied from a nearby chilled water plant. Chilled water plants will have either water- or air-cooled chillers and might have a water-side economizer. Few data centers use water towers, water-cooled cabinets, or air economizers, which all reduce energy use while maintaining interior air conditions. Data centers that can use one of these technologies are more likely candidates for DR than those that cannot.

Nearly all sizable data centers ( $>1$ MW IT load) have a control system that monitors and allows for limited regulation of HVAC, electrical, and lighting systems. In mixed-use data centers, these monitoring and control systems may also serve the office spaces.

\footnotetext{
${ }^{2}$ An SLA is a legal or informal "contractual" service requirement, usually between the data center service provider and the customer. The SLA defines the level of services and performance that the data center will provide.
} 


\subsection{Energy Use and Load Characterization}

Identifying DR opportunities requires an understanding of data center energy use and peak load impacts as well as of the metrics used to characterize data center energy performance. Initial data center load characterization for this study suggests that data centers in both summer and winter climates could benefit from DR.

U.S. data centers consumed about 61 billion kilowatt-hours (kWh) in 2006 (1.5\% of total U.S. electricity consumption) for a total electricity cost of about $\$ 4.5$ billion (EPA 2007), and, as noted in Section 1.0, Introduction, this consumption continues to increase; as a result, many existing data centers will not have sufficient cooling and power resources for next-generation servers and storage equipment. Energy-intensive data centers must meet the power needs of IT equipment (IT infrastructure) and cooling, power delivery, lighting and other support systems (site infrastructure).

Data center power comes from either the electricity grid or back-up generators. Figure 1 (Silicon Valley Leadership Group and Accenture 2008) shows a typical data center's power distribution architecture. Typically, energy management control systems (EMCS) regulate site infrastructure loads (cooling, lighting, and power delivery systems). If there is no EMCS, energy to these loads is distributed directly by the switchgear (i.e., electric power system), commonly known as the electricity grid. IT equipment (servers, storage, network devices) is composed of electronic components; delivery systems must transform and smooth power so that these devices can safely consume it. The power that comes from the grid through the switchgear is first passed through the UPS, which acts as a large energy storage device. In a battery UPS, power is first converted to Direct Current (DC) to charge the batteries and is then reconverted to Alternating Current $(\mathrm{AC})$ to pass through the power distribution system. Power may be further converted to meet IT equipment voltage requirements. IT equipment also has internal power supplies to transform power back to DC and then distribute it to various electronic components at different voltages. As noted in Section 2.0, Data Center Characteristics, IT infrastructure consumes, on average, nearly half ( $40 \%$ to $50 \%$ ) of total data center energy. Site infrastructure consumes the remaining $50 \%$ to $60 \%$. Power delivery system energy use includes transformer and UPS losses.

Appendix B (Data Center Electrical and Energy Components) shows typical electrical components of a mixed-use data center as outlined in EPA (2007).

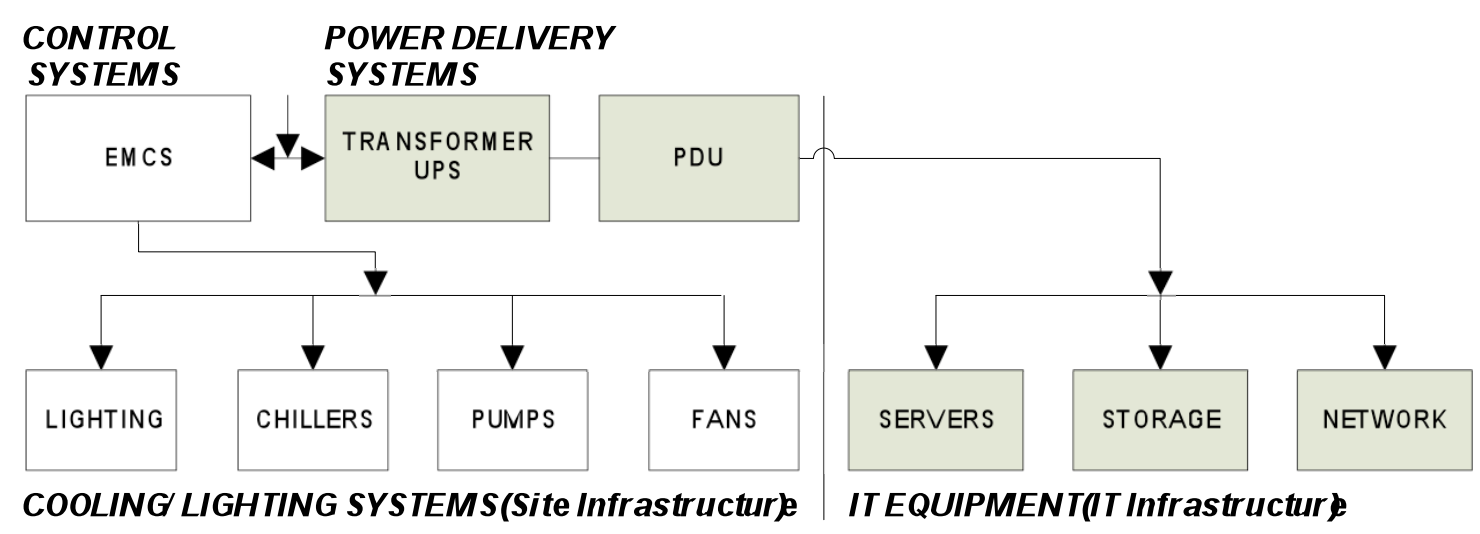

Figure 1. Typical Data Center Power Consumption and Distribution Architecture 


\subsection{Data Center Energy Metrics}

Data center energy performance is typically measured separately for IT and site infrastructure. However, whole-building energy measurements are needed to evaluate DR performance. ${ }^{3}$

\subsubsection{Power Metrics for IT and Site Infrastructure}

The metric to assess IT infrastructure energy use and overall data center utilization is a standard measurement of either billion operations per second per $\mathrm{kW}$, based on load profiling from a middleware platform. Billion operations per second is also sometimes referred to as billions of processes per second (BOPS) or floating point operations per second (FLOPS). Mixed-use data centers typically use the metrics $\mathrm{kW} /$ rack and $\mathrm{W} / \mathrm{Ft}^{2}$, which vary from $2.5 \mathrm{~kW} /$ rack to more than $20 \mathrm{~kW} /$ rack. These estimates are based on standard four-post racks that are 42 units (roughly seven feet high. The data center industries (e.g., the Green Grid) are working on defining appropriate metrics to understand true IT utilization (computing horsepower) relative to net power consumption.

Data centers use a number of metrics to measure energy performance, but only a few are relevant to this study: Physical Server Reduction Ratio (PSRR) for IT infrastructure energy use, and Power Usage Effectiveness (PUE) and Data Center Infrastructure Efficiency (DCiE) for site infrastructure energy use.

\section{Physical Server Reduction Ratio}

PSRR is the ratio of the historical installed server base to installed server base after virtualization. For example, a PSRR of 3:1 indicates a server base reduced by one-third after virtualization. Virtualization is an innovative technology that consolidates and optimizes servers, storage, and network devices in real time and thereby reduces energy use (virtualization is explained in more detail in Section 5.0, Demand-Response Opportunities).

$$
P S R R=\frac{\text { HistoricalInstalledServerBase }}{\text { PostVirtualizatinInstalledServerBase }}
$$

Other metrics that describe data center efficiency are the Site Infrastructure Energy Efficiency Ratio (SI-EER), Information Technology Energy Efficiency Ratio (IT-EER), and Data Center Energy Efficiency Ratio (DC-EER) (Brill 2008). Metrics that specifically apply to data center site infrastructure include Power Usage Effectiveness (PUE) and its reciprocal, Data Center Infrastructure Efficiency (DCiE). Both PUE and DCiE are defined in the following subsections.

\section{Power Usage Effectiveness}

PUE is the ratio of total facility power to the power draw of the IT equipment:

$$
P U E=\frac{\text { TotalFacilityPower }}{\text { ITEquipmenPower }}
$$

\footnotetext{
${ }^{3}$ The DR-service provider (utility or ISO) determine the settlement, or the calculation of the facility's load reduction following a DR event - the settlement is used to calculate payments. Settlements are typically calculated against baselines that are used to estimate what the load would have been in the absence of a DR event.
} 
For example, a PUE of 2 means that for every watt of energy consumed by IT equipment, two watts of energy are required by the entire data center. Under ideal conditions, a PUE of 1 indicates that the entire data center energy draw is for IT infrastructure. Appendix B (EPA PUE Measurement Model) presents additional PUE information for IT and site infrastructure.

\section{Data Center Infrastructure Efficiency}

DCiE is the reciprocal of PUE, or the ratio of total IT equipment power to total facility power: ${ }^{4}$

$$
D C i E=\frac{1}{P U E}=\frac{\text { ITEquipmenPower }}{\text { TotalFacilityPower }}
$$

From a purely representational point of view, DCiE may be preferable to PUE for measuring site infrastructure energy efficiency because increasing DCiE values correspond to better performance. In an ideal scenario, a DCiE value of 1 indicates that the entire data center energy draw is for IT infrastructure. IT equipment power includes the energy use associated with all of the IT equipment used for computation, storage, and networking, as well as supplemental equipment used to monitor or control the IT equipment.

\subsection{Data Center Energy Use and End Uses}

Figure 2 shows that roughly half of standalone data center energy use is for IT infrastructure. The next-biggest energy use is for cooling systems (approximately 35\%). Power delivery amounts to about $11 \%$ of total energy use, and lighting about $4 \%$ or less (Silicon Valley Leadership Group and Accenture 2008). HVAC and lighting energy use are higher in mixed-use data centers because of their larger office spaces.

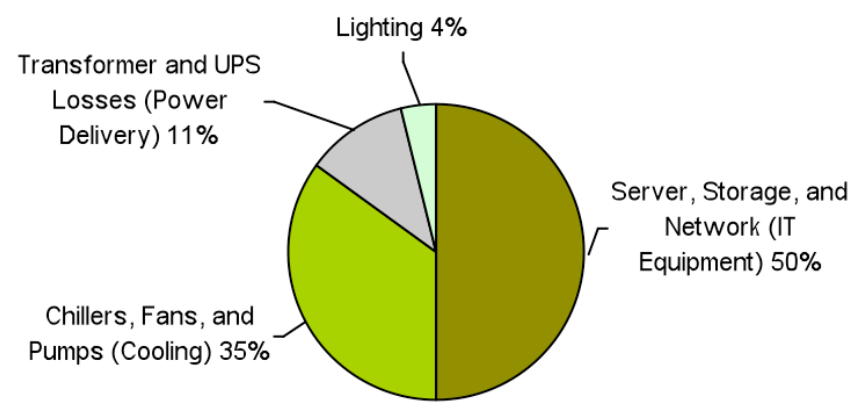

\section{Figure 2. Typical Standalone Data Center End-Use Energy Distribution: Cooling Energy End Uses}

Cooling systems condition IT equipment spaces at all times because IT equipment emits heat, which needs to be managed to ensure efficient operation. In traditional data centers, the amount of cooling needed is equal to the watts of power consumed by IT equipment.

\footnotetext{
${ }^{4}$ DCiE cannot be accurately calculated using nameplate ratings for IT equipment and other mechanical infrastructure. Actual power measurements are necessary to ensure that DCiE represents the energy use efficiency of an operational data center.
} 


\subsubsection{Office Energy Use}

Mixed-use data centers with large office spaces operate like other commercial buildings, so total facility energy use is typically higher than for a data center zone. Actual energy use will depend on the size of the building and the nature of the business operations.

\subsection{Data Center Load Characterization}

Based on long-term, 15-minute-interval meter data from eight data centers (including several mixed-use data centers), LBNL researchers, using yearly samples, classified the data center load shapes as flat or mixed-use loads and used these classifications to determine these data centers' options for participating in DR. (These load types may not be applicable to all data centers.) Mixed-use loads are related to mixed-use data centers that have large office spaces. The team classified loads as flat based on a quantitative metric, the percentage average daily load factor (DLF). Average DLF is the ratio of average daily 15 -minute-interval load ${ }^{5}$ and daily maximum load.

$$
\text { AvgerageDLF } \%=\frac{\text { AvgerageDailyIntervdLoad }}{\text { MaximumDalyLoad }}
$$

Data centers with very high average DLF ( $>90 \%)$, indicate constant flat loads. Data centers with long-term (i.e., yearly) continually increasing loads are also classified as flat loads because of their high average DLF. Mixed-use data centers have lower average DLF $(<90 \%)$, indicating higher energy use during office hours. In all cases, the average DLF is high, and daily loads are not variable. Table 1 summarizes the analysis of load characterizations of the eight data centers studied. Subsequent sections describe reference data centers for flat and mixed-use load shapes. Data center names are omitted in accordance with non-disclosure agreements.

\section{Table 1. Eight Data Center Load Shapes in Relation to Average Daily Load Factor} (DLF)

\begin{tabular}{|l|l|l|l|l|}
\hline Data Center & Data start & Data end & \multicolumn{1}{|c|}{ Load shape } & \multicolumn{1}{c|}{ Average DLF } \\
\hline CA Data Center 1 & $1 / 10 / 2008$ & $9 / 2 / 2008$ & Flat Load & $98 \%$ \\
\hline CA Data Center 2* & $4 / 6 / 2003$ & Current & Mixed-Use Load & $81 \%$ \\
\hline CA Data Center 3 & $4 / 6 / 2003$ & Current & Flat Load & $95 \%$ \\
\hline CA Data Center 4† & $7 / 21 / 2005$ & Current & Flat/ Mixed-Use Load & $83 \%$ \\
\hline CA Data Center 5* & $4 / 6 / 2003$ & Current & Flat Load & $99 \%$ \\
\hline CA Data Center 6 & $1 / 29 / 2005$ & Current & Mixed-Use Load & $88 \%$ \\
\hline CA Data Center 7† & $4 / 6 / 2003$ & Current & Flat/ Mixed-Use Load & $89 \%$ \\
\hline CA Data Center 8 & $4 / 6 / 2003$ & Current & Mixed-Use Load & $83 \%$ \\
\hline
\end{tabular}

${ }^{*}$ Reference load curve graphs are shown in Figures 3-6.

† Data centers 4 and 7 each have multiple meters, which have both flat (data centers) and mixed-use (combined or standalone offices) loads. Data center 4 has two meters with average DLFs of $68 \%$ (mixed-use) and $99 \%$ (flat). Data center 7 has eight meters with average DLFs ranging from $81 \%$ to $97 \%$ (mixed-use to flat). For the purpose of these calculations, the average DLF in the table is aggregated at the whole building level.

\footnotetext{
${ }^{5}$ Average daily 15-minute-interval load is calculated using an average of $\mathrm{kW}$ data obtained at the same
} time each day during the entire year. 


\subsubsection{Flat load Data Centers}

Figures 3 and 4 below show that the data sample collected from Data Center 5 (a research/academic data center) with high average DLF (99\%) has the following features:

- Daily and yearly loads are flat. (This is likely typical for research or academic data centers and those using efficiency measures to counter increasing energy use).

- Average load in summer and winter are almost identical (likely because this data center's operation is consistent over time).

- Office space load accounts for a small portion of total data center load.

- Energy use shows little correlation with weather.

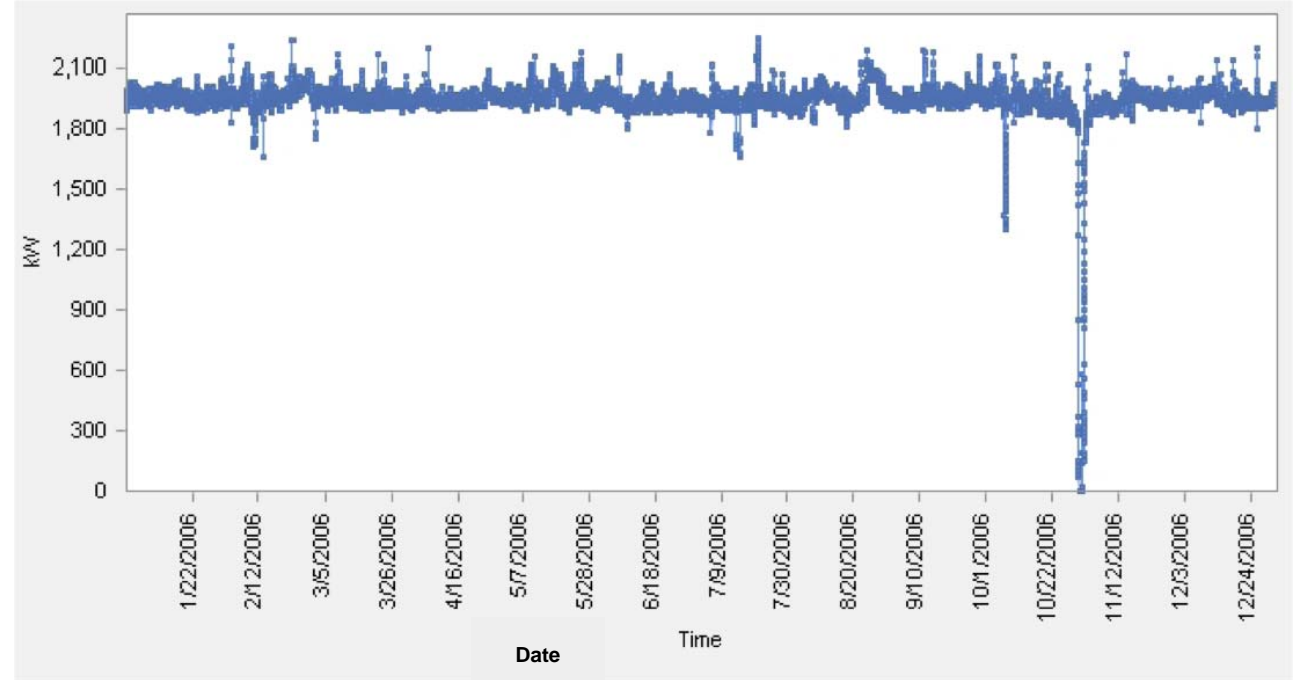

Figure 3. Data Center 5 Load Shape in 2006

Figure 4 shows negligible load deviation for combined summer and winter days, excluding weekends and holidays, indicating no weather influence on loads. Based on the information available, the small visible deviations were possibly due to efficiency tests conducted during the represented time periods. However, they should not affect the overall data center load. 


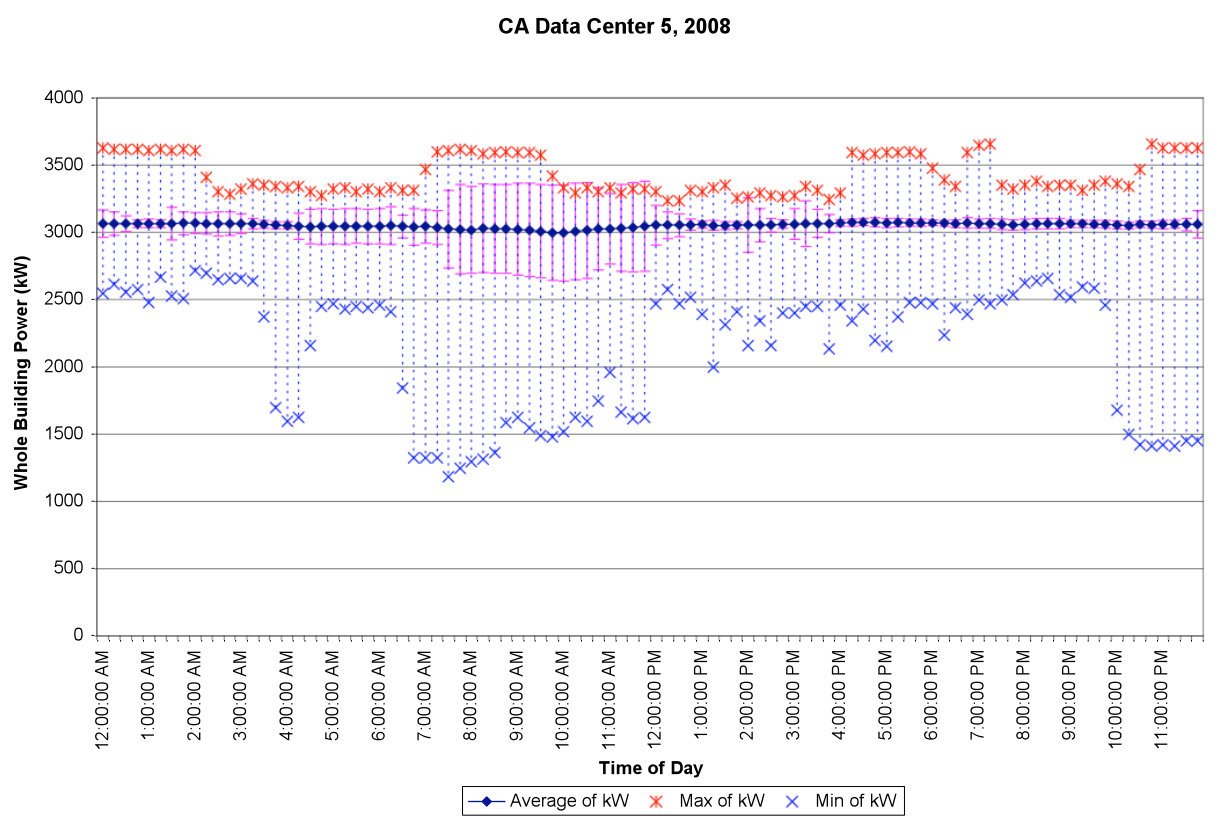

Figure 4. Data Center 5 Daily Load Shape in 2008 Summer and Winter

\subsubsection{Mixed-Use Load}

Figures 5 and 6 for Data Center 2, a mixed-use data center with a lower average DLF (<90\%), show that mixed-use load has the following features:

- The peak shapes are similar to those of typical commercial office buildings, i.e., high from 12PM-6PM on weekdays with small 10-20\% off-peak and on-peak load variation.

- Total facility daily load shapes resemble those of commercial buildings.

- The analysis, including data from mixed use data centers 4,6 , and 8 , show that office load varies depending on the size of the office space and weather.

- Almost $55 \%$ of the energy use varies, likely because of variations in office space load, which also appears to be affected by weather conditions.

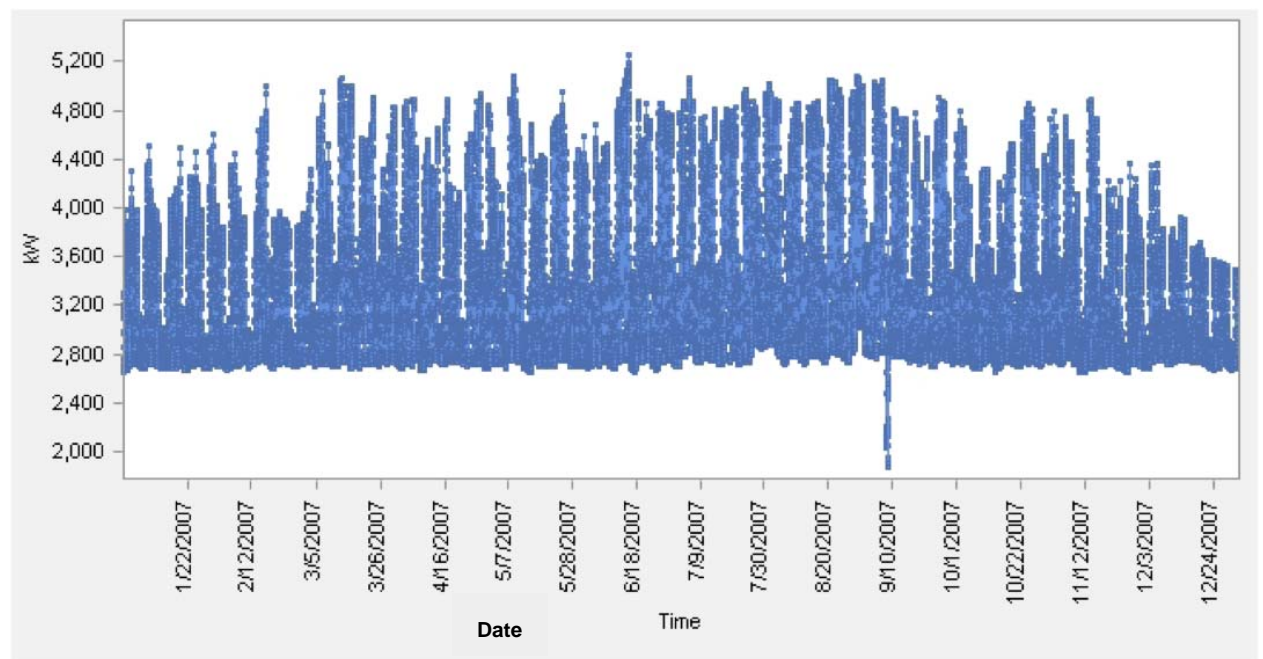

Figure 5. Data Center 2 Load Shape in 2007 
Figure 6 shows average daily summer and winter load with standard deviation, compared to maximum and minimum load.

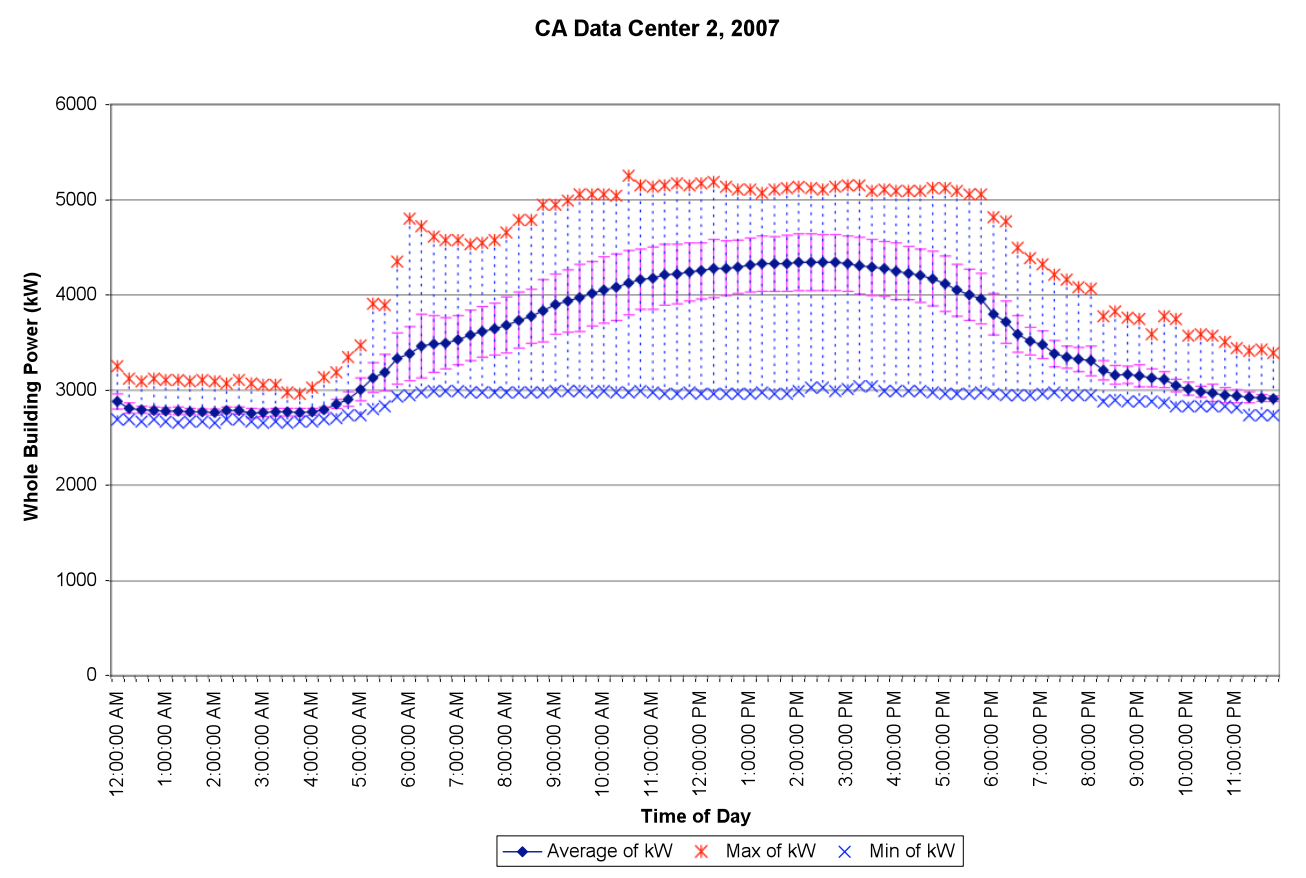

Figure 6. Data Center 2 Daily Load Shape in 2007 Summer and Winter

\subsection{Summary of Data Center Load Characterization}

Based on characterizations of data centers with flat and mixed-use load shapes, the research team concluded that data centers with high average DLF, base load, and low load variability could benefit from participating in DR. Consistent flat loads that are not sensitive to weather are indicative of a data center-only facility (i.e., not mixed use), with the loads resulting from IT and site infrastructure energy use; DR opportunities for these types of facilities have been largely unexplored. Typically, data center-only facility energy use tends not to vary with seasons. Thus, these data centers are also good candidates for DR where winter peak demand on the electricity grid is of concern. In mixed-use data centers with office spaces, energy use is sensitive to weather during office hours, depending on the size of the office spaces and on local weather conditions. DR opportunities for this type of office space have been well-studied and implemented.

Appendix B (Additional Data Center Load Characterization and Analysis) presents additional load shape characterizations and analyses for Data Centers 2 and 5 as well as Data Center 1, which is an example of long-term (i.e., yearly) increasing load shape.

\subsection{Influences on Data Center Energy Use and Peak Demand}

Factors such as weather, server workload, and business growth can influence data center peak energy use. 


\subsubsection{Weather}

Data center buildings were traditionally designed to minimize use of outside air and have little sensitivity to weather changes. Because most data centers have systems that operate with constant speed chillers, pumps, and fans, and few data centers employ water- or aireconomizers, total base loads tend to exhibit little to no variability. Efficiency could vary (not related to weather) with HVAC use and resulting use of water- or air-economizers. The variation is larger for mixed-use data centers because office space energy use is also influenced by weather changes.

\subsubsection{Server Work Load}

Server energy use fluctuates to some degree as workload varies. However, most servers and other hardware consume about $60 \%$ of their full energy even with no workload, which limits the degree of variability. Newer server hardware and software technologies may use less than $60 \%$ of full energy for part or no workload. However, even with an average server processor utilization rate as low as 10\% to 20\% (Silicon Valley Leadership Group and Accenture 2008), server energy consumption is very high.

\subsubsection{Business Growth}

To meet growing business needs, most data centers continue to add or replace servers until available HVAC and power capacity are at or near design limits. As per industry experts' assessment, reaching HVAC or power capacity could take three to five years (or longer) from the time a data center opens. Energy use then hovers around the same seasonal peak demand until new cooling and power capacity are added, allowing installation of more powerful servers and increases in server utilization rates, which, in turn, cause energy use to climb again. 


\subsection{Control Systems and Technologies}

This section reviews current efficiency technologies that are potentially applicable to data centers and could be used for DR. The key efficiency technologies for site infrastructure are control and other strategies to reduce cooling energy use; a key efficiency technology for IT infrastructure is virtualization. This study also includes synergistic technologies that integrate IT and site infrastructure efficiency efforts. This review includes both mature and emerging technologies, emphasizing those that can be used for DR and integrated with Open Auto-DR. The primary uses of almost all of the technologies addressed in this section are energy efficiency and operations optimization.

If used for DR, the technologies and control systems discussed in this section would need to allow for open integration with multiple vendors for interoperability and scalability to different types of data centers, as described in Section 5.0, Demand-Response Opportunities.

\subsection{Efficiency Technology Implementation Scenarios}

The research team categorized current data center efficiency levels using the following three scenarios developed by EPA as part of a report on data center energy-efficiency opportunities (EPA 2007):

\section{1. "Improved operation" Scenario}

2. "Best practice" Scenario

3. "State-of-the-art" Scenario

State-of-the-art data centers are the most efficient, employing strong energy-efficiency practices that result in lowered base loads; these practices may have minimized the potential for DR load shed. Data centers that fit into the "improved operation" or "best practices" are not as energy efficient as state-of-the-art data centers and thus may have higher DR load-shed potential. Conventional data centers with no efficiency measures and high DR potential are not included in these three scenarios. Each scenario is discussed below; Appendix C (EPA Energy Efficiency Implementation Scenarios) summarizes the underlying assumptions for these scenarios.

\subsubsection{Improved Operation Scenario}

In the improved operation scenario, a data center employs efficiency measures such as:

- Eliminating unused servers by optimizing computer applications.

- Adopting energy-efficient servers at the normal replacement time for existing servers.

- Enabling power management on all applicable servers.

- Improving efficiency 30\% through improved airflow management.

\subsubsection{Best-Practice Scenario}

In the best practice scenario, data centers are assumed to have implemented all of the strategies listed above for the improved operation scenario as well as the following additional measures:

- Moderately consolidating servers and storage.

- Aggressively adopting energy-efficient servers. 
- Improving efficiency by $70 \%$ using more efficient chillers, fans, pumps, improved power supplies and transformers, and free cooling where applicable.

\subsubsection{State-of-the-Art Scenario}

In the state-of-the-art scenario, a data center is assumed to have implemented all of the strategies for the best practice scenario as well as other efficiency measures, including:

- Aggressively consolidating servers and storage.

- Implementing virtualization technologies to increase server utilization rates to $50 \%-60 \%$.

- Increasing efficiency by $80 \%$ by using improved airflow management and other site infrastructure technologies from prior scenarios as well as direct liquid cooling and combined heat and power where applicable.

\subsubsection{Potential Savings from Efficiency Measures}

Using the measures listed in the three EPA scenarios, a fully efficient data center (state-of-theart) could reduce electricity use by up to $55 \%$ relative to business as usual, and a data center with some efficiency measures (improved operation), could reduce electricity use by more than 20\% (EPA 2007). The next subsections cover key efficiency technologies applicable to site and IT infrastructure. These technologies are used further for analysis of DR opportunities in Section 5.0, Demand Response Opportunities, and Section 6.0, Open Auto-DR Opportunities.

\subsection{Site Infrastructure Control System Technologies}

Energy Management Control Systems (EMCS) primarily regulate data center site infrastructure systems: cooling, power delivery, and lighting. Most current data center cooling systems use fans to push cool air to equipment. Some data centers use efficient direct water refrigerant cooling systems (Silicon Valley Leadership Group and Accenture 2008).

Several distributed EMCSs are currently on the market and are primarily used for monitoring and implementing energy-efficiency measures. Along with supervisory control and data acquisition (SCADA) systems, these automation and control systems regulate operation of HVAC, lighting, and related electrical systems in an integrated fashion. Communication building control protocols such as BACnet ${ }^{\circledR}$, Modbus $^{\circledR}$, and LonTalk ${ }^{\circledR}$ allow EMCS systems to communicate with site infrastructure equipment. These protocols are important to understand and could be programmed to communicate any efficiency or potential DR strategy and oversee technology interoperability within data centers.

\subsubsection{Cooling, Power Delivery Systems, and Lighting Technologies}

As described in Section 3.0, Energy Use and Load Characterization, IT equipment is the primary data center energy end use, consuming approximately half of total data center energy. Site infrastructure systems such as cooling, power delivery, and lighting also consume a significant amount of energy, from 35\% to 50\% of total energy use. Generally, for every watt of consumption by IT equipment, another watt is required for the entire infrastructure. There is a potential for as much as a $15 \%$ reduction in cooling system energy use based on the operations of best practice "green" data centers. In a small-sized best-practice data center, this amounts to a saving of more than 1 million kWh (Gartner 2008). Data centers using technologies, such as air economizers for cooling systems, power loss reduction for power delivery systems, and lighting controls, could also use these technologies for DR (see Section 5.0). 


\section{Cooling System Technologies}

Air or water economizers could save significant energy and costs for data centers and is also a likely DR strategy. Air economizers uses outdoor air directly for indoor cooling needs whenever the outside air temperature is lower than the return-air temperature setpoint. In one LBNL study of air economizers, mechanical cooling power dropped by approximately $30 \%$ when economizers were active, which saved significant energy costs (Shehabi, et al. 2007). Other energy-efficiency cooling system technologies that could be used for DR are:

- Raising data center temperature setpoints and improving airflow management.

- Regulating humidification controls or eliminating them completely in areas where humidification is not necessary (for example, temperate climates such as California).

Appendix C (Hot/Cold Aisle Layout, Aisle Lids and End Caps) describes additional cooling system efficiency measures for data centers.

\section{Power Delivery Systems Technologies}

Some recent technological advances to cut losses resulting from power distribution systems such as uninterruptible power supplies (UPS), transformers, and using UPS bypass can increase the overall efficiency of data centers. Almost all data centers use back-up storage system technologies and stand-by generators for power interruptions, emergencies and disaster recovery. Such power delivery system technologies could be useful for DR.

\section{Lighting Control Technologies}

Bi-level and dimmable lighting controls use sensors to automatically regulate lighting use as needed. Because lighting accounts for a small portion of data center energy use, except in mixed-use data centers, the magnitude of savings from lighting controls and more efficient lighting is smaller than for cooling and power delivery system efficiency measures.

\subsection{IT Infrastructure Virtualization Technologies}

Future data center cost management will rely on reducing IT equipment energy consumption, which, in turn, reduces site infrastructure energy use (Gartner 2007). Virtualization technologies consolidate and optimize servers, storage, and network devices in real time, reducing energy use by enabling optimal use of existing data center equipment. Use of virtualization technologies can be guided by business and operational needs and Service Level Agreements (SLAs) as well as energy management goals. Virtualization technologies are increasingly being used not only to improve energy efficiency but also to reduce the expensive floor space required for IT equipment and to manage and optimize legacy systems in real time. Virtualization allows data centers to:

- Optimize use of existing servers, storage, and network devices based on business needs.

- Reduce electricity and new hardware/software commissioning costs.

- Consolidate for improved energy efficiency of IT equipment.

- Manage bandwidth requirements, power constraints, and time-differentiated rates.

Server power supply efficiencies vary dramatically by load, with peak efficiency at $50 \%$ to $60 \%$ loads, high efficiency at high loads, and significantly lower efficiency at loads of less than $30 \%$. Most server power supplies operate at $20 \%$ to $50 \%$ of load, and power supplies are often 
oversized for equipment requirements, leading to inefficient power use and excess heat (High Performance Buildings 2005). Virtualization technologies increase server power efficiency and reduce cooling loads by eliminating redundant IT equipment, and are mature enough to meet performance and reliability needs of data centers without compromising quality of service.

The Simple Network Management Protocol (SNMP) allows IT equipment to communicate and to be used with virtualization technologies. Other communication protocols and languages such as Transmission Control Protocol over Internet Protocol (TCP/IP) and eXtensible Markup Language (XML) would enable open, standards-based information exchange within a data center's virtualization network and interoperability as well as integration with Open Auto-DR. Technologies that integrate site and IT infrastructure would be useful to provide a single source of information for integrated implementation of DR strategies. As described in Section 3.1.1., PSRR would be a good metric for estimating reduction in IT equipment use and could be used together with other DR metrics to estimate energy savings from virtualization. Appendix C (IT Infrastructure Virtualization Technologies References) describes the application of server, storage, and network virtualization technologies in more detail.

\subsection{Synergy Between IT and Control Technologies}

In 2007, LBNL's industrial DR research team's early study findings determined that "synergistic" data center control technologies, integrating IT and site infrastructure energy uses, could achieve significantly higher load reduction and energy savings for a facility than standalone controls that address IT and site infrastructure energy uses separately. For example, when a server is shut down or idled in a short-duration DR event, an immediate HVAC response would produce additional energy savings. The current use of separate, stand-alone systems and technologies for data center IT and site infrastructure does not allow for this kind of integrated response and resulting energy savings because of the time delays involved.

One key challenge of integrating the energy management of data center IT and site infrastructure is the use of different communication protocols. Many such solutions from vendors currently on the market provide middleware that could integrate IT and site infrastructure systems and provide analytical capabilities (Cisco Richards-Zeta 2009, Modius Data Center Infrastructure Manager 2009). For example, a newly developed power supply technology that can generate reports of server power supply consumption and efficiency data, could be used to coordinate with EMCS or HVAC equipment (protocols such as BACnet, Modbus, etc.) so that the cooling system communicates and responds to IT equipment (protocols such as SNMP) heat output. Appendix C (Next-Generation Control Systems and Technologies) describes next-generation IT and site infrastructure technologies in more detail. 


\subsection{Demand Response Opportunities}

Sizeable potential load-reduction/DR opportunities exist in data centers, and numerous strategies are available for data centers. Not all data centers can take advantage of all strategies because of differences in operational characteristics and features. Data center managers may perceive that some strategies are applicable for energy efficiency; further incremental benefits can be achieved by raising the bar and temporarily reducing service levels for a few hours a day and a few days a year for DR. Data center DR strategies generally fall into the categories of load-shedding (dropping load completely) and load-shifting (moving load from peak to offpeak periods).

The research team separated data center DR opportunities according to the area of the data center facility to which they apply:

1. Site infrastructure, where the opportunities in HVAC, power delivery, and lighting have been well-studied and, for example, include raising temperature setpoints.

2. IT infrastructure, where the main opportunities are in virtualization and other emerging technologies for servers, storage, and networking equipment, enabling, for example, consolidation of redundant servers.

The team also studied opportunities for combined IT and site infrastructure DR, referred to as "synergistic" DR. This research concept is discussed in the "Emerging Technologies" subsection of this section.

Table 2 summarizes the main DR data center opportunities and strategies and the advantages and challenges of each strategy. The table also notes strategies that are currently research concepts - emerging technologies that are still under development. Each of the strategies listed in the table is described in further detail in the subsections following the table. Section 6.0, Open Auto-DR Opportunities, describes the use of Open Auto-DR for some of these strategies.

The subsections below distinguish different types of data centers and their loads and availability requirements to generally assess the DR potential for each. What is feasible in a "mission critical" data center may be different than what is possible in a non-mission-critical data center that has less stringent availability requirements.

In addition to opportunities, this section looks at key challenges to implementing DR in data centers, which include:

- Traditional conservative operating strategies, for example, cooling to levels that exceed industry recommendations.

- A need for performance evaluation metrics that support DR performance assessment; current metrics separate data center site infrastructure from IT infrastructure whereas Whole-Building Power (WBP) must be measured to quantify DR performance.

- Lack of information about DR in data centers and resulting perception of the risks of DR; because research to date is limited, many data centers perceive that DR and other load management strategies might adversely impact operations. For the small subset of data centers that already have participated in energy-efficiency programs, additional benefits DR benefits may be possible. For data centers that are not already employing energy- 
efficiency strategies, DR may be a manageable first step toward energy-efficiency practices, enabling the data center to save energy and gain financial benefits.

This characterization of data center DR opportunities and challenges is based on the LBNL team's scoping research. Appendix D (Case Study Analysis of Two Strategies) describes the experiences of data centers that participated in commercial, pilot, and proof-of-concept studies entailing raising temperature setpoints and using virtualization technology for server consolidation. These case studies show promising results but represent only a small subset of data centers. Further research is needed to assess the opportunities for wide-scale adoption of some of the DR strategies.

Table 2. Summary of Data Center Demand-Response Strategies, * Advantages and Cautions

\begin{tabular}{|c|c|c|c|}
\hline \begin{tabular}{|l|} 
Data Center \\
Infrastructure
\end{tabular} & DR Strategy & Advantages & Cautions $^{6}$ \\
\hline \multirow[t]{3}{*}{$\begin{array}{c}\text { Site } \\
\text { Infrastructure } \\
\text { and Mixed-use } \\
\text { Data Centers }\end{array}$} & $\begin{array}{l}\text { 1. Adjust supply-air } \\
\text { temperature and/or } \\
\text { humidity setpoints to } \\
\text { industry and ASHRAE } \\
\text { ranges (recommended or } \\
\text { allowable): } \\
\text { a. Adjust data center zone } \\
\text { supply-air temperature and } \\
\text { humidity setpoints. } \\
\text { b. Adjust HVAC temperature } \\
\text { setpoint for mixed-use data } \\
\text { center zones. }\end{array}$ & $\begin{array}{l}\text { - Sequence of operation for } \\
\text { this strategy is well studied } \\
\text { and implemented in offices } \\
\text { and commercial buildings. } \\
\text { - Strategy could be part of } \\
\text { control system sequence of } \\
\text { operation. }\end{array}$ & $\begin{array}{l}\text { - Not applicable to data centers } \\
\text { already operating at higher } \\
\text { temperatures. } \\
\text { - Airflow management issues. } \\
\text { - Perceived risk of IT equipment } \\
\text { failure if strict environmental } \\
\text { conditions not maintained. }\end{array}$ \\
\hline & $\begin{array}{l}\text { 2. Use innovative cooling } \\
\text { system management: } \\
\text { a. Shut down redundant chillers, } \\
\text { pumps, and CRAC units in } \\
\text { response to IT equipment } \\
\text { needs. } \\
\text { b. Expand outside-air } \\
\text { temperature range for } \\
\text { economization (water or air). }\end{array}$ & $\begin{array}{l}\text { - Significant savings when } \\
\text { used with IT infrastructure } \\
\text { strategies. }\end{array}$ & $\begin{array}{l}\text { - Higher outside air wet-bulb } \\
\text { temperature may raise cooling } \\
\text { water temperature. } \\
\text { - Weather dependence of air or } \\
\text { water-side economizer. } \\
\text { - Research concept for DR. }\end{array}$ \\
\hline & $\begin{array}{l}\text { 3. Use lighting controls: } \\
\text { a. Use bi-level switching or } \\
\text { dimmable lighting controls to } \\
\text { reduce lighting levels. }\end{array}$ & $\begin{array}{l}\text { - Sequence of operation for } \\
\text { this strategy well-studied and } \\
\text { implemented in office spaces } \\
\text { and commercial buildings. } \\
\text { - Lights could be shut down } \\
\text { completely. }\end{array}$ & $\begin{array}{l}\text { - Minimal impact as stand-alone } \\
\text { strategy in non-mixed-use data } \\
\text { centers. }\end{array}$ \\
\hline
\end{tabular}

6 "Research concept" in this column indicates that this DR strategy is still under development, and the impact on energy savings and scalability needs to be quantified. 


\begin{tabular}{|c|c|c|c|}
\hline & $\begin{array}{l}\text { 4. Reconfigure redundant } \\
\text { power delivery and back-up } \\
\text { electric storage systems: } \\
\text { a. Use UPS bypass technology. } \\
\text { b. Shut down redundant } \\
\text { transformers. } \\
\text { c. Use back-up storage. }\end{array}$ & $\begin{array}{l}\text { - Strategy for shorter duration } \\
\text { - Back-up storage in use } \\
\text { outside California; system } \\
\text { testing can coincide with DR } \\
\text { event. }\end{array}$ & $\begin{array}{l}\text { - Perceived impact on } \\
\text { equipment or risk of error or } \\
\text { malfunction (a). } \\
\text { - Perceived need for additional } \\
\text { back-up storage during DR (c). } \\
\text { - Air-quality regulatory issues if } \\
\text { diesel generators are used (c). } \\
\text { - Research concept for DR (a \& } \\
\text { b). }\end{array}$ \\
\hline \multirow{4}{*}{$\begin{array}{c}\text { IT } \\
\text { Infrastructure }\end{array}$} & $\begin{array}{l}\text { 1. Use virtualization } \\
\text { technologies: } \\
\text { a. Increase server processor } \\
\text { utilization rate and } \\
\text { consolidate. } \\
\text { b. Increase storage density and } \\
\text { consolidate. } \\
\text { c. Improve networked device } \\
\text { efficiency. }\end{array}$ & $\begin{array}{l}\text { - Enabling technology } \\
\text { available (a \& b). } \\
\text { - Enabling technology maturing } \\
\text { (c). }\end{array}$ & $\begin{array}{l}\text { - Increased utilization rates for } \\
\text { servers may increase cooling } \\
\text { needs with overall efficiency } \\
\text { (a). } \\
\text { - Research concept for DR (b \& } \\
\text { c). }\end{array}$ \\
\hline & $\begin{array}{l}\text { 2. Shift or Queue IT or back- } \\
\text { up job processing }\end{array}$ & $\begin{array}{l}\text { - Enabling technology in use. } \\
\text { - Could be used as load shift. }\end{array}$ & $\begin{array}{l}\text { - Suited for laboratory or } \\
\text { research and development } \\
\text { data centers. } \\
\text { - Research concept for DR. }\end{array}$ \\
\hline & $\begin{array}{l}\text { 3. Use built-in equipment } \\
\text { power management }\end{array}$ & $\begin{array}{l}\text { - Built-in power management } \\
\text { present in most equipment } \\
\text { already. } \\
\text { - Energy savings higher in } \\
\text { newer systems. }\end{array}$ & $\begin{array}{l}\text { - Minimal energy savings for } \\
\text { most current equipment. } \\
\text { - Needs to be combined with } \\
\text { virtualization and load shifting } \\
\text { of IT or back-up job strategies } \\
\text { for DR impact. } \\
\text { - Research concept for DR. }\end{array}$ \\
\hline & $\begin{array}{l}\text { 4. Use load migration } \\
\text { technologies for shed or } \\
\text { shift }\end{array}$ & $\begin{array}{l}\text { - Enabling technology } \\
\text { available for some. } \\
\text { - Perennial strategy ("anytime } \\
\text { DR”). }\end{array}$ & $\begin{array}{l}\text { - Infrastructure available in only } \\
\text { a few data centers and used } \\
\text { primarily for disaster recovery. } \\
\text { - May need local utility and } \\
\text { coordination. } \\
\text { - Research concept for DR. }\end{array}$ \\
\hline $\begin{array}{c}\text { IT and Site } \\
\text { Infrastructure } \\
\text { Synergy }\end{array}$ & $\begin{array}{l}\text { 1. Integrate virtualization, } \\
\text { HVAC, lighting controls, etc. } \\
\text { for faster load-shed } \\
\text { response }\end{array}$ & $\begin{array}{l}\text { - These intelligent strategies } \\
\text { have higher potential energy } \\
\text { savings than stand-alone } \\
\text { strategies. }\end{array}$ & $\begin{array}{l}\text { - No enabling technologies } \\
\text { available currently. } \\
\text { - IT and site infrastructure } \\
\text { technology and performance } \\
\text { measurement currently } \\
\text { separate. } \\
\text { - Research concept for DR. }\end{array}$ \\
\hline
\end{tabular}

* Except where indicated, all strategies need DR demonstration and assessment. 


\subsection{Demand Response Strategies}

Site infrastructure DR opportunities include strategies for load sheds or shifts through changes in cooling and lighting energy use. IT infrastructure opportunities include use of virtualization strategies to consolidate redundant servers and storage and improve the efficiency of networks and tasks such as routine back-ups.

\subsubsection{Demand Response Strategies for Site Infrastructure and Mixed Use}

Data center site infrastructure loads (cooling, lighting, power delivery) support data center IT infrastructure. The site infrastructure end uses and control systems are similar to those in commercial buildings although, in data centers, these systems serve IT equipment needs rather than human comfort needs. DR strategies for cooling and lighting control systems could apply only to site infrastructure or could be designed to respond to IT equipment energy use. For mixed-use data centers that contain large office areas, extensive studies have looked at optimal DR strategies for HVAC and lighting (Motegi, et al. 2007). These studies found that HVAC and lighting are excellent candidates for DR, which achieves significant peak load reduction with no impact to occupants or facility operations and may apply to data centers as well.

\section{Site Infrastructure Strategy 1: Adjust supply-air temperature and/or humidity setpoints}

Data center cooling accounts for nearly half of the total data center load. In mixed-use data centers this may be slightly lower because of lighting and other end-use consumption related to the office spaces. ${ }^{7}$ Most data centers maintain zone cooling setpoints well below industry standards (e.g., ASHRAE 2008 recommended or allowable ranges ${ }^{8}$ and original equipment manufacturer [OEM] specifications). Intensive cooling is a result of lack of balance in data center zone air management systems and perceived risks to equipment from higher temperatures (Tschudi et al. 2006). Data centers operating below the ASHRAE recommended temperature range could shift to a higher temperature range for DR events and could also employ this range, as an energy conservation strategy. Technologies that integrate CRAC and HVAC controls with external and built-in equipment temperature sensors to dynamically balance data center air and zone management are being integrated into newer data centers. One DR strategy that could significantly reduce data center HVAC and cooling system loads would be to widen acceptable temperature setpoint ranges and humidity levels for short periods. Greater than 30\% energy savings may be possible if temperature and humidity ranges are enlarged beyond the conservative values that some data centers currently use.

As noted earlier in this report, cooling systems in a conventional data center account for 35\% to $50 \%$ of load. This means that for every watt consumed by IT equipment, another watt is consumed for cooling. Significant load reduction could come from two strategies: increasing supply air temperature setpoints for data center zones and increasing HVAC temperature setpoints for office spaces within mixed-use data centers.

\footnotetext{
${ }^{7}$ In mixed-use data centers, field tests and sub-metering are necessary to accurately estimate the DR load reduction from data centers and office spaces separately. Appendix D has data from one mixed-use data center, which showed that although the data center space was less than $10 \%$ of the total building floor area; its energy use was almost $80 \%$ of the total energy use. The building was not sub-metered.

${ }^{8}$ ASHRAE 2004 guidelines and 2008 recommendations are included in Appendix A.
} 
A. Adjust data center zone supply-air temperature and humidity setpoint. The IT equipment related HVAC accounts between $20 \%$ and $100 \%$ of total IT equipment load; $35 \%$ to $75 \%$ is typical. Increasing supply air temperature and humidity setpoints for the duration of a DR event will reduce cooling energy use. The amount of load reduction at the WBP level will depend on the individual data center's operational characteristics. For example, a $5^{\circ} \mathrm{F}$ change in supply air setpoint can reduce HVAC load by $5 \%$ to $10 \%$ but might slightly increase IT infrastructure energy use if internal fans in equipment speed up to meet increased cooling needs. Similar strategies could be used for humidity controls. One case study presented in Appendix D (Case Study Analysis of Two Strategies) demonstrates the success of DR using changes in temperature setpoints.

B. Adjust HVAC temperature setpoint for data center zones. Mixed-use data centers with significant cooling energy use within office spaces can raise the HVAC temperature setpoint for office zones. Depending on occupant comfort levels, the temperature setpoint requirements within office spaces can be more relaxed than for data center zones.

\section{Site Infrastructure Strategy 2: Use Innovative Cooling System Management}

Some data centers that currently use virtualization technologies for IT equipment can shut down unnecessary chillers and related cooling equipment when servers are consolidated. ${ }^{9}$ Water or air-side economizers can be used in some data centers to lower cooling load.

A. Shut down redundant chillers, pumps, and CRAC units: For DR, data centers can shut down redundant chillers, pumps, CRAC (or CRAH) units, and other cooling equipment in response to IT equipment needs and restart this equipment after the DR event as needed to regulate data center temperature.

B. Use water or air economizers: Air economizers uses outside air rather than conditioned air for cooling, and water economizers increases chilled water supply temperatures. Few data centers currently employ significant air economizers. When DR events coincide with hot weather, outside air may be too warm to utilize for cooling. However, even in warmer weather, data centers can expand the useable outside air temperature range, and chilled water plants can reset water supply temperatures higher with little effect on data center zone temperature to significantly reduce peak load.

Depending on the system configuration and the use of variable-speed drives, shutting down cooling equipment when not needed can, if the system is not configured correctly, cause remaining equipment to ramp up and work harder, result in increased energy use. Appendix D (Additional Analysis for Water or Air-Side Economizers) discusses this issue.

\section{Site Infrastructure Strategy 3: Use Lighting Controls}

\footnotetext{
${ }^{9}$ Due to the design and operational characteristics of most data centers, the use of thermal energy storage (TES) systems such as chilled water or ice, may not offer scalability or larger opportunities for their use during DR events. Very few existing data centers have TES, and the ones that do have TES use them routinely to take advantage of time-of-use rates. Also, data center operations are continuous and their use of any back-up storage for emergencies may preclude them from using TES during DR events, which is when their need is perceived most. The use of TES for DR strategies could be potentially considered for data centers on an individual basis (e.g., with large storage capabilities) for pre-cooling during non-peak hours and subsequently reduce on-peak chiller load.
} 
Using a bi-level switching and dimming system, lights can be controlled in individual data center zones. Strategies of this type have been studied and implemented successfully (Rubinstein and Kiliccote 2007). With advance warning, data center lights could also be shut down completely. Because lighting accounts for only about $2 \%$ to $4 \%$ of the total data center load, reducing lighting loads would have minimal impact on WBP consumption for data centeronly facilities. Lighting control strategies would have more impact on mixed-use data center loads because office spaces use more lighting energy.

\section{Site Infrastructure Strategy 4: Reconfigure Redundant Power Delivery and Back-Up Electricity Storage Systems}

Recent data center studies and technology advances show that energy-saving strategies by reconfiguring redundant systems, such as those affecting power delivery systems and using back-up storage systems, might have DR potential, depending on utility DR programs, state policies (e.g., California air-quality restrictions on using diesel back-up generators), and data center operational characteristics. Appendix D (DR Opportunities Using Power Delivery and BackUp Storage Systems Technologies) describes a few technologies used for these strategies.

\section{Mixed-use Data Center Strategies}

Mixed-use data centers include significant office space, and many already use HVAC and lighting load reduction strategies in office spaces and/or site infrastructure. In PG\&E's 2007 Open Auto-DR programs, high-tech and data centers reduced the total load by $1.6 \mathrm{MW}(7.3 \%)$ the total peak load reduction goal for the program was 22.8 MW (Wikler et al. 2007) using DR for lighting and HVAC within office spaces or site infrastructure. However, significant IT infrastructure and synergistic load reduction opportunities remain untapped in mixed-use data centers.

\section{Field Testing}

Other types of commercial buildings have implemented DR strategies for cooling and lighting systems. Before wide-scale adoption in data centers, these strategies require field testing and operator training. Field tests should quantify data-center-specific energy savings and identify data center-specific implementation guidelines as well as appropriate recovery measures to avoid significant rise in demand (also known as "rebound effect") immediately following a DR event.

\subsubsection{Demand-Response Strategies for IT Infrastructure}

Data center IT infrastructure end uses include servers, storage, and network devices, which typically account for half of total data center energy use. Cooling systems protect these devices from failure by eliminating the heat they generate. Any DR strategy for IT infrastructure load will, by definition, reduce cooling load. Virtualization technologies can be used to consolidate redundant servers. The subsection below details a few virtualization technologies available today. As little or no information exists on applicability to DR, no empirical DR load reduction estimates are provided.

\section{IT Infrastructure Strategy 1: Use Virtualization Technologies}

Virtualization technologies consolidate and optimize servers, storage, and network devices in real time to reduce energy use. Today's virtualization technologies can shut down and restart 
redundant servers automatically on short notice. For example, for data centers operating at low to medium utilization, virtualization can shift workloads and manage resources or capacity without any down time and can automate provisioning and reconfiguration of virtual machines for DR events, taking into account times, workloads, and Service Level Agreements (SLAs) (Virtual Iron, 2007). One data center DR proof-of-concept study in Appendix D (Case Study Analysis of Two Strategies) demonstrates the use of virtualization for server consolidation and load reduction in a data center. Virtualization technologies have recently entered the market, so experience with them is limited, but initial assessments show significant potential. Further research and field tests are needed to evaluate performance and quantify savings.

\section{A. Server Consolidation Strategies}

Table 3. Server consolidation using virtualization

\begin{tabular}{|c|c|}
\hline Definition & $\begin{array}{l}\text { Automatically limit or adjust server processor utilization rate as conditions permit by } \\
\text { using virtualization technologies in response to a DR signal. The resulting higher } \\
\text { utilization rates would free redundant servers which could be shut down. }\end{array}$ \\
\hline Applicability & IT Infrastructure \\
\hline End-Use type & Server, hardware \\
\hline Target loads & Server processor load \\
\hline Category & Load shed \\
\hline $\begin{array}{l}\text { Development } \\
\text { Status }\end{array}$ & Research, proof-of-concept studies, demonstrations \\
\hline \multirow[b]{2}{*}{$\begin{array}{c}\text { Summary of } \\
\text { Potential Strategy }\end{array}$} & $\begin{array}{l}\text { Option 1: Set absolute server processor utilization rate } \\
\text { - Selectively adjust (increase) server processor utilization rate to a pre-set } \\
\text { absolute value (for example, } 70 \% \text { ). This absolute value is referred to as } \mathrm{SE}_{\mathrm{au}} \% \text {, } \\
\text { server absolute utilization rate. } \\
\text { - Gracefully consolidate and shut down* redundant applications and servers that } \\
\text { are not needed. }\end{array}$ \\
\hline & $\begin{array}{l}\text { Option 2: Set relative processor utilization rate } \\
\text { - Select high-limit server processor utilization rate (for example, } 70 \% \text { ). We } \\
\text { designate this high-limit value } \mathrm{SE}_{\mathrm{hu}} \% \text {, server high-limit utilization rate. } \\
\text { - Selectively adjust (increase) server processor utilization rate by certain } \mathrm{X} \% \text { from } \\
\text { pre-DR-mode operation (for example, increase processor utilization rate by } \\
15 \% \text { to } 30 \% \text { ). This percent change from pre-DR operation is referred to as } \\
\mathrm{SE}_{\mathrm{ru}} \% \text {, server relative utilization rate. } \\
\text { - Limit sum of pre-DR mode and } \mathrm{SE}_{\mathrm{ru}} \% \text { to less than or equal to } \mathrm{SE}_{\mathrm{hu}} \% \text {. } \\
\text { - Gracefully consolidate and shut down redundant applications and servers that } \\
\text { are not needed. }\end{array}$ \\
\hline Rebound & $\begin{array}{l}\text { Rebound avoidance strategy required to gracefully restart software applications and } \\
\text { servers. }\end{array}$ \\
\hline Caution & $\begin{array}{l}\text { Higher processor utilization rates may lead to marginally higher energy use and } \\
\text { subsequent cooling. Impact on energy savings and scalability needs to be } \\
\text { quantified. }\end{array}$ \\
\hline
\end{tabular}

* A "graceful" consolidation, shutdown, or restart refers to a consolidation, shutdown, or restart in which applications or equipment goes through the normal consolidation, shut down, or startup process, as opposed to an abrupt consolidation or shutdown, e.g., when a plug is pulled or an application process is forced to quit. 
Server load, typically, is one-third of IT equipment energy use or $17 \%$ of WBP use. Because server processor utilization is often low (studies have found utilization rates as low as $10 \%$ to $20 \%$ ), a number of servers are likely to be running idle or at low utilization rates in a data center. Virtualization can optimize resources by consolidating underutilized servers, improving utilization rates to $70 \%$ to $90 \%$ (Silicon Valley Leadership Group and Accenture 2008), and thereby reducing total IT equipment energy use. For DR, it might be possible to automatically increase server utilization to at least $15 \%$ to $30 \%$ or higher as conditions permit, using absolute $\left(\mathrm{SE}_{\mathrm{au}} \%\right)$ or relative $\left(\mathrm{SE}_{\mathrm{ru}} \%\right)$ and high-limit $\left(\mathrm{SE}_{\mathrm{hu}} \%\right)$ server utilization percent values.

Underutilized servers and related hardware could be shut down to save energy and costs. The $\mathrm{SE}_{\mathrm{au}} \%$ would be applicable to data centers that would like to maximize DR potential without risking high utilization rate. The $\mathrm{SE}_{\mathrm{ru}} \%$ is more relevant to data centers that are using some form of virtualization technologies on a regular basis for efficiency purposes and would like to use a stepped DR strategy without risking a high utilization rate.

New intelligent server control mechanisms, such as active server power management (automatic server shutdown and restart using control algorithms), could consolidate and automatically shut down redundant servers during a DR event. These servers could be restarted at the end of the event or whenever capacity needs require. Virtualization technologies take into account capacity, process-load management, and common administrative operations to create a consolidated server pool so fewer servers are running in real time. The 5- to 10-minute lead time needed for consolidation and shutdown of redundant servers, this is consistent with most current DR program and notification requirements. ${ }^{10}$ During a DR event, consolidation to fewer servers will increase power supply loads in the remaining active units. Because most server power supplies operate inefficiently at low loads, this shift will likely result in increased power supply efficiency during the DR event and therefore an overall load reduction.

\section{B. Storage Consolidation Strategies}

Table 4. Storage consolidation using virtualization

\begin{tabular}{|c||l|}
\hline Definition & $\begin{array}{l}\text { Use virtualization technologies to increase server storage density in response to a } \\
\text { DR signal. The resulting added storage capacity would free redundant storage } \\
\text { servers, which could be shut down. }\end{array}$ \\
\hline Applicability & IT Infrastructure \\
\hline End-Use type & Server, storage disks, hardware \\
\hline Target loads & Server, storage devices \\
\hline Category & Load shed \\
\hline $\begin{array}{c}\text { Development } \\
\text { Status }\end{array}$ & Research, proof-of-concept studies \\
\hline
\end{tabular}

\footnotetext{
${ }^{10}$ For example, PG\&E's and SCE's day-ahead and day-of notifications for DR programs such as Critical Peak Pricing (CPP) and Demand Bidding Program (DBP).
} 


\begin{tabular}{|c||c|c|}
\multicolumn{1}{|c|}{} & $\begin{array}{l}\text { Consolidate individual or groups of storage systems } \\
\text { Option 1: Set absolute storage density }\end{array}$ \\
- Selectively adjust (increase) storage densities to a pre-set absolute value (for \\
example 60\%). This absolute value is referred to as $\mathrm{ST}_{\mathrm{ad}} \%$, storage absolute \\
density.
\end{tabular}

* A "graceful" consolidation, shutdown, or restart refers to a consolidation, shutdown, or restart in which applications or equipment goes through the normal consolidation, shut down, or startup process, as opposed to an abrupt consolidation or shutdown, such as when a plug is pulled or an application process is forced to quit.

High-storage-density technologies consolidate and power down individual or groups of storage systems that are not being used. ${ }^{11}$ Between $37 \%$ and $40 \%$ of equipment energy use is driven by storage requirements, so storage consolidation would reduce WBP consumption (Copan Systems 2008). Research has shown that storage density as low as $10 \%$ to $20 \%$ can be increased to $60 \%$ through resource optimization (Silicon Valley Leadership Group and Accenture 2008). Storage virtualization technologies are sophisticated enough to automate this process. Virtualization could be used to increase storage density by $15 \%$ to $30 \%$ or more as part of DR when conditions permit using absolute $\left(\mathrm{ST}_{\mathrm{ad}} \%\right)$ or relative $\left(\mathrm{ST}_{\mathrm{rd}} \%\right)$ and high-limit $\left(\mathrm{ST}_{\mathrm{hd}} \%\right)$ storage density percent values, with short notification times, depending on data transfer rates.

\section{Network Virtualization Strategies}

\section{Table 5. Network Virtualization}

\begin{tabular}{|c||l|}
\hline Definition & $\begin{array}{l}\text { Use Storage Area Networks (SANs) } \\
\text { devices, which would improve local storage device efficiency, or shut down local } \\
\text { storage devices for greater load reduction. }\end{array}$ \\
\hline Applicability & IT Infrastructure \\
\hline
\end{tabular}

\footnotetext{
${ }^{11}$ Reportedly, more than $50 \%$ of storage drives are powered off at any time (Copan Systems 2008).

${ }^{12} \mathrm{SAN}$ is commonly referred to as the architecture of remotely connected storage equipment (disks, tapes, etc.) accessed locally by servers using a network.
} 


\begin{tabular}{|c|c|}
\hline End-Use type & Network devices, hardware \\
\hline Target loads & Networked storage devices \\
\hline Category & Load shift and shed \\
\hline $\begin{array}{c}\text { Development } \\
\text { Status } \\
\end{array}$ & Research \\
\hline $\begin{array}{c}\text { Summary of } \\
\text { Potential Strategy }\end{array}$ & $\begin{array}{l}\text { Increase efficiency of devices using SANs } \\
\text { - Use high-speed SANs to virtualize storage with remote storage devices. } \\
\text { - Increase efficiency of networking devices and shut down local storage after } \\
\text { storage virtualization. This efficiency and shutdown process is referred to as } \\
\mathrm{ST}_{\mathrm{nv}} \% \text {, storage network virtualization. }\end{array}$ \\
\hline Rebound & Rebound avoidance strategy required to restore to local storage. \\
\hline Caution & $\begin{array}{l}\text { Enabling technology yet to mature. Impact on energy savings and scalability needs } \\
\text { to be quantified. }\end{array}$ \\
\hline
\end{tabular}

We can virtualize SANs and remote storage devices that are connected via a high-speed network and that perform the same functions as the local server. Because of current high storage costs, bigger enterprises tend to use SANs. By separating storage from server processing power, SANs efficiently utilize server power for business and mission-critical applications while providing required network capacity. Advancements in cloud computing ${ }^{13}$ can enhance network virtualization by $10 \%$ to $30 \%\left(\mathrm{ST}_{\mathrm{nv}} \%\right.$ ) or more as conditions permit. Network virtualization as part of DR could reduce facility energy use. Depending on size and transfer rates, implementing the strategy to move the data may require advanced notification.

\section{IT Infrastructure Strategy 2: Shift or Queue IT and Back-Up Job Processing}

Table 6. Shifting or Queuing IT and back-up job processing

\begin{tabular}{|c||l|}
\hline Definition & $\begin{array}{l}\text { Use virtualization technologies to intelligently identify, enable, and manage job } \\
\text { priorities and queues as permitted to defer IT processes and workloads to off-peak } \\
\text { periods in response to DR event. }\end{array}$ \\
\hline Applicability & IT Infrastructure \\
\hline End-Use type & Server, storage disks, hardware \\
\hline Target loads & Server, storage devices \\
\hline Category & Load shift or shed \\
\hline $\begin{array}{c}\text { Development } \\
\text { Status }\end{array}$ & Research \\
\hline
\end{tabular}

${ }^{13}$ Cloud computing is described in Appendix C (Next Generation Controls Systems and Technologies). 


\begin{tabular}{|c|c|}
\hline $\begin{array}{c}\text { Summary of } \\
\text { Potential Strategy }\end{array}$ & $\begin{array}{l}\text { Shift or shed loads by shifting IT and back-up processing: } \\
\text { - Use virtualization to shift a percent of server processes and workloads as } \\
\text { permitted during a DR event. This percent shift is referred to as } \mathrm{PR}_{\mathrm{st}} \% \text {. } \\
\text { - After this shift, shut down resulting redundant servers, storage devices, and } \\
\text { hardware. } \\
\text { - As an alternative to shut down, where applicable, shed loads based on efficient } \\
\text { hardware performance resulting from lowered processes. This percent shed is } \\
\text { referred to as } \mathrm{PR}_{\mathrm{sd}} \% \text {. }\end{array}$ \\
\hline Rebound & $\begin{array}{l}\text { Rebound avoidance strategy may be required to restore IT and back-up processing } \\
\text { and normal hardware performances. }\end{array}$ \\
\hline Caution & $\begin{array}{l}\text { Applicable to non-mission-critical applications. Impact on energy savings and } \\
\text { scalability needs to be quantified. }\end{array}$ \\
\hline
\end{tabular}

Current virtualization technologies use real-time priorities and queues, which enable efficient IT job and data processing, back-ups, simulations, and other tasks. Virtualization technologies could also be used to shift a percentage of IT processes and workloads $\left(\mathrm{PR}_{\mathrm{st}} \%\right)$ from on-peak to off-peak periods during DR events. ${ }^{14}$ This strategy could be used in non-mission-critical data centers to shift server processes to non-peak time and to consolidate servers to temporarily reduce energy use. In the future, server power management capabilities may be built in that consume less power relative to lowered processes and workloads $\left(\mathrm{PR}_{\mathrm{sd}} \%\right)$ even when servers are powered on and in stand-by mode.

\section{IT Infrastructure Strategy 3: Use Built-in Equipment Power Management}

Table 7. Built-in equipment power management

\begin{tabular}{|c|c|}
\hline Definition & $\begin{array}{l}\text { Similar to deferring IT process and workloads, intelligent built-in power } \\
\text { management in newer systems could shed load in real time when enabled and } \\
\text { combined with virtualization strategies. }\end{array}$ \\
\hline Applicability & IT Infrastructure \\
\hline End-Use type & Server, storage disks, hardware \\
\hline Target loads & Server, storage devices \\
\hline Category & Load shed \\
\hline $\begin{array}{c}\text { Development } \\
\text { Status }\end{array}$ & Research \\
\hline $\begin{array}{c}\text { Summary of } \\
\text { Potential Strategy }\end{array}$ & $\begin{array}{l}\text { Enable intelligent built-in equipment power management: } \\
\text { - As an alternative to shutdown resulting from IT equipment virtualization or } \\
\text { shifting IT and back-up processing, selectively enable built-in power } \\
\text { management features in a certain percent of equipment in real time. The } \\
\text { percent of equipment power management is referred to as } \mathrm{PM}_{\mathrm{eq}} \% \text {. } \\
\text { - Load could be shed based on increased efficiency resulting from lowered } \\
\text { equipment workload. }\end{array}$ \\
\hline Rebound & Same as virtualization technologies and IT and back-up processing. \\
\hline
\end{tabular}

14 Compute functions are often not processor constrained but instead memory or input/output constrained, so low processor utilization does not always indicate low workload. 
Built-in power management capabilities in data center IT equipment regulates energy use based on processor utilization rate and other factors. Although current equipment consumes significant energy even during idle periods and therefore must be shut down to save energy, newer systems allow more efficient energy management. If this strategy is used for DR, it needs to be combined with other virtualization technology or load shifting of IT and back-up processing strategies. This strategy may be preferable in some situations to complete server shutdown. DR notifications could be used to virtualize servers and storage devices or prioritize IT and back-up processes using software and to trigger built-in power management capabilities within equipment $\left(\mathrm{PM}_{\mathrm{eq}} \%\right)$ to temporarily reduce operations for short periods.

\section{IT Infrastructure Strategy 4: Use Load Migration Technologies for Shed or Shift}

Ongoing research seeks data center technologies that can save energy; increase reliability, efficiency, and availability; and, ideally, also minimize data center operational costs. Some energy-saving technologies and strategies, such as synergistic DR for both IT and site infrastructure and temporary load migration, are already in use at a small number of data centers but are not mature enough for wide-scale implementation for DR. These technologies could, either in their existing form or once mature, be used to shed or shift data center load.

\section{Temporary Work Load Migration (or Shifting) Strategy}

Table 8. Temporary work load migration

\begin{tabular}{|c|c|}
\hline Definition & $\begin{array}{l}\text { Data centers with fully networked infrastructure within different electrical grids, } \\
\text { zones, or geographic locations, can shift loads temporarily to other locations in } \\
\text { response to a DR event. }\end{array}$ \\
\hline Applicability & IT and Site Infrastructure \\
\hline End-Use type & Server, storage, and networking devices \\
\hline Target loads & Potentially all loads \\
\hline Category & Load shed \\
\hline $\begin{array}{c}\text { Development } \\
\text { Status } \\
\end{array}$ & Research \\
\hline $\begin{array}{c}\text { Summary of } \\
\text { Potential Strategy }\end{array}$ & $\begin{array}{l}\text { Temporarily shift IT load to redundant networked location: } \\
\text { - Use fully remote networked redundant infrastructure and automation } \\
\text { capabilities to selectively or completely shift IT equipment load in response to a } \\
\text { DR event. This percent of IT load migration is referred to as } L_{\text {it }} \% \text {. } \\
\text { - Unused IT equipment could be shut down. } \\
\text { - A percentage of the load of supporting site infrastructure services could be } \\
\text { minimized. The percent of site load migration is referred to as } L_{\mathrm{st}} \% \text {. } \\
\text { - The resulting lowered energy use could be significant. }\end{array}$ \\
\hline Rebound & Rebound avoidance strategy required to restore local operations. \\
\hline Caution & $\begin{array}{l}\text { Emerging technology. Used primarily for disaster recovery. Advance notification and } \\
\text { coordination among local utilities may be required. Impact on energy savings and } \\
\text { scalability needs to be quantified. }\end{array}$ \\
\hline
\end{tabular}


Some data centers maintain fully networked redundant locations on different electrical grids in different climate zones or geographic locations as back-up for disaster recovery. In 2007, LBNL discussed with data center experts the emerging technologies currently available or in development that could allow temporary load migration of data center IT equipment loads outside a region that is experiencing a DR event. As a result of this shift, IT equipment could be shut down or enabled for intelligent power management. Although this is primarily an IT infrastructure strategy $\left(\mathrm{LM}_{\mathrm{it}} \%\right)$, the shift in IT loads would reduce supporting site infrastructure (cooling) loads $\left(\mathrm{LM}_{\mathrm{st}} \%\right.$ ) as well. Data centers that participate in DR using this strategy would likely need advance notice of the need for load migration for planning and coordination purposes. With such notice, transferring a partial or total data center workload to another data center outside the utility service territory or electric grid is possible during a DR event. Even data centers running at $100 \%$ efficiency could use this strategy.

\subsubsection{IT and Site Infrastructure Synergy}

In 2007, the LBNL team determined that "synergistic" DR using IT and building control technologies to manage IT and site infrastructure loads together could have significantly greater impact than standalone DR in either IT or site infrastructure. This determination was consistent with the results of other studies that show greater potential energy savings from integrated building controls. For example, an integrated lighting, HVAC controls, and automated blind system that monitored light levels and temperature, can control the building systems to achieve least energy cost (Roth, et al. 2005). In data centers, intelligent coordination of site infrastructure controls to respond automatically to IT infrastructure load reductions could enable fast and efficient whole-building load reduction. Improved interaction between site and IT management (and technologies) would not only allow for general efficiency improvements, it could also facilitate the synergy between virtualization or server consolidation for significant IT energy reduction and corresponding reductions in the need for site infrastructure (e.g., cooling) (Brill 2008). Current technologies and systems do not provide a platform for integrating IT and site infrastructure. Current market partial solutions provide middleware to bridge this gap.

Technologies currently in use in data centers would allow central distribution units, formerly known as power distribution units, to be configured at the plug level, enabling SNMP integration for all back-up and redundant IT equipment that could be utilized for DR. The backup and redundant equipment could encompass $20 \%$ or more of rack-mounted equipment that is left running in what data center operators characterize as in an idle state ("hot standby").

\subsection{Challenges to Implementing Demand Response}

In addition to the cautions for implementing specific DR strategies listed in Table 2, some key organization and decision-making challenges need to be addressed before data centers consider DR participation. These key challenges are:

1. Perception of risk to business and operations: Operators of "mission-critical" data centers are concerned if load reduction strategies might adversely impact reliability of their operations. Some of the strategies described in this report are research concepts whose performance and impact need to be quantified before they are adopted for DR. 
2. Performance measurement strategies: Data centers currently measure energy performance separately for site and for IT infrastructure. However, for DR purposes, performance must be evaluated at the WBP level. Measuring WBP indicates how much total energy the building has saved. The utility needs to quantify WBP savings for settlement purposes.

3. Lack of Information: Data centers may not perceive that DR is feasible for them and those currently employing energy-efficiency measures may not recognize that additional savings are possible from DR.

\subsubsection{Perceived Risk to Business and Operations}

Many facilities maintain data center zone temperatures at the low end of the recommended ranges because of the risk of equipment damage from overheating. Most external data centers have SLAs that specify the environmental conditions they must maintain although minor variations to temperature setpoint within recommended ranges could be allowed during a DR event. Data centers that can readily test and allow temperature variations are likely to be internal, R\&D, or laboratory data centers offering non-mission-critical services.

In most mixed-use data centers, office HVAC and lighting account for a good portion of energy use. Office spaces use HVAC systems that are separate from the rest of the plant except when air handling units for the office space utilize chilled water from the plant that is also used for data center cooling. For integrated HVAC and CRAC systems, any DR strategy to raise temperature setpoints within data center zones could also affect office occupants. With welldesigned strategies for mixed-use data centers, HVAC and lighting load could be reduced temporarily with no immediate impact on office occupant comfort or data center operation. The perceived risks are applicable to both Tier III and IV data centers and their underlying types. Appendix A (Data Center Design Types, Size and Equipment Characteristics) has more details.

\section{Data Center Design Characteristics: Tier Levels and Types}

Data centers that are designed to meet high standards for availability are classified as Tier III or Tier IV, as described in Section 2.0, Data Center Characteristics. In Tier IV data centers, redundant components consume non-workload energy, add to peak demand, and often decrease the efficiency of remaining units as they operate below their optimum power efficiency. Although Tier IV data centers have significant redundancy, managers are often reluctant to participate in DR because, these data centers are have the most stringent availability requirements.

\section{Internal Data Centers}

As described earlier, production data centers have high reliability needs and thus little ability to curtail load except when transferring it to another site, which would likely be a redundant site used primarily for disaster recovery. In mixed-use data centers, office spaces may have some potential for load reduction although the percent reduction at the WBP level will be smaller. Internal production data centers can usually vary environmental conditions.

Typically, R\&D or laboratory data centers must be highly available for periods of a few days to a month at a time, but otherwise have less stringent requirements. Thus, these data centers often have significant opportunities to curtail loads by shutting off servers during non-use periods or consolidating servers using virtualization technologies when utilization rates are low. R\&D data 
centers could also implement DR by raising temperature setpoints and shifting IT job queue processing to non-peak hours.

\section{External Data Centers}

The participation in DR by external data centers depends on the business type (co-location, managed hosting, etc.) that determines its operation. Some key observations were:

A co-location or "co-lo" data center typically has high availability requirements and does not manage customer hardware and software, so it cannot curtail those loads, except in the case of underutilized or redundant infrastructure.

Managed hosting data centers are similar to co-lo data centers except that they manage thousands of smaller clients and have relatively rigid SLAs. Even though their hardware is often owned and operated by the managed hosting provider, each server is dedicated to a customer. As a result, participating in DR would be difficult unless, as with co-location, the focus is on underutilized or redundant infrastructure.

Web hosting data centers often have multiple customers on each server, with hardware, software, and infrastructure redundancy all operated by the same company. DR opportunities include consolidating redundant or underutilized servers, which is possible without compromising SLA requirements.

Real Estate Investment Trust or Wholesale data centers have less stringent SLAs than other types and therefore more operational flexibility to participate in DR. Customers typically pay for electricity directly or through a pro-rata charge and thus are economically motivated to save energy. Each data center is usually occupied by one or at most a few customers, and the data center operator often controls the shared equipment infrastructure. Such data centers could be good candidates for DR as these factors ease coordination between customers and operator.

\subsubsection{Performance Measurement and Verification}

Data center energy use is unique in that IT and site infrastructure operations are separate and subject to different performance measurement practices. Although metrics such as PUE and its counterpart DCiE are used to measure efficiency within the site infrastructure, PSRR is used for measuring efficiency within the IT infrastructure. These metrics were described earlier in Section 3.0, Energy Use and Load Characterization.

DR strategies to reduce IT infrastructure energy use can also reduce site infrastructure energy use because site end-use loads respond to IT equipment energy use. Therefore, a metric is needed that captures these savings. Current data center efficiency measurement practices would not capture WBP changes (if those data even exist) because, technically, PUE values used as an efficiency metric for site infrastructure energy use should remain the same as they are dependent on IT infrastructure load. For this reason, PUE is not an accurate metric for measuring DR performance for either IT infrastructure only or IT and site infrastructure combined. The same is true for DCiE as it's the inverse of PUE. PSRR is an accurate measure of IT infrastructure load reduction and efficiency improvements in general. A PSRR of 3:1 indicates that the server base is reduced by one-third following virtualization. 
To evaluate DR performance at the WBP level, combined IT and site infrastructure performance measurements are needed. For a mixed-use data center, office energy use should also be included. To measure DR performance, the following measurements should be made at the WBP peak demand level (Motegi, et al. 2004):

- Total watts reduced

- Total Percent reduction

- Watts $/ \mathrm{Ft}^{2}$ reduced

Experience with WBP DR-performance measurement in commercial buildings teaches us that the above metrics are used in the following ways: total watts reduced are used by utilities for DR load reduction estimates and payments, percent reduction shows change from normal operations against a baseline, and watts / $\mathrm{Ft}^{2}$ measurement normalizes performance to a benchmark for similar sites. All of these measurements must conform to the DR baseline specifications of the individual utility, ISO, or DR service provider for the site being evaluated.

\subsubsection{Lack of Information}

Lack of information encompasses both data center operators who do not perceive that participating in DR is feasible at all and those already practicing energy efficiency and not aware that additional savings are possible from DR. Even efficient data centers that have relatively high base load characteristics could temporarily reduce service levels during a DR event and realize additional incremental energy (and financial) savings.

As described in earlier sections, EPA has defined three operating scenarios for data center energy efficiency: "improved operation," "best practice," and "state-of- the art." Most data centers fit one of these scenarios, and the level of efficiency at which a data center is operating can be an indicator of the opportunities for DR at that data center. Data centers that do not currently employ energy-efficiency measures do not fit into any of the EPA categories and have significant DR potential. Appendix D (Demand Response Strategies and EPA Scenarios) contains examples and a table summarizing the relationship between EPA operating scenarios and DR strategies, including those that applicable to Open Auto-DR.

\subsection{Summary of Demand Response Strategies}

Data center DR opportunities depend on several factors, including the institutional and technical capabilities identified in previous sections. The main opportunities, from those listed in order of ease of implementation in Table 2; include:

1) those with the largest potential using virtualization and other emerging technologies for the servers, storage, and networking equipment that make up IT infrastructure in a data center along with corresponding reductions in cooling energy use and

2) those with the most immediate opportunities, such as raising temperature and humidity setpoints and lighting strategies, which have been well-studied in prior research.

Challenges to implementing DR in data centers include traditional conservative operational strategies with regard to temperature and other conditions, current energy performance metrics that do not give the information needed to assess the success of DR, and lack of information 
about DR - its risks, benefits, and possibilities - in data centers. Additional field studies are needed to validate the performance of these strategies in data centers. 


\subsection{Open Auto-DR Opportunities}

Open Auto-Demand Response, also known as OpenADR or Open Auto-DR, is a set of specifications for continuous, open, secure two-way signals over a communication channel such as the internet that allows facilities to automate their DR programs with "no human in the loop (Piette et al. 2009). In the National Institute of Standards and Technology draft roadmap report to DOE, OpenADR was recommended as a national Smart Grid (U.S. DOE 2009) standard for DR (EPRI 2009). Considering the sophistication of data center technology, fully automated DR (Auto-DR) should be a feasible option. Open Auto-DR offers the following benefits:

- Reliable, automated DR for existing and new IT and site infrastructure technologies.

- Integration with existing control and software systems for interoperability.

- Application to commercial and industrial end uses such as lighting, HVAC, and IT equipment using existing technology and controls infrastructure.

Open Auto-DR has demonstrated increased reliability in comparison to the performance of facilities with manual ${ }^{15}$ or semi-automated ${ }^{16} \mathrm{DR}$. The feasibility of Open Auto-DR in a data center depends on the specific Open Auto-DR program offering and its suitability for integration with the data center's IT and site infrastructure systems, networks, and communications security. California utilities have invested significantly in Open Auto-DR technology and communication infrastructure which data center technologies can utilize. As described in Section 5.0, Demand Response Opportunities, site infrastructure control strategies, such as changing supply air and zone temperature setpoints and adjusting lighting, have already been demonstrated as Open Auto-DR strategies within data centers that include commercial office spaces. IT infrastructure virtualization technologies have also been used to consolidate servers in proof-of-concept studies. These virtualization technologies could be integrated with utility Open Auto-DR infrastructure using a software client (Cassatt 2009).

Further study of data center equipment and technologies is needed for vendors to offer built-in Open Auto-DR features. "Open Auto-DR ready" systems would allow data centers to participate in utility DR communications infrastructure and integrate with pre-programmed DR strategies. Most data centers using Open Auto-DR for external communications will be concerned about network and security. Knowledgeable network administrators and software programmers can ensure secure communication of control systems and integration of automation.

\subsection{Open Auto-DR Architecture}

Figure 7 shows typical auto-DR architecture using open auto-DR standards, which is commercially implemented by California's three investor-owned Utilities: PG\&E, SCE, and San Diego Gas and Electric. The Demand Response Automation Server (DRAS) is a middleware or broker between the utility or ISO and the participating facility's systems. DRAS can enable a

\footnotetext{
${ }^{15}$ Manual DR: Manual turning off or changing of comfort setpoints or processes or of individual equipment, switches, or controllers.

${ }^{16}$ Semi-Automated DR: Automation of one or more processes or systems within a facility using an EMCS or centralized control system, with the remainder of the facility on manual operation.
} 
standard internet-based interface. Participating facilities or DR aggregators (Koch and Piette 2008) use a hardware or software "client" to communicate with the DRAS and retrieve DR event information; the facility then programs the DR strategies into its EMCS or other end-use technology. The client can be a hardware relay client, such as Client and Logic with Integrated Relay (CLIR); any third-party device; or a software-based client directly integrated within existing facility controls and technology subsystems, as shown in Figure 7. Data center technologies could use a software-based client for Open Auto-DR.

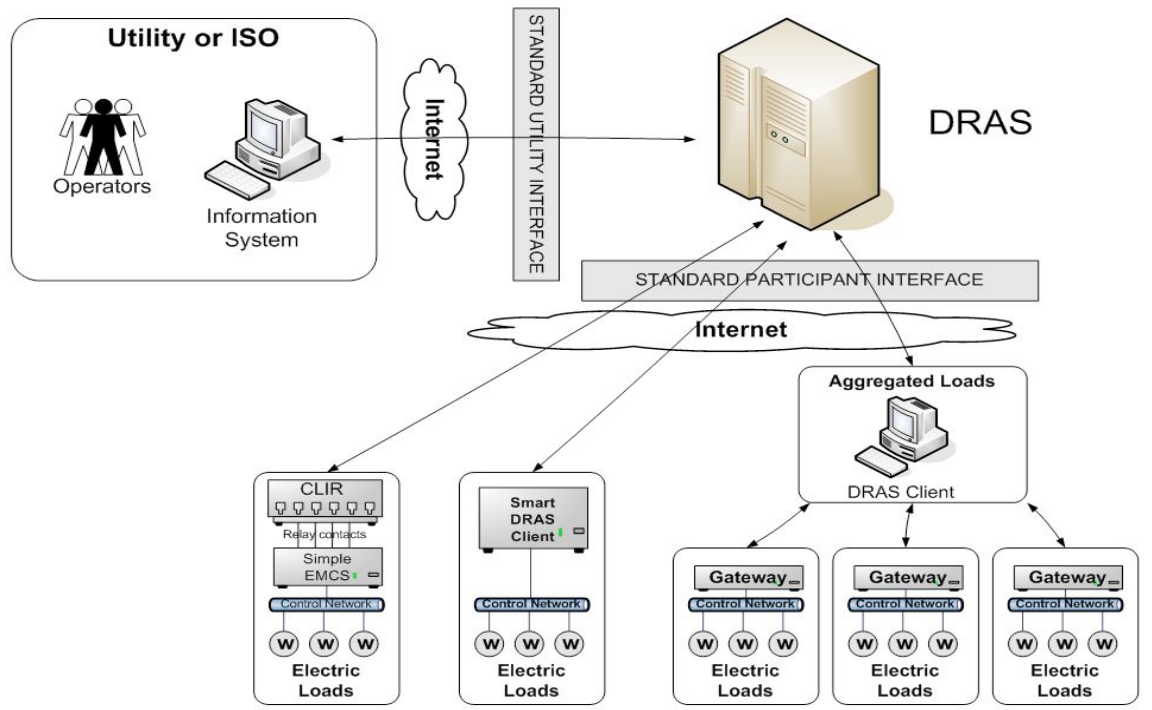

Figure 7. Auto-DR Architecture Concept and Open Auto-DR Standards

\subsubsection{Open Auto-DR Integration with Control Systems}

All sizeable data centers (greater than 1 MW IT load) have control systems to monitor and allow regulation of cooling, power delivery, and lighting. These systems could be used for DR though they might require custom programming to reduce load automatically for DR events.

\subsubsection{Open Auto-DR Integration with Virtualization Technologies}

Virtualization technologies designed to improve IT infrastructure energy efficiency could also be used for DR strategies via a software client. For example, more aggressive virtualization strategies than normal could be activated in response to a DR event notification to increase energy savings for the duration of the event. The California ISO started a demonstration project in 2008 testing three servers in a laboratory setting; this project has shown that virtualization technologies could be integrated with existing utility or ISO Open Auto-DR infrastructure. 


\subsection{Conclusions and Recommendations}

\subsection{Conclusions}

The results of this scoping study suggest that there is significant potential for cost and energy savings from implementation of DR in data center facilities. Specific characteristics of data center loads that make them promising candidates for DR include: minimal load variability and weather sensitivity, ${ }^{17}$ increasing energy costs and peak demand, and lack of existing DR programs for data center IT infrastructure.

Data centers' unique operational characteristics and use of highly advanced technology and control systems for both IT and site infrastructure make them good candidates Open Auto-DR, using the technology already deployed by California's investor-owned utilities. Implementation of DR in data centers faces a number of challenges, both practical and perceived. These include:

- Lack of studies and demonstrations of DR in data centers (both IT and site infrastructure) lead to perceived uncertainties about the capabilities of data centers to participate in DR programs and the potential impacts of DR, particularly on sensitive IT equipment and data center performance.

- Concerns about interrupting data center processes and adversely affecting quality of service and IT equipment life-span drive data center energy use, particularly cooling loads, and hesitation to participate in DR.

- No comprehensive strategy guide exists for implementing DR strategies in data centers.

- Energy-efficiency and DR technologies and practices are underutilized in data centers.

- Wide variation in different data center sizes, types, energy use, processes, and business strategies means there is no "one size fits all" data center DR solution.

- Resource-dependent load patterns that are driven by outside factors such as customer needs, mission-critical applications, and resource availability lead to continuous data center availability and redundant IT equipment.

- No comprehensive assessment has quantified the value to data centers of participating in DR programs.

- Most data centers currently measure energy performance separately for site and IT infrastructure. However, for DR purposes, performance must be evaluated at the WBP level because utilities need WBP savings for DR settlement purposes

Production data centers, which run business mission-critical applications and are fully operational at all times, have the greatest perceived equipment reliability and continuity-ofservice risks, making them less motivated to participate in DR. Laboratory, research, and other "non-mission-critical" data centers are the likeliest candidates for early adoption of DR.

DR strategies applicable to data center site infrastructure have been well-studied for other types of commercial buildings and could be readily deployed in data centers. These include:

\footnotetext{
${ }^{17}$ Mixed-use data centers, which contain large office spaces, have more weather-dependent loads than other types of data centers. Even within mixed-use data centers, however, the base load is very high, and load variability is only about $20 \%$.
} 
- Energy-efficiency measures for HVAC (for example, raising cooling setpoints)

- Optimization and use of lighting control systems

DR strategies applicable to data center IT infrastructure include:

- Raising environmental setpoints to conform to industry standards and recommendations (for example, raise zone supply air temperature and humidity limits).

- Using virtualization technologies to temporarily improve IT equipment efficiency, such as server consolidation and workload migration as is typically used for disaster recovery and situations where availability requirements are high.

- Using lighting control systems to reduce or turn off unnecessary lighting.

- Using synergistic strategies to integrate IT and site infrastructure energy use and load reductions.

- Using other emerging technologies, such as built-in equipment power management, UPS, transformers, bypass, and back-up storage strategies.

The results of this scoping study suggest that using virtualization technologies as a DR strategy to turn off underutilized IT infrastructure equipment will likely result in the greatest reduction of data center energy use because this strategy reduces both direct IT loads and supporting loads, particularly cooling. Virtualization technologies using Open Auto-DR can integrate with utility communications infrastructure and data center strategies to respond to Auto-DR events.

This scoping study also found that most data centers maintain temperature and humidity levels well below industry recommended standards. A moderate increase in temperature setpoints would result in immediate load reduction. If no negative impacts are experienced from reductions in cooling loads during DR events, permanent adjustments could be made to temperature setpoints, reducing overall data center energy use. Data centers that already employ efficient lighting and HVAC practices could benefit from additional DR strategies. Previous commercial DR program studies have shown that building control systems can be integrated with Open Auto-DR (Wikler et al. 2007).

\subsection{Commercialization Potential}

This report looks at the potential use of existing and emerging energy-efficiency technologies for DR and Open Auto-DR. Significant commercial potential may exist in integration of Open Auto-DR clients with data center virtualization technologies. The "integrated systems" approach of IT and a site infrastructure technology is another area that has significant energyefficiency and DR potential and could be integrated with Open Auto-DR. The adoption of DR strategies will depend on data centers' willingness to participate in DR, which in turn will depend on technology maturity and quantification of the energy savings of these strategies and their scalability.

\subsection{Recommendations}

Further research is needed on the deployment of DR in data centers to determine the specifics of DR strategies - which loads to shed, for what duration, using which technologies, and how best to interact with utilities. Studies and demonstrations of both specific strategies for DR in data centers, particularly strategies applicable to IT infrastructure, are needed to quantify the value 
to data centers of participating in DR programs and to create confidence that participation in DR will not undermine data center performance or equipment reliability and life span. The 2007 PG\&E Auto-DR program assessment recommends further studies of data centers for Open Auto-DR in particular (Wikler et al. 2007).

Future studies and demonstrations could include the participation of two to four data centers using some or all of the strategies examined in this report. Virtualization and emerging technology strategies are promising and need further research. Cooling system strategies are easy short-term targets that should be explored further. Proof-of-concept and field-test pilots in close collaboration with DR-service providers (e.g., utilities, aggregators), consumers (e.g., facilities), industrial partners, and experts will expedite data center DR adoption. These proofof-concept and pilot studies using manual tests will further comprehensive analysis and identification of key opportunities and automation of DR strategies and understand the data center load's flexibility and ability to respond to different DR program dispatches related to intermittent energy resources (for example, wind/solar). The product of these studies could be a comprehensive DR strategy guide containing sequences of operations and documentation of engineering and technology for data center DR as well as identification of requirements and barriers to data center DR, if any. Such a guide could instill confidence in data center operators to participate in DR.

\subsection{Benefits to California}

The data center industry is heavily concentrated in California, and data center energy use contributes significantly more to California's peak electricity load than the national average of $1.5 \%$ to $2 \%$. EPA study findings suggest that, in the PG\&E service territory alone, data centers represent an estimated $500 \mathrm{MW}$ of peak load. This energy use is increasing rapidly both within and outside California (EPA 2007). Concentration of data centers in certain areas of the state will strain the electricity distribution and supply system if current trends continue. This DRRC study is the first comprehensive exploration of data center DR opportunities. Although the emphasis is on impacts of data center DR in California, the study findings and recommendations also apply to other regions as well. 


\subsection{References}

ASHRAE. 2004. Thermal Guidelines for Data Processing Environments.

ASHRAE. 2008. 2008 ASHRAE Environmental Guidelines for Datacom Equipment - Expanding the Recommended Environmental Envelope. Available at http: / / tc99.ashraetcs.org/documents / ASHRAE_Extended_Environmental_Envelope_F inal_Aug_1_2008.pdf

ASHRAE Technical Committee 9.9. 2009. Available at http:/ / tc99.ashraetcs.org/ Accessed on July 11, 2009.

Belady, Christian, et al. 2007. The Green Grid Data Center Power Efficiency Metrics, PUE and DCiE. The Green Grid Association.

Brill, Kenneth G. 2008. Special Report: Energy Efficiency Strategies Survey Results. Uptime Institute.

Cassatt PG\&E feature pack:

http:// www.cassatt.com/infocentral/PGE/1.0/docs/InstallingPGE/ Accessed on July 11, 2009.

Cisco Richards-Zeta Mediator. http:/ / www.richards-zeta.com/Products/mediator.html Accessed on July 11, 2009.

Copan Systems. 2008. MAID: Attacking the energy demands of storing large volumes of persistent data. , Silicon Valley Leadership Group Presentation.

Coughlin, Katie, M.A. Piette, C. Goldman, and S. Kiliccote. 2008. Estimating Demand Response Load Impacts: Evaluation of Baseline Load Models for Non-Residential Building in California. Lawrence Berkeley National Laboratory Report LBNL-63728.

Electrical Power Research Institute (EPRI). 2009. Report to NIST on Smart Grid Interoperability Standards Roadmap. Available at http:/ / www.nist.gov/smartgrid/InterimSmartGridRoadmapNISTRestructure.pdf Accessed on July 11, 2009.

Energy Star. Energy Star Program Requirements for Computer Servers, DRAFT 3: Partner Commitments. Available at http:/ / www.energystar.gov/ia/partners/prod development/new specs/downloads/ servers/Draft3 Server_Spec 110408.pdf. Accessed on July 11, 2009.

EPA. 2007. EPA Report to Congress on Server and Data Center Energy Efficiency Public Law 109-431. Available at http:/ / www.energystar.gov/index.cfm?c=prod development.server efficiency, http:/ / www.energystar.gov/ia/partners/prod development/downloads/EPA Datace nter_Report_Congress_Final1.pdf. Both accessed on July 11, 2009.

EPA ENERGY STAR Enterprise Server and Data Center Energy Efficiency Initiatives. Available at http:/ / www.energystar.gov/index.cfm?c=prod_development.server_efficiency Accessed July 11, 2009. 
Flex your Power. 2008. Demand Response Programs. Available from:

http://www.fypower.org/flexalert/demand resp faq.html. Accessed on July 13, 2009

Gartner. 2006. Available at http:/ / www.gartner.com/it/page.jsp?id=499090 Accessed on July 11, 2009.

Gartner. 2008. Available at http://www.gartner.com/it/page.jsp?id=799812 Accessed on July 11, 2009.

Gartner. 2007. Available at http:/ / www.gartner.com/it/page.jsp?id=535714 Accessed on July 6, 2009.

The Green Grid. 2008. The Green Grid: Quantitative Efficiency Analysis of Power Distribution Configurations for Data Centers. The Green Grid Association.

Lawrence Berkeley National Laboratory and Rumsey Engineers. 2007. Data Center Air Management Report. Pacific Gas and Electric Company Emerging Technologies Program. Application Assessment Report \# 0517.

Lawrence Berkeley National Laboratory (LBNL), High Performance Buildings for High-Tech Industries: Data Center Server Power Supplies. 2009. Available at http:/ / hightech.lbl.gov/ Accessed on July 13, 2009.

Koch, Ed, and M.A. Piette. 2008. Scenarios for Consuming Standardized Automated Demand Response Signals. Presented at the Grid Interop Forum, Atlanta GA, November 11-13. Lawrence Berkeley National Laboratory Report LBNL-1362E. Available at http://drrc.lbl.gov/openadr/pdf/1362e.pdf

Lekov, Alex, L. Thompson. A. McKane, A. Rockoff, and M.A. Piette. 2009. Opportunities for Energy Efficiency and Automated Demand Response in Industrial Refrigerated Warehouses in California. Lawrence Berkeley National Laboratory Report LBNL-1991E.

McKane A.T., M.A. Piette, D. Faulkner, G. Ghatikar, A. Radspieler Jr., B. Adesola, S. Murtishaw, and S. Kiliccote. 2008. Opportunities, Barriers, and Actions for Industrial Demand Response in California. LBNL-1335E.

Modius Data Center Infrastructure Manager (DCiM). http: / / www.modius.com/ product Accessed on July 11, 2009.

Motegi, Naoya, M.A. Piette, D. Watson, and O. Sezgen. 2004. Measurement and Evaluation Techniques for Automated Demand Response Demonstration. Presented at the 2004 ACEEE Summer Study on Energy Efficiency in Buildings, Pacific Grove CA, August 23-27. Lawrence Berkeley National Laboratory Report LBNL-55086. Available at http: / / drrc.lbl.gov/pubs/LBNL_55086.pdf

Motegi, Naoya, M.A. Piette, D.S. Watson, S. Kiliccote, and P. Xu. 2007. Introduction to Commercial Building Control Strategies and Techniques for Demand Response. California Energy Commission, PIER. Lawrence Berkeley National Laboratory Report LBNL-59975. 
Pacific Gas and Electric Company. 2008. What is Demand Response? Available from: http://www.pge.com/mybusiness/energysavingsrebates/demandresponse/ whatisde mandresponse/ Accessed June 26, 2009.

Piette, Mary Ann, G. Ghatikar, S. Kiliccote, E. Koch, D. Hennage, P. Palensky, and C. McParland. 2009. Open Automated Demand Response Communications Specification (Version 1.0). California Energy Commission, PIER Program. CEC-500-2009-063. Lawrence Berkeley National Laboratory Report LBNL-1779E.

Roth, Kurt, D. Westphalen, M. Feng, P. Llana, and L. Quartararo. 2005. Energy Impact of Commercial Building Controls and Performance Diagnostics: Market Characterization, Energy Impact of Building Faults and Energy Savings Potential. TIAX LLC.

Rubinstein, Francis, and S. Kiliccote. 2007. Demand Responsive Lighting: A Scoping Study. Lawrence Berkeley National Laboratory Report LBNL-62226.

Rumsey Engineers and Lawrence Berkeley National Laboratory. 2006. High-Performance Data Centers: A Design Guidelines Sourcebook. Pacific Gas and Electric Company. Available at http:/ / hightech.lbl.gov/documents/DATA_CENTERS/06_DataCenters-PGE.pdf

Samson, Tom. 2008. Intel pushes the limits of free cooling to 90 degrees. Available at http:/ / www.infoworld.com/d/green-it/intel-pushes-limits-free-cooling-90-degrees-852 Accessed on July 16, 2009.

Shehabi, Arman, W. Tschudi, A. Gadgil. 2007. Data Center Economizer Contamination and Humidity Study. Lawrence Berkeley National Laboratory report to Pacific Gas and Electric Company. LBNL-2424E.

Silicon Valley Leadership Group and Accenture. 2008. Data Center Energy Forecast.

Stanley, John R., K.G. Brill, and J. Koomey. Four Metrics Define Data Center “Greenness." Uptime Institute.

Sullivan, Robert F. 2006. Alternating Cold and Hot Aisles Provides More Reliable Cooling for Server Farms. Uptime Institute.

Sun Modular Data Center. 2008. IBM Addresses Designs for the New Enterprise Datacenter.

Tschudi, William, E. Mills, S. Greenberg, and P. Rumsey. 2006. Measuring and Managing DataCenter Energy Use. HPAC Engineering. March. Available at http://hightech.lbl.gov/documents/DATA CENTERS/HPAC DC BestPrac.pdf

U.S. DOE. 2009. Press release on Smart Grid standards. http:/ / www.energy.gov/news2009/7408.htm Accessed on July 11, 2009.

Verdun, Gary, et al. 2008. The Green Grid Metrics: Data Center Infrastructure Efficiency (DCiE) Detailed Analysis. The Green Grid Association.

Virtual Iron Software, Inc., 2007. The New Economics of Virtualization: Applying Server Virtualization for Greater ROI. 
Wikler, Greg, I. Bran, J. Prijyanonda, S. Yoshida, K. Smith, M.A. Piette, S. Kiliccote, G. Ghatikar, D. Hennage, and C. Thomas. 2008. Pacific Gas E Electric Company 2007 Auto-DR Program: Task 13 Deliverable: Auto-DR Assessment Study. Report to PG\&E. 


\subsection{Glossary}

\begin{tabular}{|c|c|}
\hline$A C$ & alternating current \\
\hline ASHRAE & American Society of Heating, Refrigerating, and Air-Conditioning Engineers \\
\hline Auto-DR & automated demand response \\
\hline BOPS & billion operations per second or billion processes per second \\
\hline CAISO & California Independent System Operator \\
\hline CLIR & client and logic with integrated relay \\
\hline CRAC & computer room air conditioner \\
\hline $\mathrm{CRAH}$ & computer room air handler \\
\hline $\mathrm{DC}$ & direct current \\
\hline DC-EER & data center energy-efficiency ratio \\
\hline DCiE & data center infrastructure efficiency \\
\hline DLF & daily load factor \\
\hline $\mathrm{DOE}$ & U.S. Department of Energy \\
\hline DR & demand response \\
\hline DRAS & demand response automation server \\
\hline DRRC & demand response research center \\
\hline EMCS & energy management control system \\
\hline EPA & United States Environmental Protection Agency \\
\hline FLOPS & floating point operations per second \\
\hline HVAC & heating, ventilation, and air conditioning \\
\hline IP & internet protocol \\
\hline ISO & independent system operator \\
\hline IT & information technology \\
\hline IT-EER & information technology energy-efficiency ratio \\
\hline $\mathrm{kWh}$ & kilowatt-hour \\
\hline LBNL & Lawrence Berkeley National Laboratory \\
\hline MW & megawatt \\
\hline $\mathrm{MWh}$ & megawatt-hour \\
\hline OEM & original equipment manufacturer \\
\hline OpenADR & open automated demand response \\
\hline PG\&E & Pacific Gas and Electric Company \\
\hline PIER & Public Interest Energy Research \\
\hline PSRR & physical server reduction ratio \\
\hline PUE & power usage effectiveness \\
\hline$R \& D$ & research and development \\
\hline SAN & storage area network \\
\hline SCADA & supervisory control and data acquisition \\
\hline SCE & Southern California Edison \\
\hline SDG\&E & San Diego Gas and Electric \\
\hline SI-EER & site infrastructure energy-efficiency ratio \\
\hline SLA & service level agreement \\
\hline SNMP & simple network management protocol \\
\hline
\end{tabular}




\begin{tabular}{|l|l|} 
TCP & transmission control protocol \\
\hline UPS & uninterruptible power supply \\
\hline VAV & variable air volume \\
\hline W & watt \\
\hline WBP & whole-building power \\
\hline XML & eXtensible mark-up language \\
\hline
\end{tabular}




\section{Appendix A. Recommendations and Guidelines, Data Center Classifications}

This appendix, in reference to section 2.0, details examples of industry practices relating to recommendations and guidelines such as ASHRAE and EPA ENERGY STAR and details on classification of data centers by design, type, size, and equipment characteristics.

\section{ASHRAE 2008 TC 9.9 Recommendations}

The figure below shows, in the shaded region, the allowable temperature and humidity ranges for data centers and similar facilities from ASHRAE Technical Committee 9.9's updated 2008 recommendations (ASHRAE Technical Committee 9.9. 2009). By ASHRAE definition, those data centers relevant to this study are:

- Class 1 is "typically a data center with tightly controlled environmental parameters (dew point, temperature, and relative humidity) and mission critical operations; types of products typically designed for this environment are enterprise servers and storage products."

- Class 2 is "typically an information technology space or office or lab environment with some control of environmental parameters (dew point, temperature, and relative humidity); types of products typically designed for this environment are small servers, storage products, personal computers, and workstations."

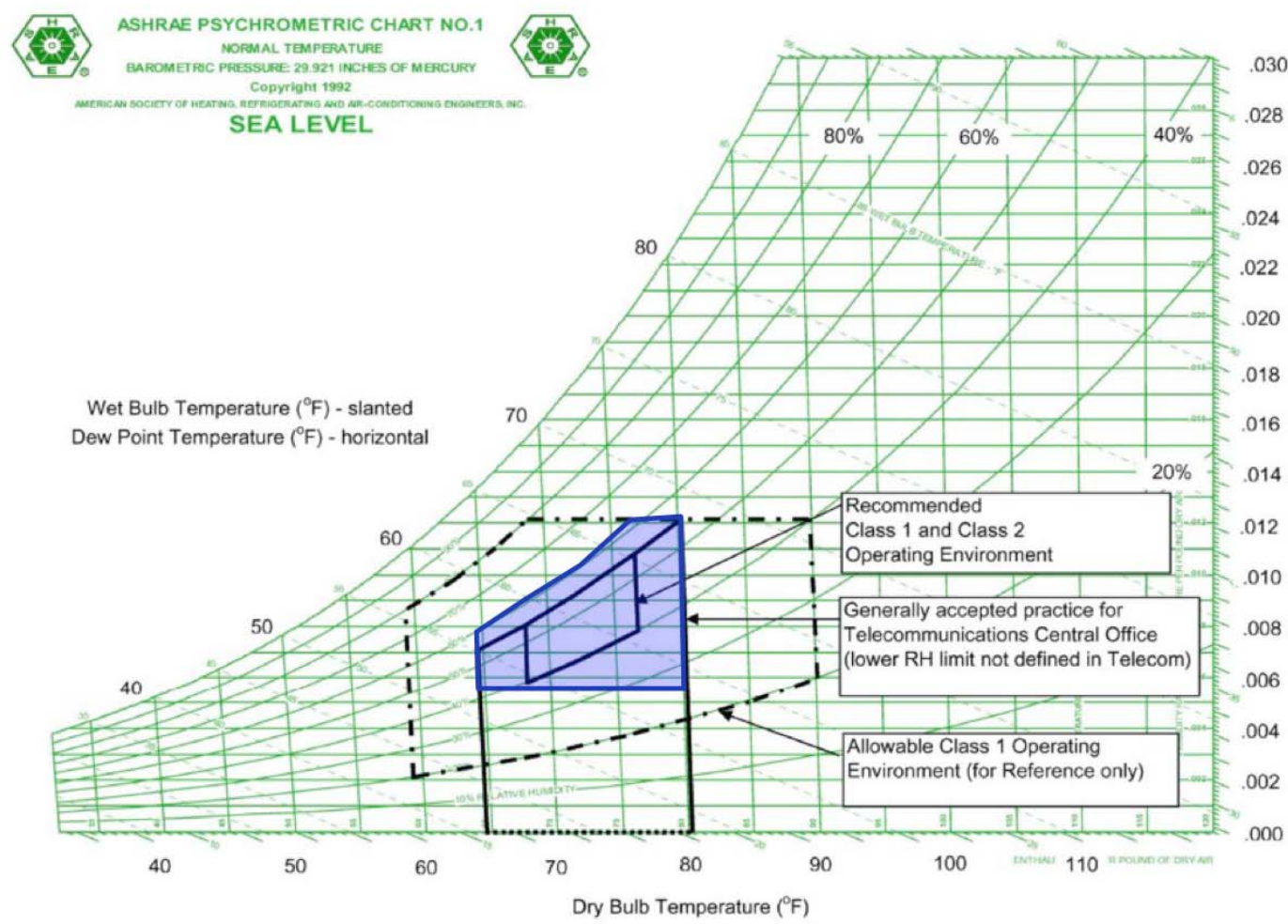

Figure 8. ASHRAE 2008 Recommended Design Conditions at the Inlet to IT Equipment 


\section{EPA ENERGY STAR Recommendations}

The following tables present the Tier 1 ENERGY STAR efficiency requirements for enterprise class computer servers, effective February 1, 2009 (Energy Star 2009).

Table 9. ENERGY STAR Computer Server Power Supply and Power Factor Specifications

\begin{tabular}{|l|l|l|l|l|l|}
\hline Efficiency Requirements & Rated Output Power & $\begin{array}{l}\mathbf{1 0 \%} \\
\text { Load }\end{array}$ & $\begin{array}{l}\mathbf{2 0} \% \\
\text { Load }\end{array}$ & $\begin{array}{l}\mathbf{5 0} \% \\
\text { Load }\end{array}$ & $\begin{array}{l}\mathbf{1 0 0} \% \\
\text { Load }\end{array}$ \\
\hline Multi-Output (AC-DC \& DC-DC) & All Output Levels & N/A & $82 \%$ & $85 \%$ & $82 \%$ \\
\hline Single-Output (AC-DC \& DC-DC) & $\leq 1,000$ Watts & $75 \%$ & $85 \%$ & $89 \%$ & $85 \%$ \\
\cline { 2 - 7 } & $>1,000$ Watts & $80 \%$ & $88 \%$ & $92 \%$ & $88 \%$ \\
\hline \hline Power Factor Requirements & All Output Levels & N/A & N/A & N/A & N/A \\
\hline DC-DC (All) & $\leq 1,000$ Watts & 0.65 & 0.80 & 0.90 & 0.90 \\
\hline AC-DC Single-Output & 0.80 & 0.90 & 0.90 & 0.90 \\
\hline AC-DC Single-Output & $>1,000$ Watts & NA & 0.80 & 0.90 & 0.90 \\
\hline AC-DC Multi-Output & All Output Levels & & & \\
\hline
\end{tabular}

Table 10. ENERGY STAR Idle Server Power Consumption Limits

\begin{tabular}{|l|l|}
\hline System Type & Idle Power Limit \\
\hline Single Installed Processor & 60 Watts \\
\hline Two or Three Installed Processors & 151 Watts \\
\hline Standard Availability Systems & 169 Watts \\
\hline High Availability, Low Installed Memory $(<16 \mathrm{~GB})$ Systems & 221 Watts \\
\hline High Availability, High Installed Memory $(\geq 16 \mathrm{~GB})$ Systems & 271 Watts \\
\hline Four Installed Processors &
\end{tabular}

\section{Data Center Design Types, Size, and Equipment Characteristics}

The following table defines data center types by size and equipment characteristics (EPA 2007).

Table 11. Data Center Types, Typical Sizes, and IT Equipment Characteristics

\begin{tabular}{|l|l|l|}
\hline Space Type & Typical Size & Typical IT Equipment Characteristics \\
\hline Server closet & $<200 \mathrm{ft}^{2}$ & $\begin{array}{l}1-2 \text { servers } \\
\text { No external storage }\end{array}$ \\
\hline Server room & $<500 \mathrm{ft}^{2}$ & $\begin{array}{l}\text { A few to a few dozen servers } \\
\text { No external storage }\end{array}$ \\
\hline Localized data center & $<1000 \mathrm{ft}^{2}$ & $\begin{array}{l}\text { Dozens to hundreds of servers } \\
\text { Moderate external storage }\end{array}$ \\
\hline Mid-tier data center & $<5000 \mathrm{ft}^{2}$ & $\begin{array}{l}\text { Hundreds of servers } \\
\text { Extensive external storage }\end{array}$ \\
\hline Enterprise-class data center & $5000+\mathrm{ft}^{2}$ & $\begin{array}{l}\text { Hundreds to thousands of servers } \\
\text { Extensive external storage }\end{array}$ \\
\hline
\end{tabular}


Data centers can be categorized as internal or external, and also by their particular purpose with a company, such as research and development or web hosting. Internal and external data center characteristics are described in detail below.

1. Internal: Internal data centers primarily provide for internal organization needs and can be divided into two main functions:

- Production: Production data centers provide IT functions such as servers for printing, email, web access and hosting, financial, sales, inventory and other management systems, and storage of company data. These data centers are usually quite homogenous in the style and type of equipment and often have high availability requirements.

- Research and Development (R\&D): R\&D data centers contain hardware equipment to design, test, and model products. The hardware in these data centers often varies widely in type, size and age. R\&D data centers often have lower availability requirements than production data centers, as well as lower equipment density requirements.

2. External: External data centers provide outsourced services to other companies. These data centers vary in service offerings but generally have similar availability goals. Although they typically have $5 \mathrm{MW}$ to $15 \mathrm{MW}$ of IT load, their size can vary as can the sophistication of their infrastructure controls and staff. Some provide and manage all IT equipment for their customers, but most provide only power, cooling, and building services, and there is a full range of services in between. External data centers include the following business models and product offerings:

- Co-location - Co-location data centers provide data center services (power, cooling, network connectivity and sometimes managed services) per half-rack, full-rack or cage, and sometimes have a room dedicated to a single customer. Services are usually sold per space unit (rack) and per electrical circuit; co-location data centers rarely charge for energy usage. They do not provide hardware or software except through third-party arrangements, and they rarely manage hardware full time but often sell managed services to support hardware part-time.

- Real-Estate Investment Trust, Real Estate, and Wholesale - Wholesale data centers are like co-location providers except that they usually provide data center services on a perroom basis and sell these services by the electrical capacity of the UPS to that area. They do not offer any managed services, hardware and software services, or network services. Wholesale data centers also charge for metered electricity consumption for the leased area and power capacity provided.

- Managed Hosting - Managed hosting companies are similar to co-location data centers except they charge by the rack unit and often include hardware as well as network transfer and managed services. They do not charge for electricity. Essentially, each customer manages its own equipment and services remotely, and in some cases customers can access their hardware directly. Servers are dedicated to one customer, but network gear, back-up storage, and other hardware are often shared, as well as much if not all of the server management.

- Web Hosting - Web hosting companies provide all services (hardware, network, software), with little to no involvement by the customer. Server capacity is shared 
between customers and the provider manages all services. Customers do not directly pay for electricity.

- Cross-Over - Any data center, internal or external, can have sections or groups of servers that provide any of the managed services mentioned above. 


\section{Appendix B. Data Center Components, Measurements, and Case Studies}

This appendix, in reference to section 3.0, details data center components and measurement practices for energy use and further analysis of case studies and metrics used for load characterization of data centers.

\section{Data Center Electrical and Energy Components}

The main electrical components of data centers are described in the main body of this report. Figure 9 describes electrical components for both data center and office spaces (EPA 2007).

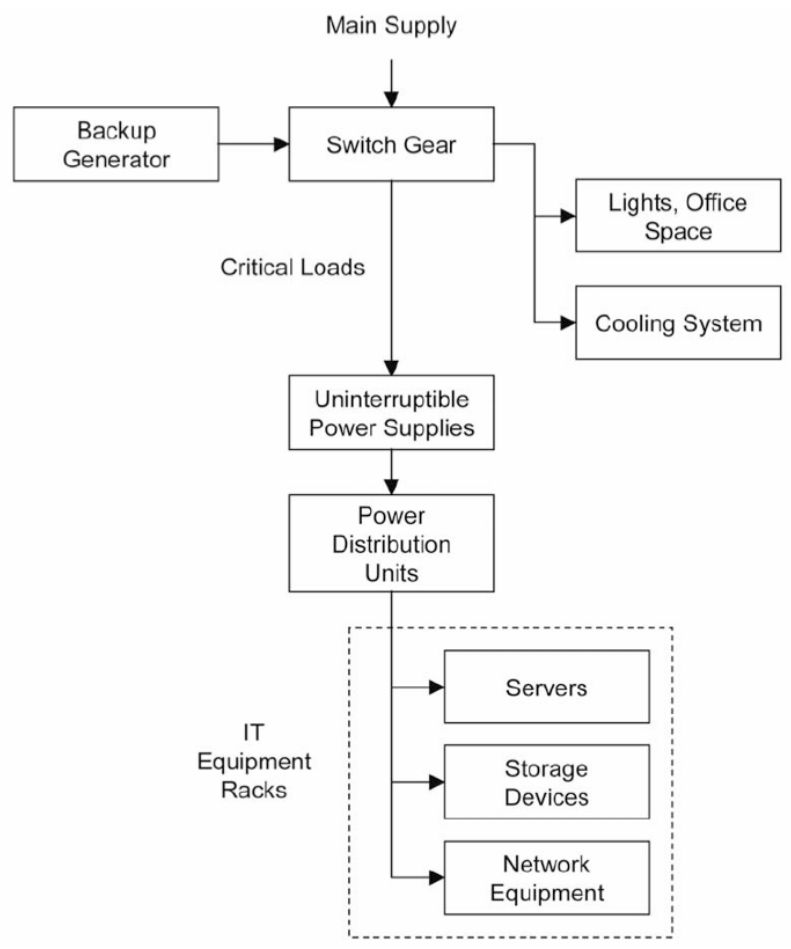

\section{Figure 9. Typical Electrical Components in a Data Center and Office}

\section{EPA PUE Measurement Model}

In the model used by EPA, site and IT infrastructure PUE measurements are broken down into the individual components, and the total facility PUE is measured by adding power delivery (transformer and UPS losses), cooling (chilled water systems and fans), and lighting within site and IT infrastructures. The figure below shows some data center PUE values (Silicon Valley Leadership Group and Accenture 2008). 


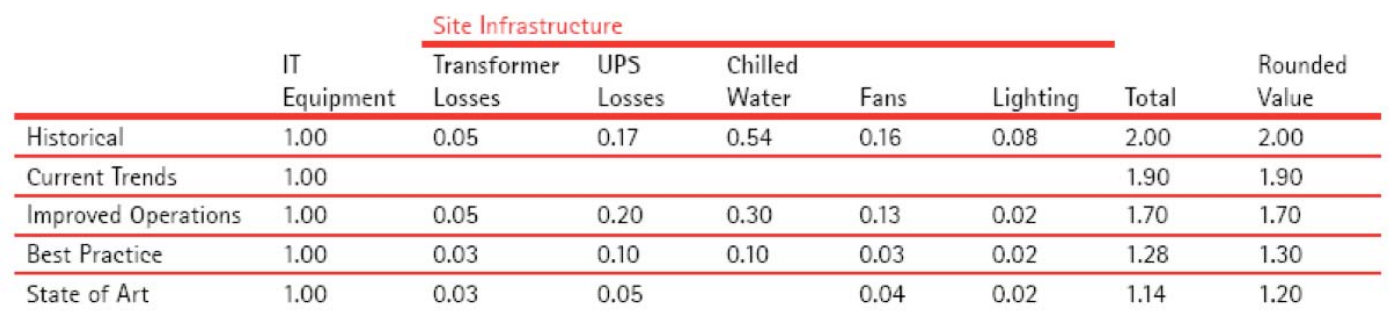

Figure 10. PUE by Site Infrastructure End Uses in Relation to IT Equipment and Scenarios

\section{Additional Data Center Load Characterization and Analysis}

The subsections below further analyze data center load characterization and load shapes summarized in section 3.0 of the report. The analysis looks at data center loads from a DR event perspective - weekly, daily, and seasonal loads and variations in operational scenarios.

\section{Data Center 1}

Typically, data centers have long-term, continually increasing load; however, they have loads that are classified as flat because data centers have high average DLF, e.g., 98\%, which indicates flat short-term loads. Figure 11 shows data from Data Center 1; a trend of continuous long-term increasing load is evident during 2008, with a cumulative increase of about $33 \%$.

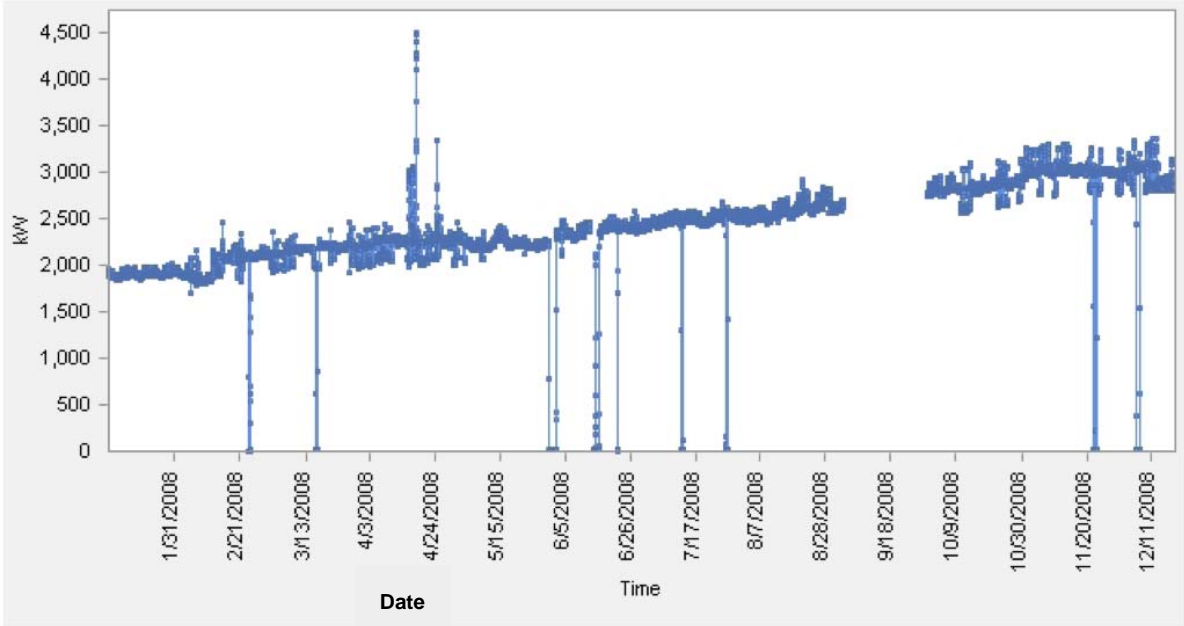

Figure 11. Data Center 1 Load in 2008

Figure 12 shows the summer and winter daily loads for Data Center 1 ; the average load deviates very little and does not appear to be influenced by weather. 


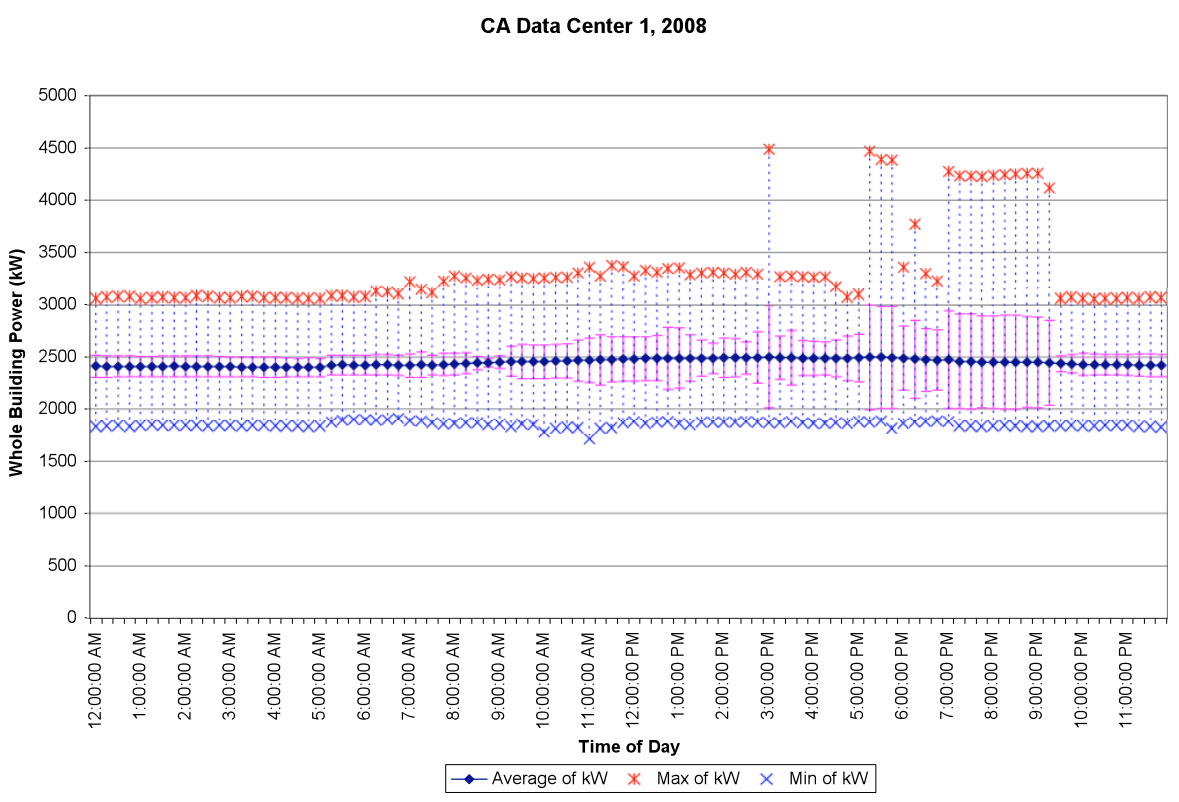

Figure 12. Data Center 1 Load on Summer and Winter Days 2008, with Standard Deviation

Figures 13 and 14 shows the load during the week of August 3-9, 2008 (Figure 13) and on August 6, 2008 (Figure 14). Both show relatively flat load with some variation during on- and off-peak times. The load remains relatively flat during the day, although it varies among the days in the week.

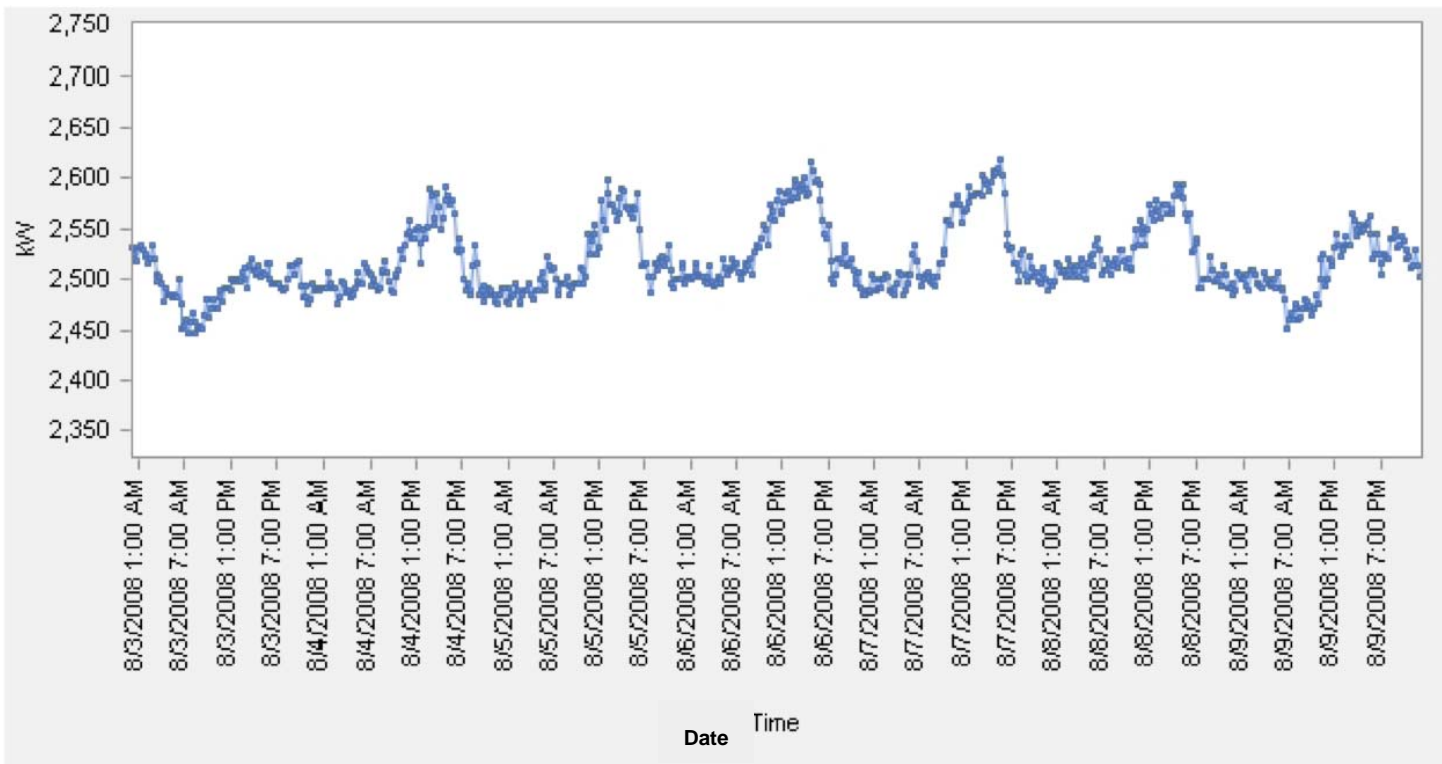

Figure 13. Some Variation in Data Center 1 Load during the week of August 3-9, 2008 


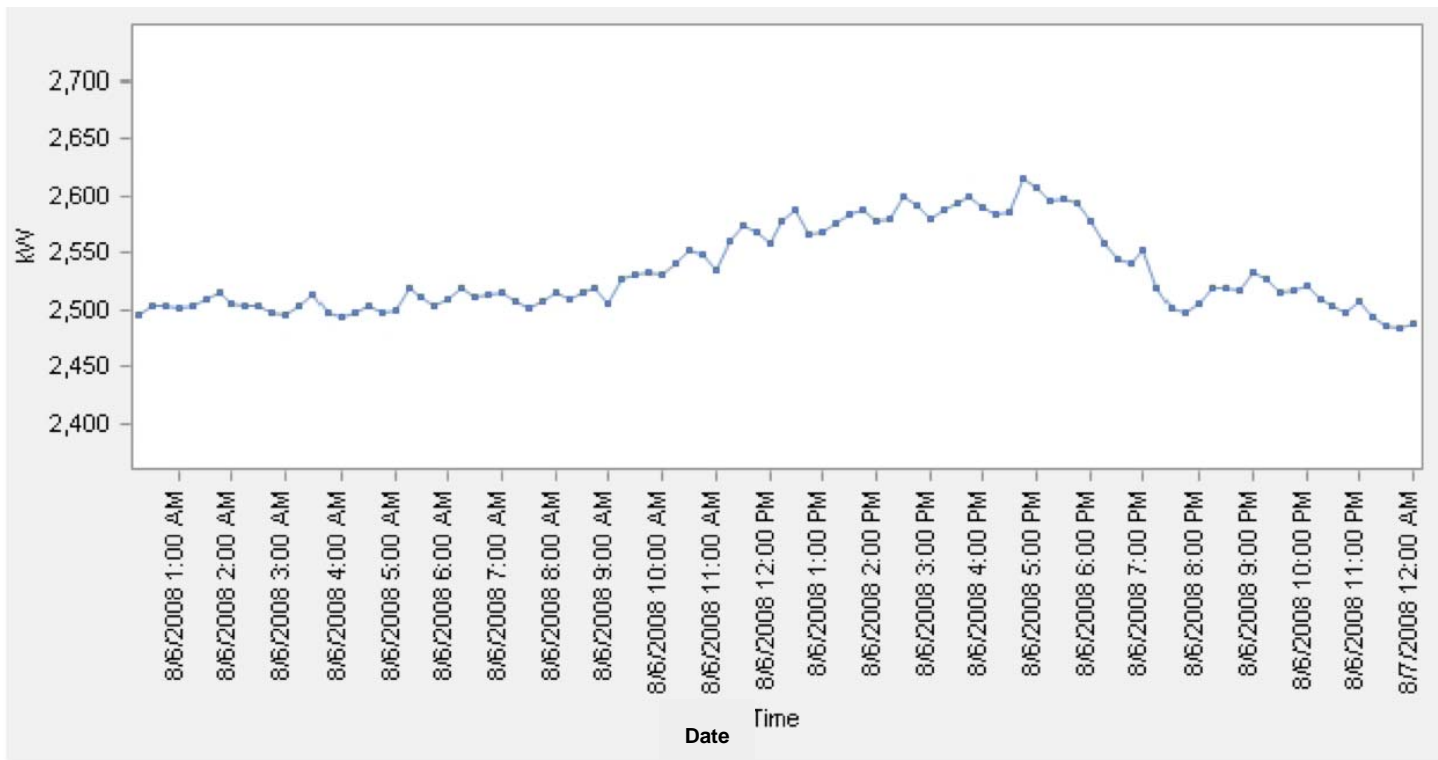

Figure 14. Relatively Flat Data Center 1 Load on August 6, 2008

Figures 15 and 16 show 2008 summer (Figure 15) and winter days (Figure 16) for Data Center 1. The figures show very little deviation between minimum and maximum loads when averaged over the season. This suggests that the load is not influenced by (has no correlation to) the weather.

CA Data Center 1, Summer/2008

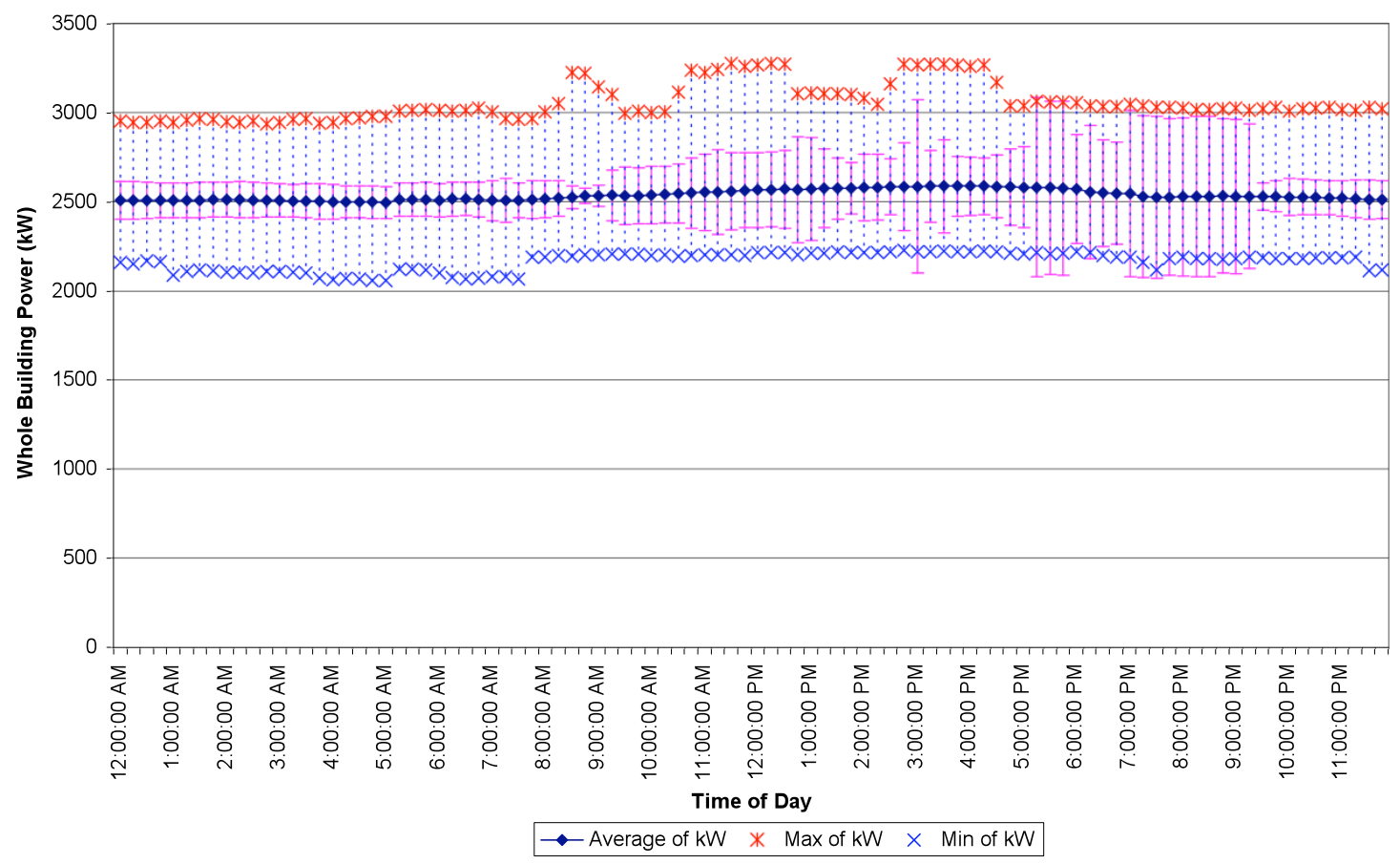

Figure 15. Data Center 1 Load during 2008 Summer Days with Standard Deviation 
CA Data Center 1, Winter/2008

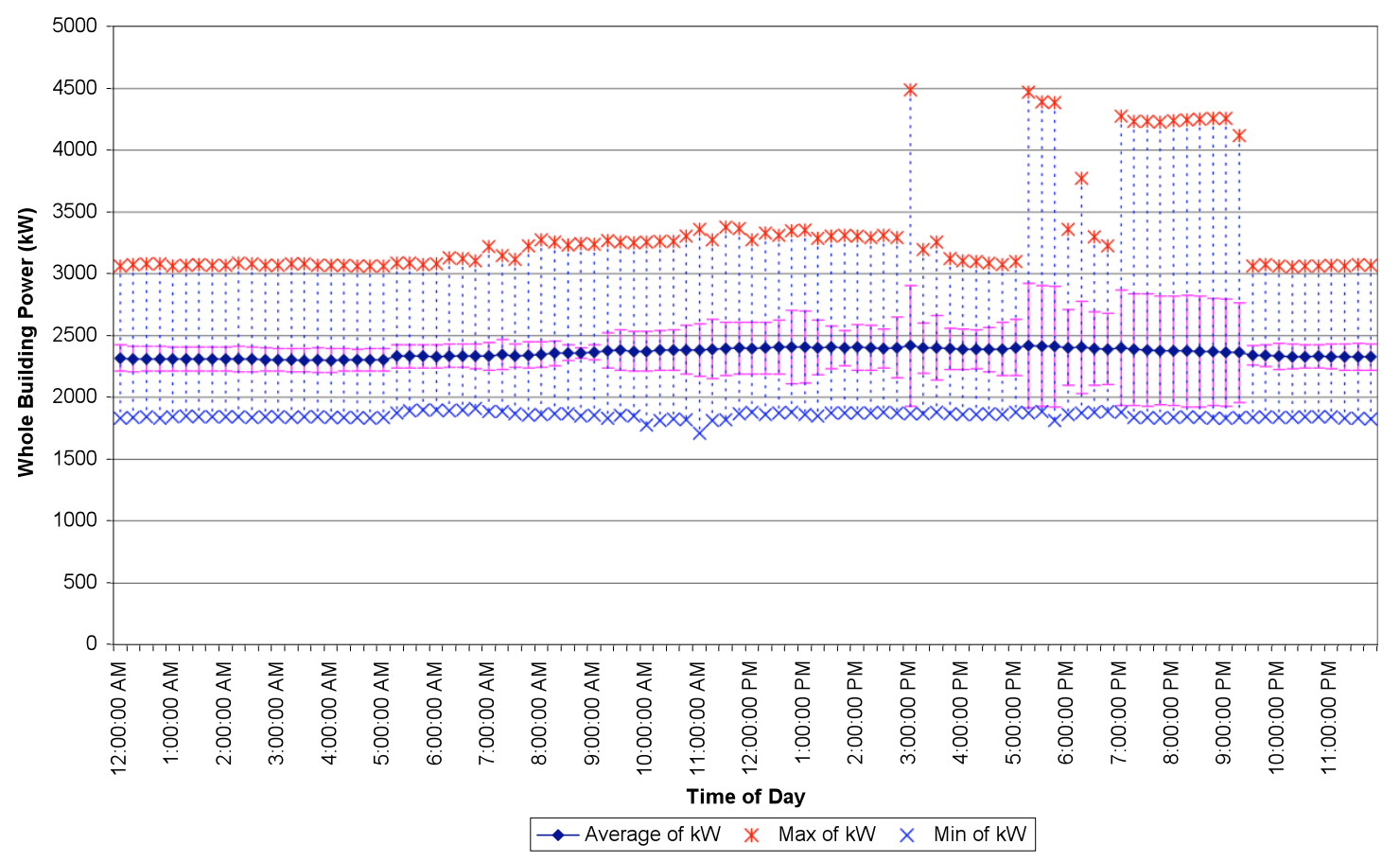

Figure 16. Data Center 1 Load during 2008 Winter Days with Standard Deviation

\section{Data Center 2}

Figure 17 are 18 are from the mixed-use Data Center 2. Due to the office space, the typical daily load is similar to what was found in LBNL's study of commercial building DR, with some onand off-peak variation although high loads persist during off-peak hours.

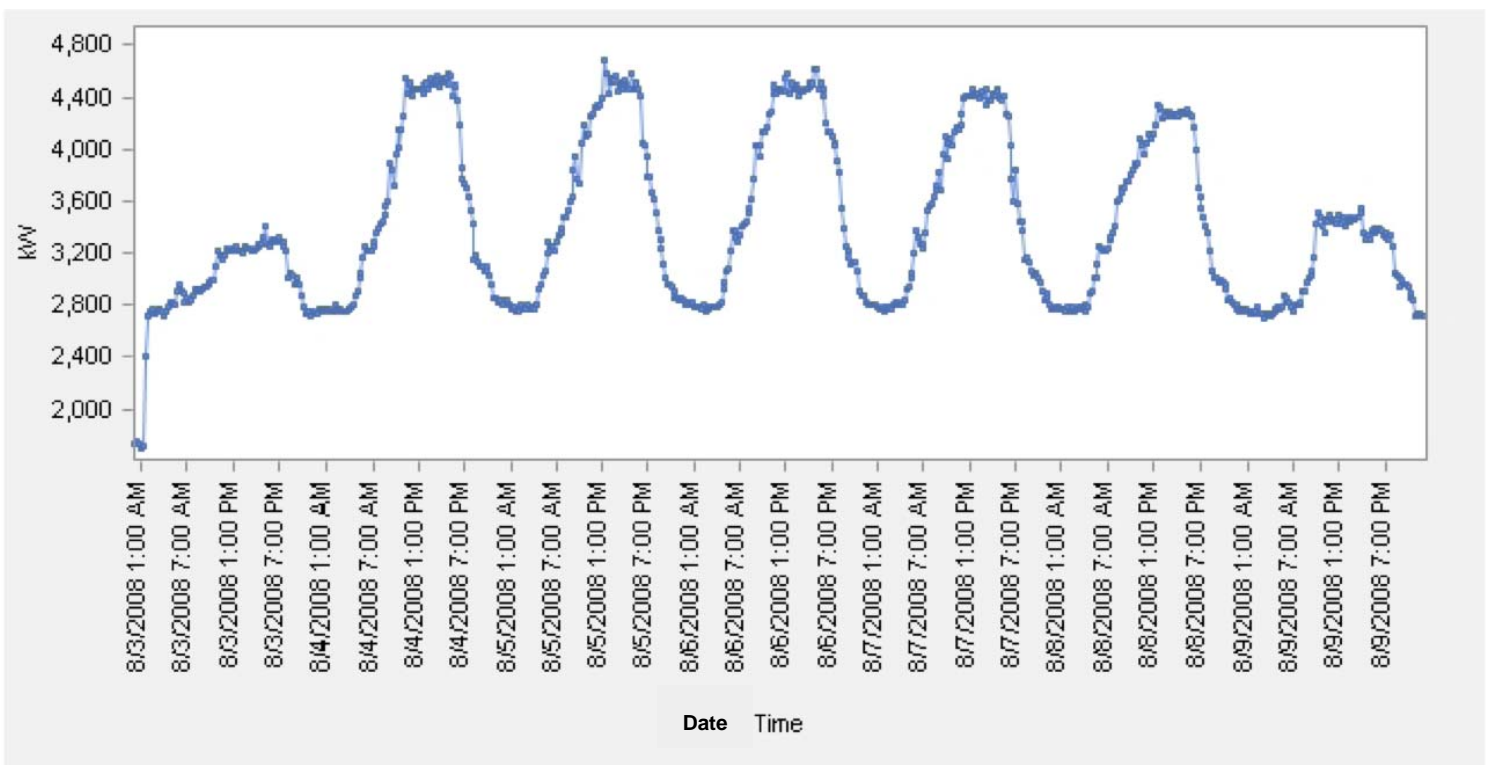

Figure 17. Varying Mixed-use Data Center 2 Load during the Week of August 3-9, 2008 


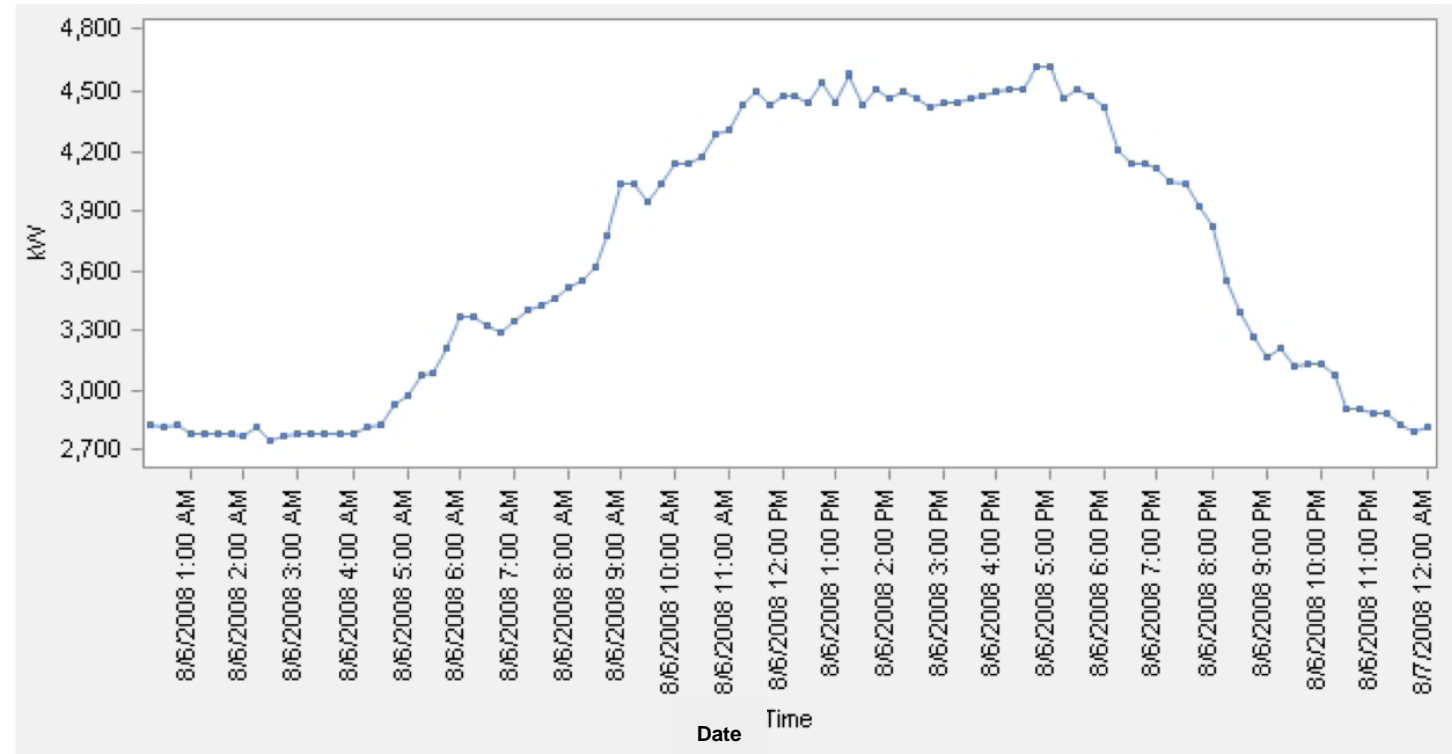

Figure 18. Mixed-use Data Center 2 Load on August 6, 2008

Figures 19 and 20 are similar to the daily load figure above, showing average loads in comparison to maximum and minimum load. The calculated standard deviation is small, indicating that mixed-use data centers are better DR candidates for summer peaks.

CA Data Center 2, Summer/2007

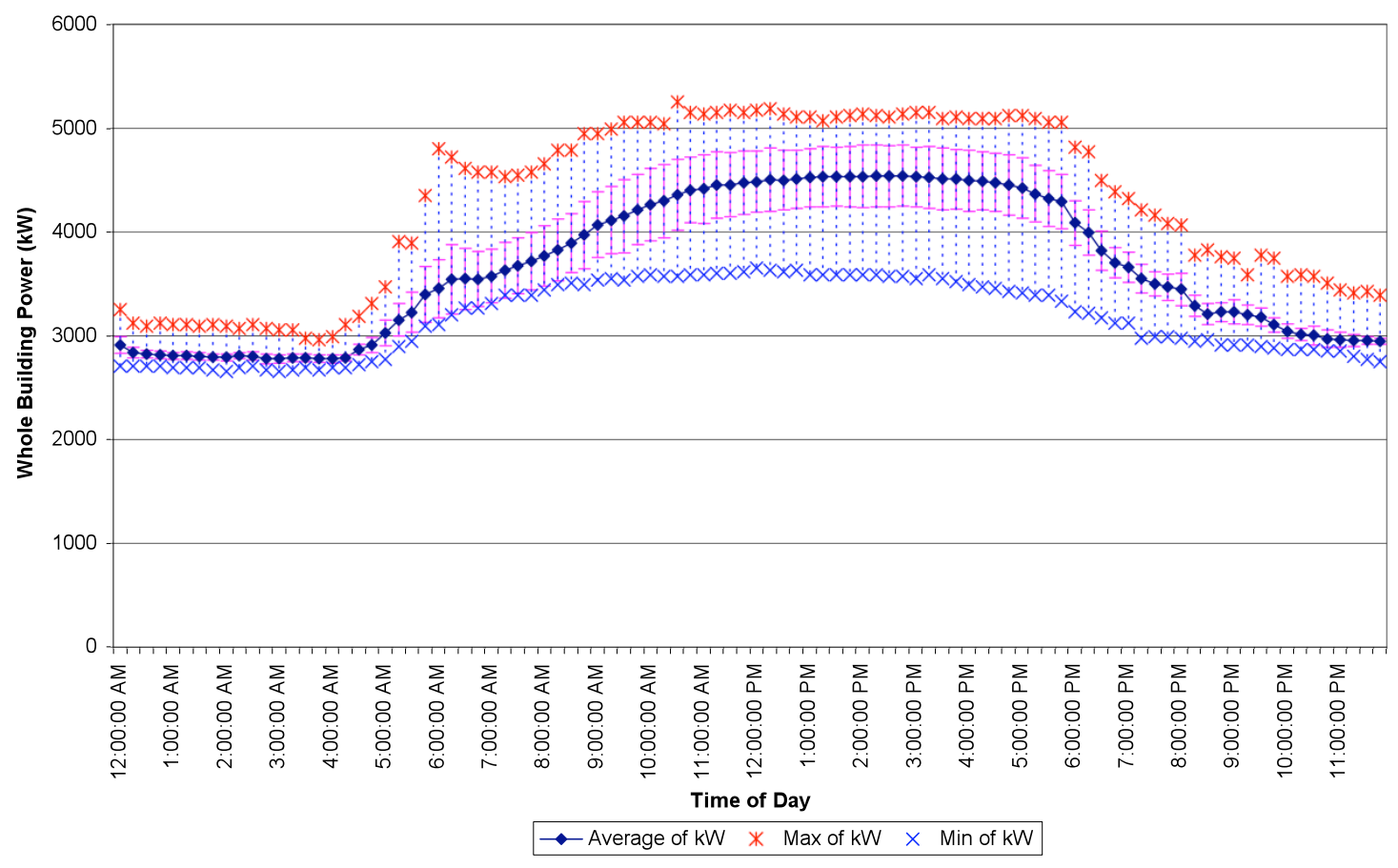

Figure 19. Mixed-use Data Center 2 Summer Days Load in 2007 
CA Data Center 2, Winter/2007

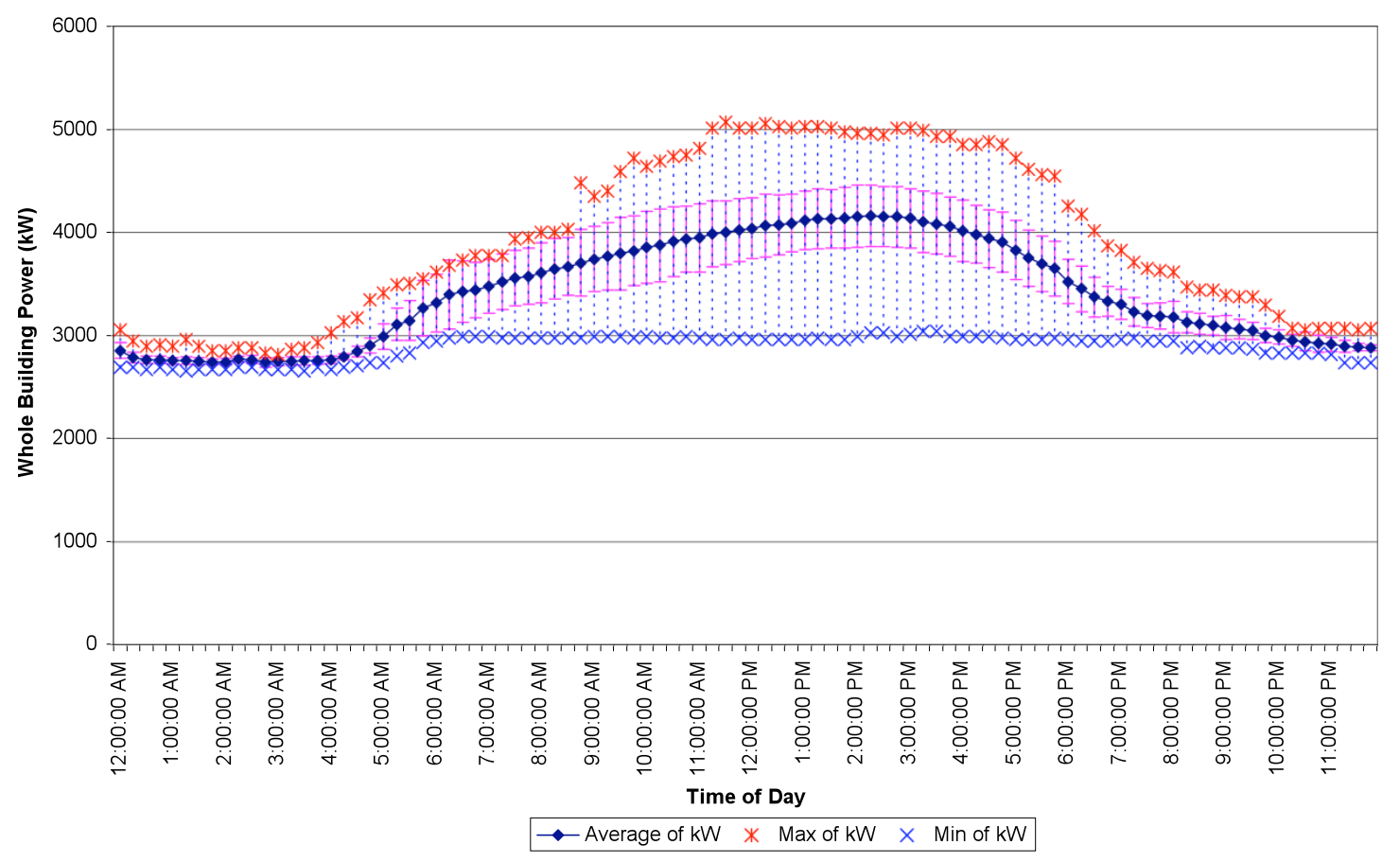

Figure 20. Mixed-use Data Center Winter Days Load in 2007

\section{Data Center 5}

Figures 21 and 22 show a flat data center load varying little during a week or day, so energy use is predictable.

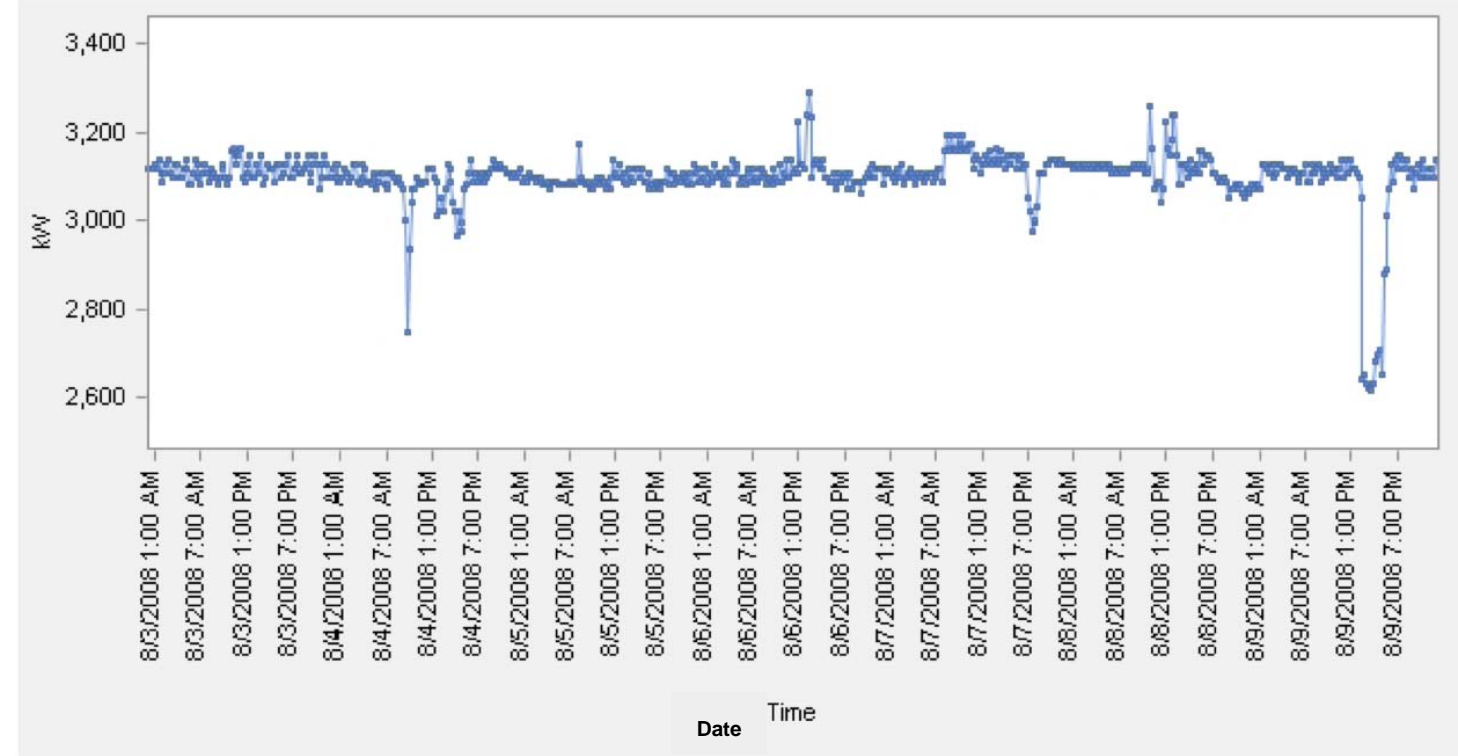

Figure 21. Relatively Flat Data Center 5 Load in the week of August 3-9 of 2008 


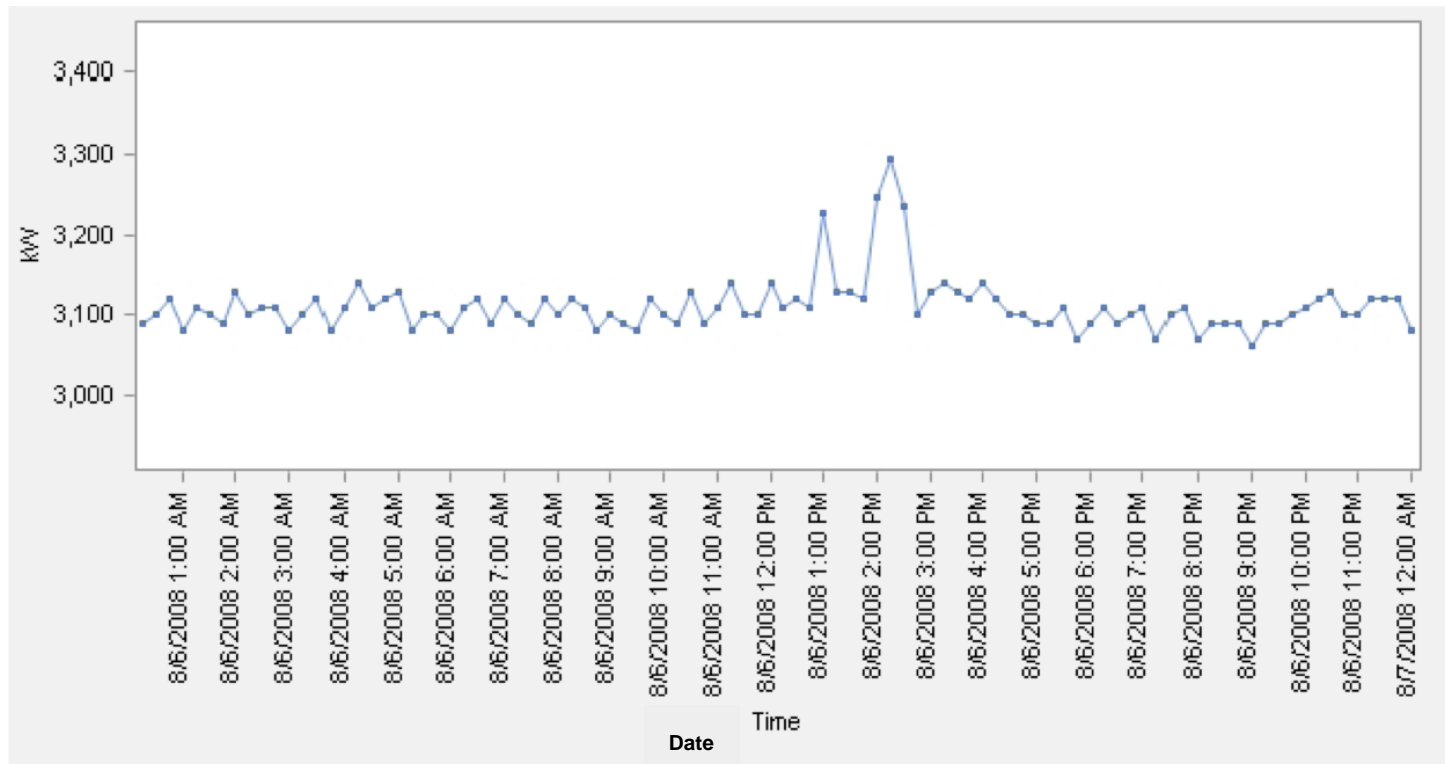

Figure 22. Relatively Flat Data Center 5 Load on August 6, 2008

Figure 23 is an example of continued rise in energy use. The steep load rise (almost 100\%) seen here is common for data centers that add more powerful and faster IT equipment due to increasing operational demands, though typically the increase takes place over a longer period of time and is not as noticeable in average daily load factors. The load then tends to remain flat until the next round of equipment upgrades.

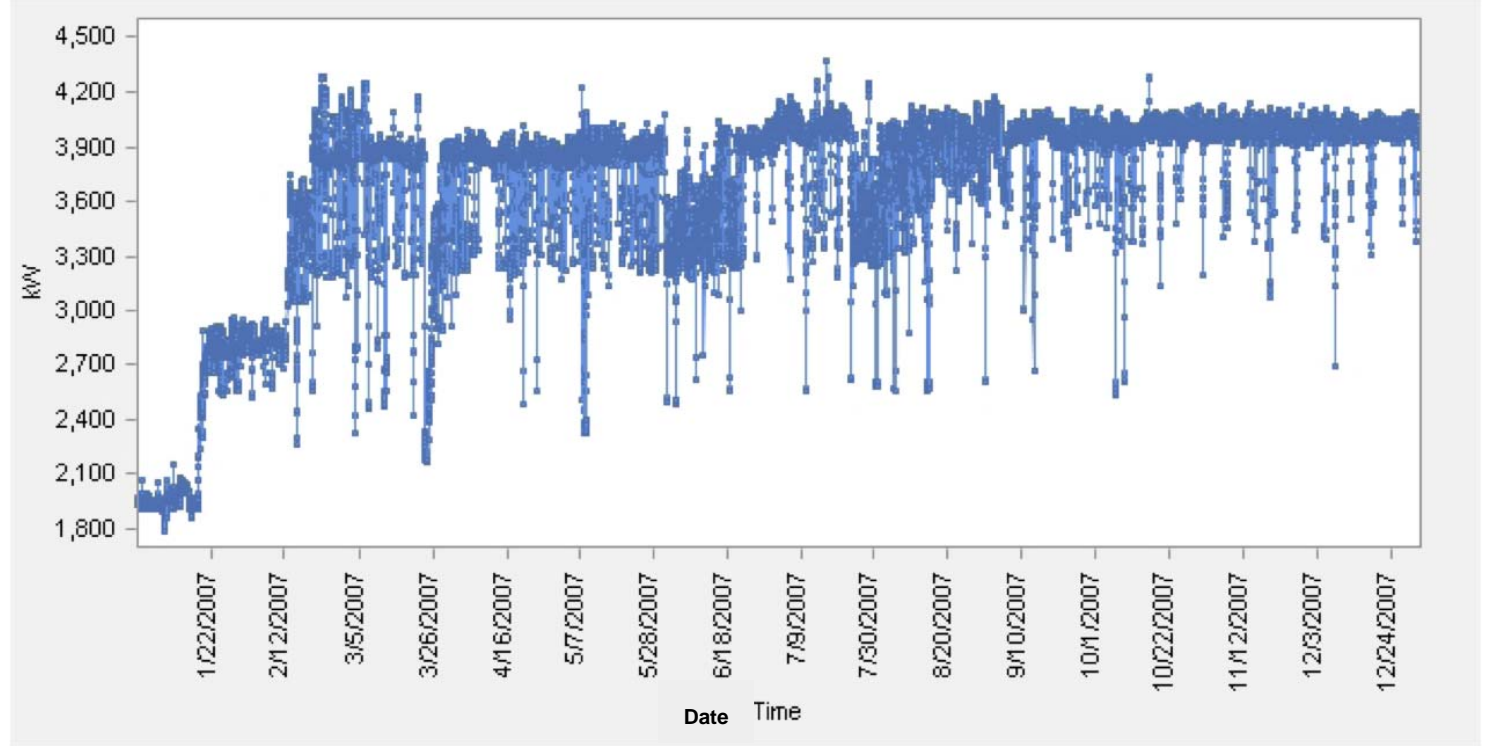

Figure 23. Steep Rise in Data Center 5 Load in 2007

Figure 24 below illustrates an opposite impact from that of Figure 23 above. Here Data Center 5 likely installed energy efficient IT equipment (possibly from a funding cycle upgrade or 
business policies put in place to reduce energy load) and/or implemented additional measures that lowered energy use by about $25 \%$ then continued to be flat over the rest of year.

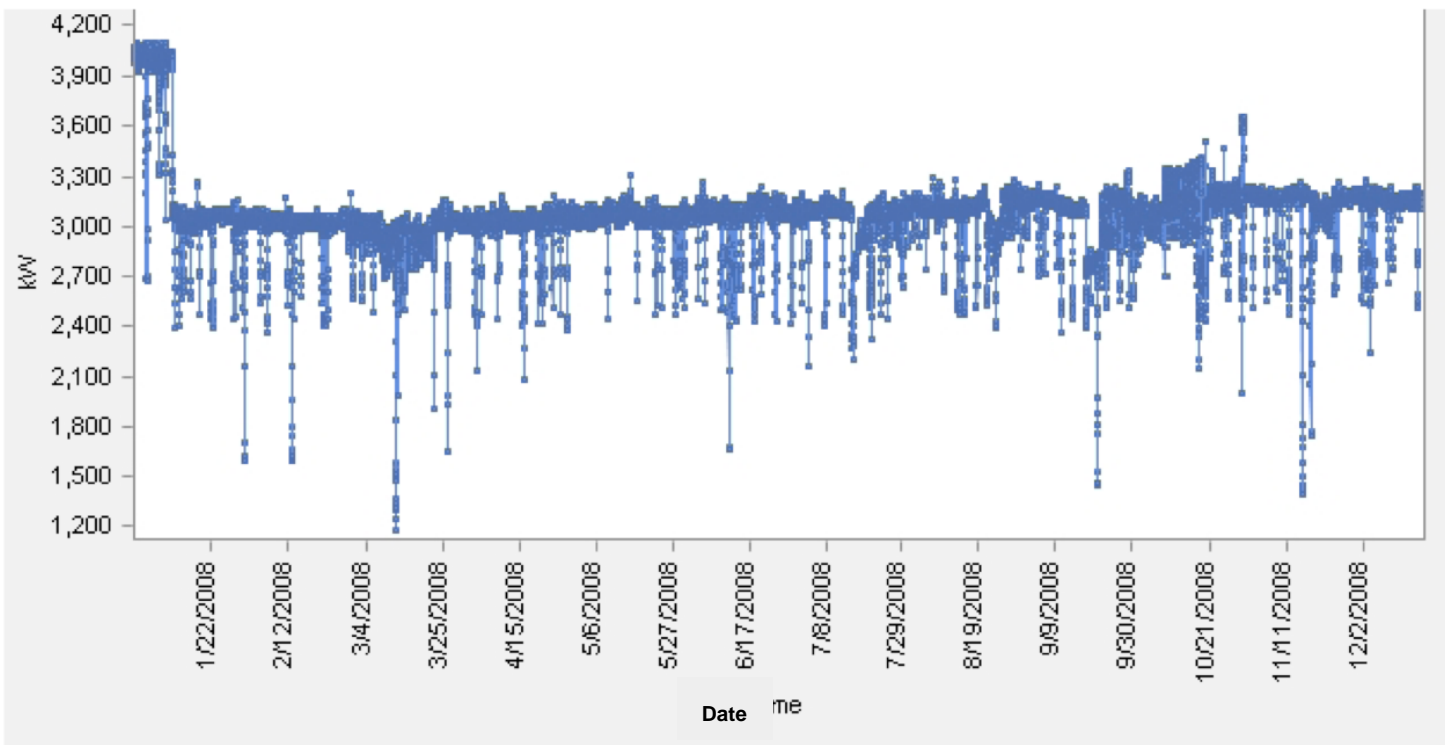

Figure 24. Decline in Data Center 5 Load in 2008

Figures 25 and 26 show negligible load deviations for 2008 summer (May 1-October 31) and winter (November 1-April 30) days, excluding weekends and holidays. During these periods, Data Center 5 was undergoing tests, which could explain the few large variations. For the most part, variation in the electrical load is mostly minimal.

CA Data Center 5, Summer/2008

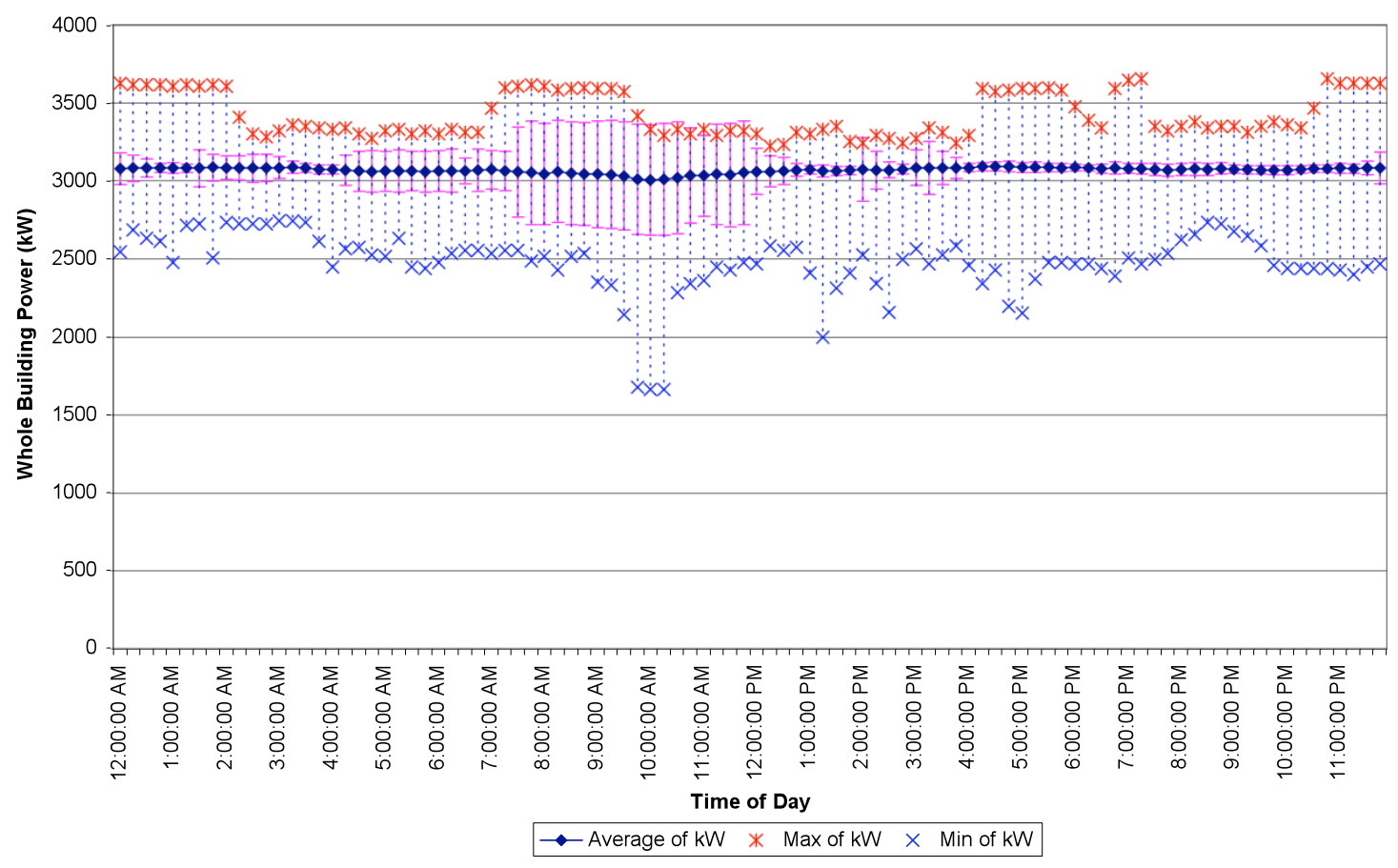

Figure 25. Data Center 5 Load for 2008 Summer Days 
CA Data Center 5, Winter/2008

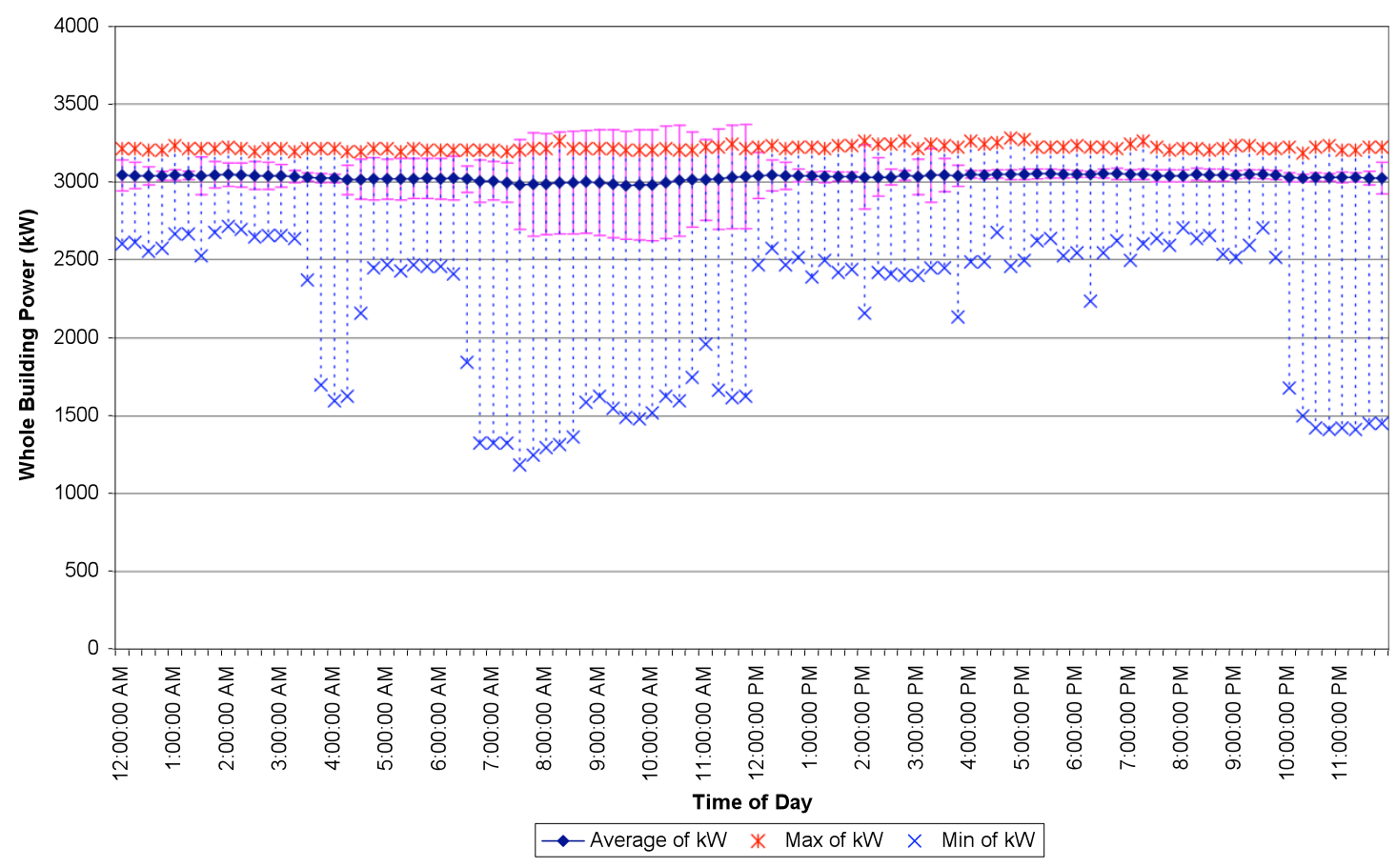

Figure 26. Data Center 5 Load for 2008 Winter Days 


\section{Appendix C. EPA Energy Efficiency Scenarios and Data Center Designs and Technologies}

This appendix, in reference to section 4.0, details some EPA energy efficiency scenarios, designs, and technologies for continuous energy management. These include hot/cold aisle design, Virtualization and next-generation technologies and systems.

\section{EPA Energy Efficiency Implementation Scenarios}

The current EPA guidelines for energy efficiency scenarios that formed the basis for evaluating DR strategies in the main report are detailed in Table 12 (EPA 2007).

\section{Table 12. EPA Scenarios and IT and Site Infrastructure Efficiency Measures}

\begin{tabular}{|c|c|c|}
\hline & \multicolumn{2}{|c|}{ Data Center Subsystem } \\
\hline Scenario & IT Equipment & Site Infrastructure (Power and Cooling) \\
\hline $\begin{array}{l}\text { Improved } \\
\text { operation }\end{array}$ & $\begin{array}{l}\text { - } \begin{array}{l}\text { Continue current trends for server } \\
\text { consolidation }\end{array} \\
\text { - Eliminate unused servers (e.g., legacy } \\
\text { applications) } \\
\text { - Adopt "energy-efficient" servers to } \\
\text { modest level } \\
\text { - Enable power management on } 100 \% \text { of } \\
\text { applicable servers } \\
\text { - Assume modest decline in energy use of } \\
\text { enterprise storage equipment }\end{array}$ & $\begin{array}{l}30 \% \text { improvement in infrastructure energy } \\
\text { efficiency from improved airflow management }\end{array}$ \\
\hline $\begin{array}{l}\text { Best } \\
\text { practice }\end{array}$ & $\begin{array}{l}\text { All measures in "Improved operation" } \\
\text { scenario, plus: } \\
\text { - Consolidate servers to moderate extent } \\
\text { - Aggressively adopt "energy-efficient" } \\
\text { servers } \\
\text { - Assume moderate storage consolidation }\end{array}$ & $\begin{array}{l}\text { Up to } 70 \% \text { improvement in infrastructure energy } \\
\text { efficiency from all measures in "Improved } \\
\text { operation" scenario, plus: } \\
\text { - improved transformers and uninterruptible } \\
\text { power supplies } \\
\text { - improved efficiency chillers, fans, and } \\
\text { pumps } \\
\text { - free cooling }\end{array}$ \\
\hline $\begin{array}{l}\text { State-of-the- } \\
\text { art }\end{array}$ & $\begin{array}{l}\text { All measures in "Best practice" scenario, plus: } \\
\text { - Aggressively consolidate servers } \\
\text { - Aggressively consolidate storage } \\
\text { - Enable power management at data center } \\
\text { level of applications, servers, and } \\
\text { equipment for networking and storage }\end{array}$ & $\begin{array}{l}\text { Up to } 80 \% \text { improvement in infrastructure energy } \\
\text { efficiency, due to all measures in "Best practice" } \\
\text { scenario, plus: } \\
\text { - direct liquid cooling } \\
\text { - combined heat and power }\end{array}$ \\
\hline
\end{tabular}

Note: These measures should be considered illustrative of efficiency opportunities in a typical data center. Some measures may only be applicable in new or expansion data centers or may be infeasible for a given data center because of local constraints. Selection of efficiency measures for a particular facility should be based on a sitespecific review.

\section{Hot/Cold Aisle Layout, Aisle Lids, and End Caps}

Data center design, particularly the layout of server racks, can have a significant impact on the amount of cooling energy required. One design technique is to arrange server racks face to face, 
with either floor or ceiling cooling, to create a cold aisle, and back to back to create a hot aisle, which returns warm air to the CRAH or CRAC (Sullivan 2006).

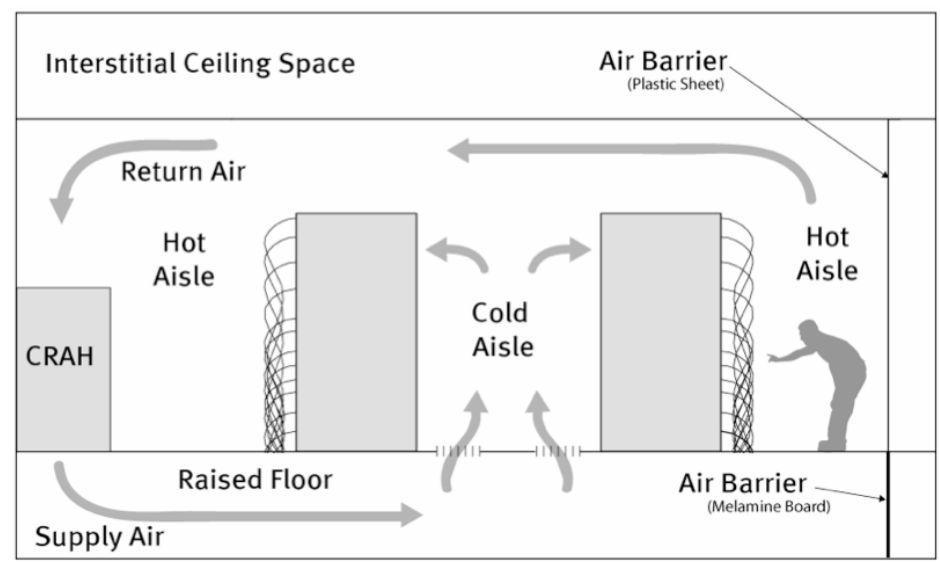

Figure 27. Hot/Cold Aisle Layout

Source: LBNL and Rumsey Engineers 2006.

As shown in Figure 28, the energy efficiency of a hot and cold aisle layout can be enhanced by installing aisle lids and end caps to prevent supply and return air from mixing. Aisle lids may be wood or plastic barriers that prevent return airflow along the ceiling from infiltrating the cold aisle. End caps are plastic sheeting or doors that prevent warm air from flowing around the server racks from a hot aisle to a cold aisle. Increasing the temperature differential between supply and return air flows improves the heat transfer capacity of the CRAH units. With a homogenous cold aisle temperature, it may be possible to raise the temperature of the supply air flow and remain within the ASHRAE recommended range.

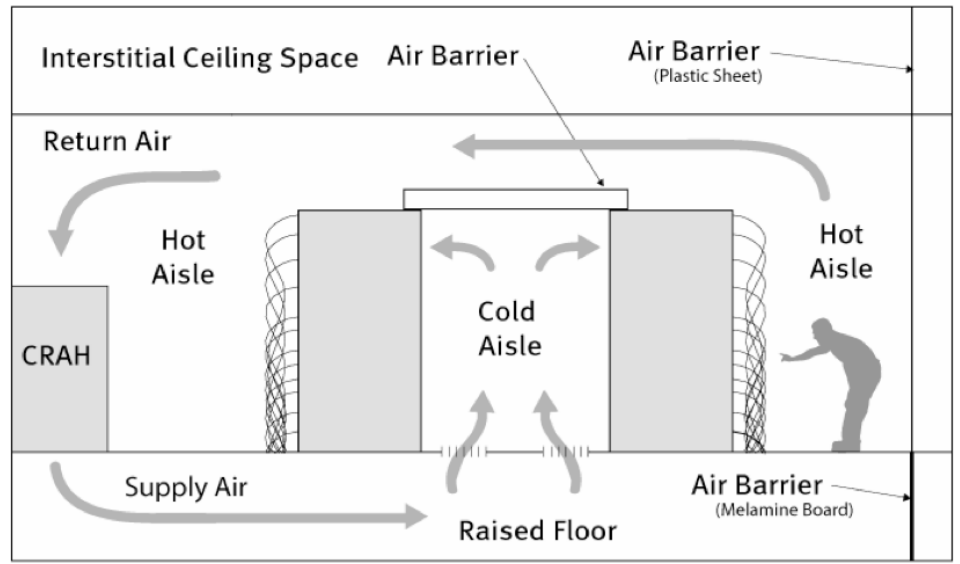

Figure 28. Hot/Cold Aisle with Aisle Lid and End Cap

Source: LBNL and Rumsey Engineers 2007.

In a traditional hot and cold aisle configuration, mixing of supply and return air streams often leads to higher intake air temperatures for servers in the upper reaches of racks. As these conditions may shorten server lifetimes, an additional benefit of hot and cold air separation may be extended server lifetime (LBNL and Rumsey Engineers 2007). 


\section{IT Infrastructure Virtualization Technologies References}

\section{Server Virtualization Technologies}

Server virtualization technologies present a virtual view of hardware to an operating system to allow the creation of virtual machines that share the same physical server in isolation from each other. Virtualization can be used to improve data center performance by consolidating servers, optimizing development and testing, ensuring high availability, and providing for disaster recovery and capacity management. Virtualization technologies are already available and have been demonstrated to achieve PSRR of 3:1 to 2.1:1, matching the EPA's best practice efficiency levels (Silicon Valley Leadership Group and Accenture 2008). Higher PSSR values may be achievable for DR events.

Typically the resource utilization of servers in data center is $15 \%$ to $20 \%$, which means there is a significant opportunity for energy savings from using server virtualization technologies for consolidation. Figure 29 shows that servers running with low utilization rates can be consolidated to fewer servers, based on operational and business policies, using a virtualization technology layer to reduce energy costs and also permanently retire unused servers.

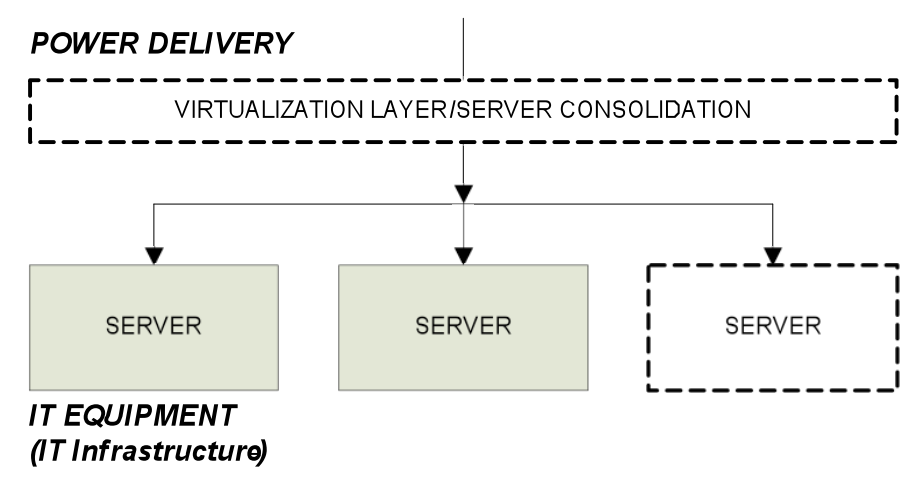

\section{Figure 29. Server Consolidation Using Virtualization Technologies}

\section{$\underline{\text { Storage Virtualization Technologies }}$}

Data center storage technologies have evolved from SANs in which data from computing storage resources are accessed via a network, and persistent data are part of transactional storage. Typically, $37 \%$ to $40 \%$ of equipment energy use is driven by storage requirements, and this percentage is growing exponentially (Copan Systems 2008). Using storage virtualization technologies, servers within data centers can access SANs independent of platform, proprietary technologies, and areas where data is stored. This enables effective consolidation of storage disks, improved storage density, lowered transactional storage, and subsequent reduction in energy use.

Figure 30 shows an example of a storage virtualization technology layer involving low-density storage disks consolidated into fewer high-density storage disks, achieving a better PSRR. 


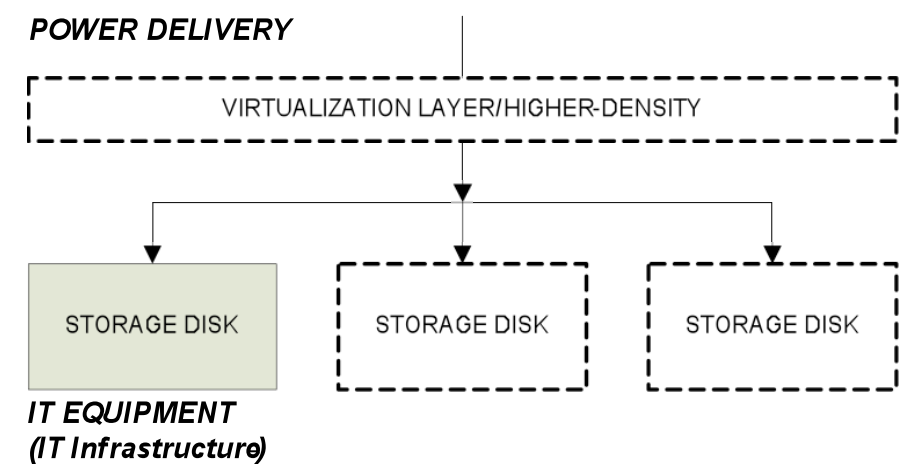

\section{Figure 30. Storage Consolidation Using Virtualization Technologies}

\section{Network Virtualization Technologies}

Network virtualization technologies have recently evolved and matured significantly, reducing data center infrastructure and energy costs through efficient use of both hardware and software resources via a distributed network (also called as cloud) rather than physically located in one building. The technology allows servers and networking devices to share resources (e.g., applications, storage devices, etc.) and processing power, thus enabling data center clients (e.g., desktop computers, servers, mobile devices, etc.) to effectively use the computing and operations infrastructure and reduce energy costs while maintaining the SLAs.

As shown in Figure 31 below, networking hardware running different applications and storage could be virtualized into a single network node, at a same facility or over a distributed network, which is subsequently accessed by networked clients. The effective consolidation of network equipment and input-output would allow deployment of more applications on a common infrastructure with less networking equipment that eventually would achieve better PSRR.

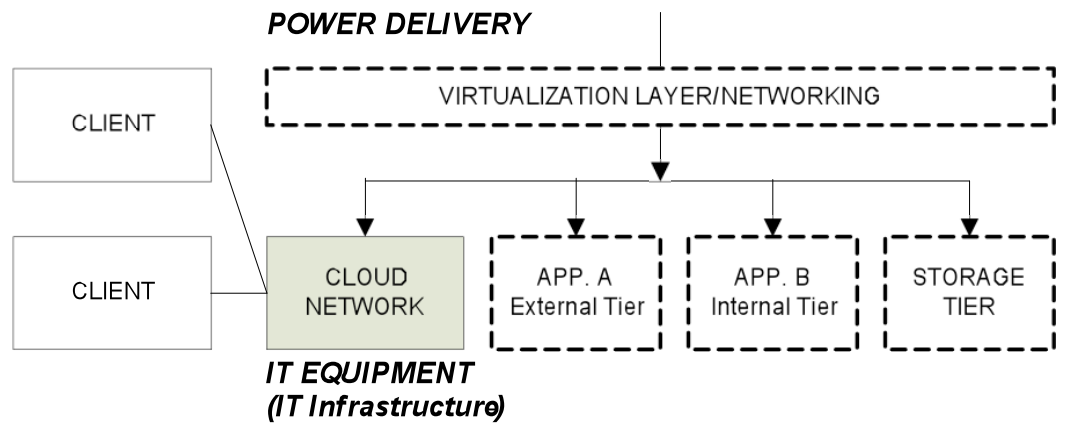

Figure 31. Network Consolidation Using Virtualization Technologies

\section{Next Generation Controls Systems and Technologies}

Several types of servers in the new generation of 64-bit server hardware include virtualizationaware processors. Virtualization-aware processors can manage some memory- and hardwaresharing functions that would otherwise be left to the server's virtualization management 
software (Microsoft 2008). By leveraging virtualization-aware processors, data centers may be able to expand and improve the performance of their virtualization efforts.

\section{Modular Data Centers}

In the past, most data centers have been individually designed, at significant cost. Several options are now available for modular data centers (or modular computer rooms), offering predesigned, standardized layouts of server racks and HVAC infrastructure that can be relatively quickly installed to replace an existing outdated data center or to expand capacity. Modular data center designs that are currently available incorporate many best practices or state-of-theart IT equipment and infrastructure, including water cooling and virtualization compatibility. Modular data centers are often a low-cost solution to data center renovation or expansion (Sun Modular Data Center 2008).

These modular data centers each typically hold 1,000 to 2,000 servers and come in different forms, such as Enterprise Modular Data Centers and other factory formats being pushed by the industry. It is likely that data center industry expansion will trend toward the use of back-up data centers constructed from these low-cost designs and used for storage and disaster recovery needs; these back-up facilities could be installed independent of data center and office location and could also be used for load migration for DR.

\section{Cloud Computing}

Cloud computing is a form of connecting distributed networks using virtualization or similar technology and in most cases "cloud" refers to the Internet. Cloud computing is an emerging business model for data centers and other companies and is increasingly being used by facilities as an alternative to owning and controlling their own software. Although it is likely that companies will continue owning software for various reasons (security, privacy, compliance with regulations, data control, intellectual property concerns, etc.), ease of technology use, savings, minimal initial capital investment, and reduced maintenance costs are helping fuel cloud computing popularity. Use of cloud computing will increase the need for more data centers as the equipment will be physically distributed across networked places. 
APC-6 


\section{Appendix D. Analysis of DR Strategies Using Case Studies}

This appendix, in reference to section 5.0, details additional analysis of data center DR strategies using case studies and technologies for water or air-side economizers, power delivery systems, UPS bypass, and back-up generators. In particular, the case studies include strategies to raise temperature setpoints and server consolidation using virtualization technologies. The EPA energy efficiency scenarios from Appendix $C$ is used as a guide to recommend some potential DR strategies and examples for data centers that are likely using any of the scenarios.

\section{Case Study Analysis of Two Data Center DR Strategies}

Understanding DR strategies and their performance is critical in determining the opportunities for facility participation. LBNL examined actual DR participation data from one mixed-use data center and summary of results for a proof-of-concept virtualization technology. These studies are indicative of strategies that are applicable to IT and site infrastructure and are not included for the purposes of performance evaluation. LBNL examined the following key end-use strategies using field tests:

1. Raise supply air and data center zone temperature setpoints to reduce cooling loads

2. Use virtualization technologies to consolidate servers and reduce equipment energy use.

\section{Demand Response Strategy to Raise Temperature Setpoints}

A mixed-use data center, Network Appliance (NetApp), participated in two PG\&E localized DR events from 12-8 p.m. on May 15 and 16, 2008 (two of the hottest days in May) and one commercial DR test event from 2-6 p.m. on July 9, 2008. Analysis of the DR data and performance, exclusive of office spaces, shows that raising supply-air and data center zone temperature setpoints within industry recommended ranges is possible and can be used with Open Auto-DR. Due to the lack of sub-metering and availability of data, the estimates of DR load reductions of data center and office spaces separately was not possible.

\section{$\underline{\text { Analysis Results }}$}

Table 13 summarizes data center DR strategies for both HVAC supply-air and zone temperature setpoints and lighting end uses. The total area for the eight buildings that participated in DR, including the data center, offices, and common spaces, was $1,113,740 \mathrm{ft}^{2}$. The data center is less than $10 \%$ of the total area $\left(101,355 \mathrm{fFt}^{2}\right)$.

Table 13. Summary of NetApp DR Case Study for End-Use Strategies

\begin{tabular}{|c|l|l|l|l|}
\hline End-Use Strategies & DR Operation & $\mathbf{2 0 0 6}$ (Temperature in F) & $\mathbf{2 0 0 7}$ (Temperature in F) & 2008 (Temperature in F) \\
\hline \multirow{4}{*}{ Supply-Air Setpoint } & Normal Operation & 52 & 59 & 70 \\
\cline { 2 - 6 } & DR Operation & 62 & 64 & NA \\
\cline { 2 - 6 } & Note & Manual demand response & Auto-demand response & Auto? \\
\hline \multirow{5}{*}{ Zone Setpoint } & Normal Operation & 57 & 64 & 75 \\
\cline { 2 - 6 } & DR Operation & 67 & 69 & 78 \\
\cline { 2 - 5 } & Note & Delta of 5 Deg. F from SA & Delta of 5 Deg. F from SA & Delta of 5 Deg. F from SA \\
\hline \multirow{5}{*}{ Lighting } & Normal Operation & $100 \%$ & $100 \%$ & $100 \%$ \\
\cline { 2 - 5 } & DR Operation & & & $50 \%$ \\
\cline { 2 - 5 } & Note & & & Programmed to be off \\
\hline
\end{tabular}




\begin{tabular}{|c|l|l|l|}
\multirow{3}{*}{ Chilled water } & Normal Operation & & $42^{*} \mathrm{~F} \%$ \\
\cline { 2 - 4 } & DR Operation & & $46^{*} \mathrm{~F} \%$ \\
\hline & Note & & \\
\hline \multirow{3}{*}{$\begin{array}{c}\text { DR Strategies } \\
\text { Summary }\end{array}$} & $\begin{array}{l}\text { 1. Space HVAC setpoints are raised to } 78^{*} \mathrm{~F} \text { from } 75^{*} \mathrm{~F} . \\
\text { 2. Supply air for remote terminal and air handling units for general buildings are reset to } 62^{*} \mathrm{~F} \text { from } 55-60^{*} \mathrm{~F} . \\
\text { 3. } 50 \% \text { of lights are turned off (and kept off by programming). } \\
\text { 4. Chilled water setpoints are reset to } 46^{*} \mathrm{~F} \text { from } 42^{*} \mathrm{~F} .\end{array}$ \\
\hline
\end{tabular}

Figures 33 and 34 show the DR load shed results for two localized test DR events from 12-8 p.m. for May 15 and 16, 2008 and one commercial DR test event from 2-6 p.m. on July 9, 2008. These results calculate DR performance using Demand Bidding Program (DBP) baseline with morning adjustment factor (DBP-MA) for both localized events and for the commercial test DR event. Because office space energy use is weather sensitive in this mixed-use data center, the DR load reduction estimate for WBP is improved significantly using the DBP-MA baseline calculation method (Coughlin et al. 2008). The figures also validate that mixed-use data centers are sensitive to weather. The above results are summarized in figures below:

- For May 15 and 16, 2008 localized events; average peak load for the 8-hour period was 8,979 and $9,035 \mathrm{~kW}$.

- For July 9, 2008 commercial Auto-DR event, average peak load for the 8-hour period was $8,191 \mathrm{~kW}$.

- Due to the high concentration of office space, the loads are weather sensitive.

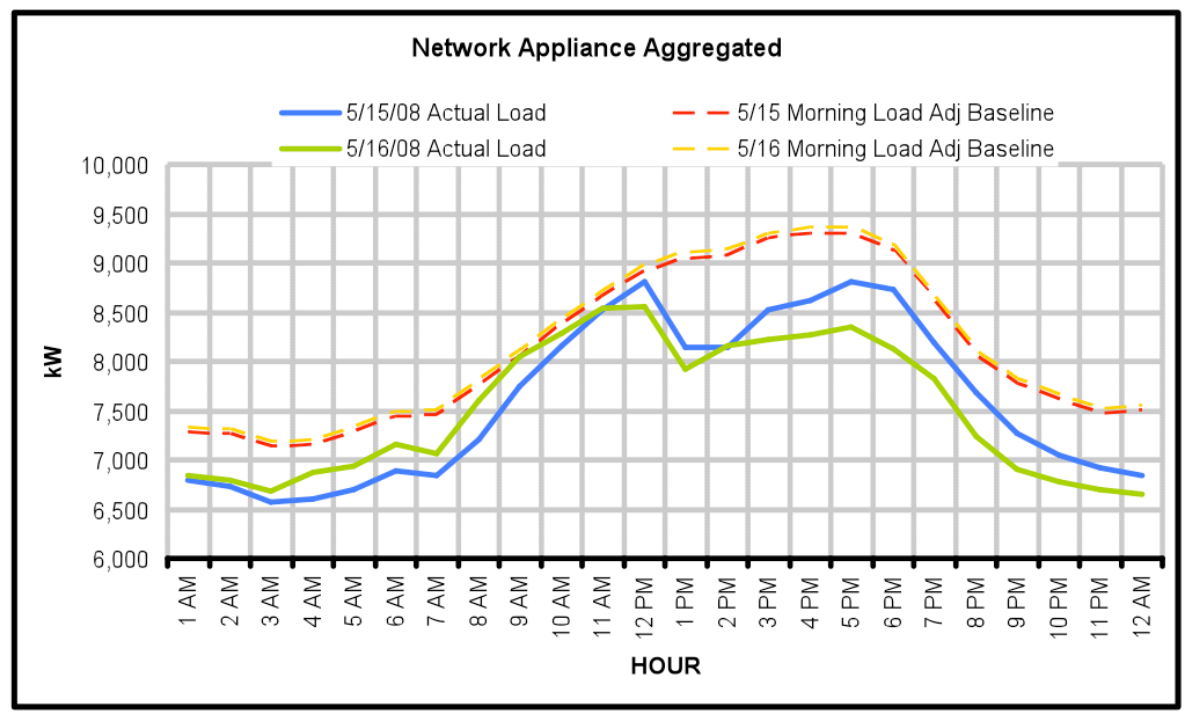

Figure 32. Aggregated Load Results from NetApp's May 15 and 16, 2008 Localized Event 


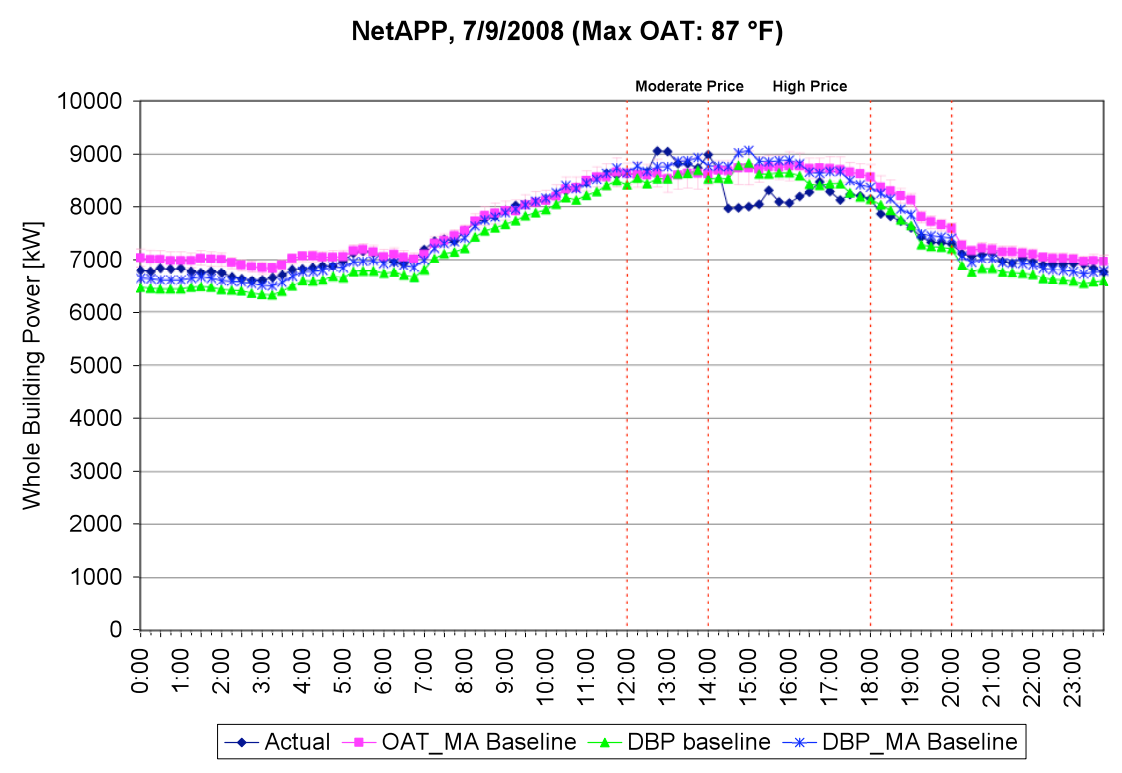

Figure 33. Aggregated Load Results from NetApp's Test DR Event on July 9,2008

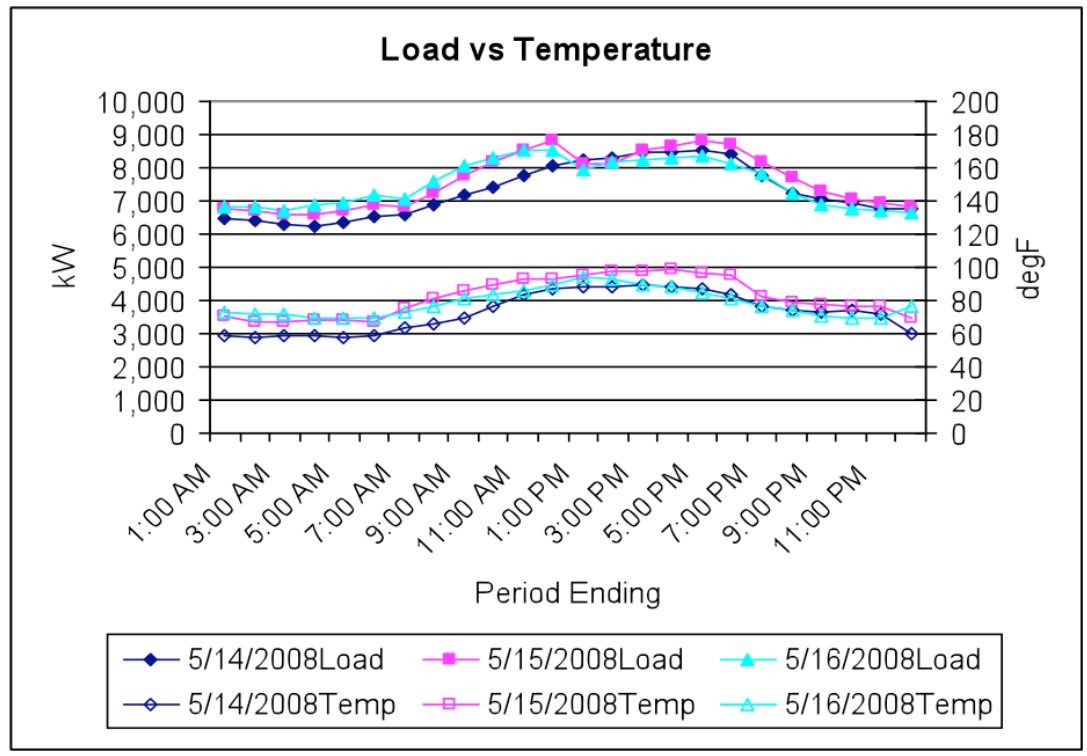

Figure 34. May 2008 Data Indicative of Weather Sensitivity for NetApp

Tables 14 and 15 summarize the two localized DR events and one commercial DR test event. These results use conventional 3/10 DBP baseline (DBP), DBP baseline with morning adjustment factor (DBP-MA), and outside air-temperature with morning adjustment baseline (OAT-MA). The DR baselines are detailed because, they were used for performance measurement and verification within PG\&E. Because the mixed-use data center's office space energy use is weather sensitive, the estimate of DR load reduction for WBP is improved significantly using DBP-MA; thus, this is recommended for use over other baselines (Coughlin, et al. 2008). 
- With DBP-MA, the DR savings for two 8-hour localized events averaged $452 \mathrm{~kW}$ and 847 $\mathrm{kW}$. This is 5\% and 10\% reduction from peak load.

- With DBP-MA, the DR savings for 4-hour commercial Auto-demand response event averaged $672 \mathrm{~kW}$ or $6 \%$ from peak load.

Table 14. NetApp DR Results Summary Table for Localized and Auto-DR Event (kW)

\begin{tabular}{|c|c|c|c|c|c|c|c|c|c|c|}
\hline & & \multicolumn{9}{|c|}{ Actual Load Shed (kW) } \\
\hline & & $\begin{array}{c}12 \mathrm{pm}- \\
1 \mathrm{pm}\end{array}$ & $\begin{array}{l}1 \mathrm{pm}- \\
2 \mathrm{pm}\end{array}$ & $\begin{array}{l}2 \mathrm{pm}- \\
3 \mathrm{pm}\end{array}$ & $\begin{array}{l}3 \mathrm{pm}- \\
4 \mathrm{pm}\end{array}$ & $\begin{array}{l}4 \mathrm{pm}- \\
5 \mathrm{pm}\end{array}$ & $\begin{array}{l}5 \mathrm{pm}- \\
6 \mathrm{pm}\end{array}$ & $\begin{array}{l}6 \mathrm{pm}- \\
7 \mathrm{pm}\end{array}$ & $\begin{array}{l}7 \mathrm{pm}- \\
8 \mathrm{pm}\end{array}$ & Average \\
\hline \multirow{3}{*}{$5 / 15 / 2008$} & DBP Baseline & -315 & -261 & -492 & -542 & -745 & -795 & -696 & -689 & -567 \\
\hline & DBP MA Baseline & 710 & 771 & 558 & 515 & 312 & 242 & 284 & 226 & 452 \\
\hline & OAT MA Baseline & 569 & 608 & 381 & 481 & 392 & 559 & 320 & 84 & 424 \\
\hline \multirow{3}{*}{$5 / 16 / 2008$} & DBP Baseline & -102 & -268 & -193 & -202 & -275 & -199 & -336 & -238 & -227 \\
\hline & DBP MA Baseline & 978 & 819 & 914 & 912 & 838 & 895 & 697 & 726 & 847 \\
\hline & OAT MA Baseline & 998 & 746 & 642 & 614 & 534 & 668 & 510 & 560 & 659 \\
\hline \multirow{3}{*}{$7 / 9 / 2008$} & DBP Baseline & & & 626 & 635 & 261 & 161 & & & 421 \\
\hline & DBP MA Baseline & & & 883 & 891 & 512 & 405 & & & 672 \\
\hline & OAT MA Baseline & & & 544 & 615 & 433 & 456 & & & 512 \\
\hline
\end{tabular}

Table 15. NetApp demand response Results Summary Table for Localized and Autodemand response Event (\%)

\begin{tabular}{|c|c|c|c|c|c|c|c|c|c|c|}
\hline & \multicolumn{9}{|c|}{ Actual Load Shed (\%) } \\
\hline & & $\begin{array}{l}12 \mathrm{pm}- \\
1 \mathrm{pm}\end{array}$ & $\begin{array}{l}1 \mathrm{pm}- \\
2 \mathrm{pm}\end{array}$ & $\begin{array}{l}2 \mathrm{pm}- \\
3 \mathrm{pm}\end{array}$ & $\begin{array}{l}3 p m- \\
4 p m\end{array}$ & $\begin{array}{l}4 \mathrm{pm}- \\
5 \mathrm{pm}\end{array}$ & $\begin{array}{l}5 \mathrm{pm}- \\
6 \mathrm{pm}\end{array}$ & $\begin{array}{l}6 \mathrm{pm}- \\
7 \mathrm{pm}\end{array}$ & $\begin{array}{l}7 \mathrm{pm}- \\
8 \mathrm{pm}\end{array}$ & Average \\
\hline \multirow{3}{*}{$5 / 15 / 2008$} & DBP Baseline & $-4 \%$ & $-3 \%$ & $-6 \%$ & $-7 \%$ & $-9 \%$ & $-10 \%$ & $-9 \%$ & $-10 \%$ & $-7 \%$ \\
\hline & DBP MA Baseline & $8 \%$ & $9 \%$ & $6 \%$ & $6 \%$ & $3 \%$ & $3 \%$ & $3 \%$ & $3 \%$ & $5 \%$ \\
\hline & OAT MA Baseline & $7 \%$ & $7 \%$ & $4 \%$ & $5 \%$ & $4 \%$ & $6 \%$ & $4 \%$ & $1 \%$ & $5 \%$ \\
\hline \multirow{3}{*}{$5 / 16 / 2008$} & DBP Baseline & $-1 \%$ & $-3 \%$ & $-2 \%$ & $-3 \%$ & $-3 \%$ & $-3 \%$ & $-4 \%$ & $-3 \%$ & $-3 \%$ \\
\hline & DBP MA Baseline & $11 \%$ & $9 \%$ & $10 \%$ & $10 \%$ & $9 \%$ & $10 \%$ & $8 \%$ & $9 \%$ & $10 \%$ \\
\hline & OAT MA Baseline & $11 \%$ & $8 \%$ & $7 \%$ & $7 \%$ & $6 \%$ & $8 \%$ & $6 \%$ & $7 \%$ & $8 \%$ \\
\hline \multirow{3}{*}{$7 / 9 / 2008$} & DBP Baseline & & & $6 \%$ & $6 \%$ & $2 \%$ & $1 \%$ & & & $4 \%$ \\
\hline & DBP MA Baseline & & & $8 \%$ & $8 \%$ & $4 \%$ & $4 \%$ & & & $6 \%$ \\
\hline & OAT MA Baseline & & & $6 \%$ & $7 \%$ & $5 \%$ & $5 \%$ & & & $6 \%$ \\
\hline
\end{tabular}




\section{Demand Response Strategy with Virtualization}

A proof-of-concept study in 2008 involving the mixed-use data center, NetApp, showed that virtualization technologies can be used for server consolidation without any equipment failures.

\section{Preliminary Analysis Results}

The results also show significant energy savings from server energy use. Because this was a proof-of-concept study, the specific details of this study are not public. The results are summarized as follows:

- Diverse production environment and multiple groups could be used for server consolidation.

- Servers have a potential of $26 \%$ idle time opportunity to power off for significant energy savings.

- Graceful power-on and power-off are possible using virtualization policies for usage patterns, environmental conditions, user input, etc.

While server virtualization has matured and been tested, further analysis and advancements in storage and network virtualization are necessary before they can be used for DR.

\section{Additional Analysis for Water- or Air-Side Economizers}

Concerns are sometimes raised about increases in indoor temperature, humidity, and particle concentration when air economizers are used. However, a study conducted by Intel, in which IT equipment was subjected to free cooling using outside air as hot as 90 degrees $\mathrm{F}$, concluded that at these temperatures, data centers can rely on air-side economizers $91 \%$ of time with no equipment failure and save significant cooling energy (Samson 2008). Although particle concentrations increase when economizer vents are open, these concentrations decrease rapidly once vents are closed. Because outside air is only admitted some of the time, air economizers can maintain annual average particle concentration and humidity levels that meet ASHRAE standards. However, concerns remain regarding acceptable average particle concentrations on a daily or hourly basis. An issue is, if water-side economizers is not properly designed, it may result in higher wet-bulb temperatures that can increase loads on cooling towers or raise cooling water temperatures.

\section{DR Opportunities Using Power Delivery and Back-Up Storage Systems Technologies}

Power delivery systems constitute about $11 \%$ of total data center load and comprise UPSs and transformers. Most static UPSs have about 5\% to 14\% losses at near full load and higher losses at reduced loads, which results in efficiency of $86 \%$ to $95 \%$ near full load (LBNL 2005). UPSs can be based on battery banks, rotary machines, fuel cells, or other technologies, and average load is often $60 \%$ to $80 \%$. Flywheel-based units typically have $2 \%$ to $4 \%$ losses and are often located outside without cooling or heating requirements. Because of redundant units, each UPS operates at a sub-optimal load and lowered efficiency. Transformers tend to use about $2 \%$ to $4 \%$ of their load through heat losses within the data center, such as with a power distribution unit.

It is possible that redundant UPSs and transformers could be powered down during a DR event to curtail their losses, which could improve efficiency by increasing the load of the in-use units. However, transferring load from one UPS or transformer to another is a manual task with risk of error or malfunction. 


\section{Use UPS Bypass Technology}

Nearly all hardware in data centers of any size is powered through UPSs. These systems will vary in size from a unit one-rack tall serving a few servers in a "telecom closet/ data center" to multi-unit systems combined to serve many MWs of IT load. UPSs use a variety of battery systems (static UPS) or flywheels for energy storage. Static UPSs are often sized to provide five to 30 minutes of energy storage at full load whereas flywheel-based systems provide from two to 30 seconds, just long enough for back-up generators to start up and provide power.

UPS power bypass technology could be activated for a DR event. Although many data center operators are reluctant to use this technology as an energy-efficiency measure due to reliability concerns (The Green Grid 2008), it is possible to use it for at least two hours in a DR event.

Because each outage on a static UPS causes battery wear, and battery replacements are costly, some data center managers will be concerned about wear on their UPS systems from DR events. Managers of data centers with flywheel-based UPSs don't have this concern as each outage has no material affect on maintenance costs, but they will have a much greater concern for the UPS and generator systems properly starting and providing power to the data center, as there would be limited time to go back onto utility power should the systems not work properly.

Because all hardware, power strips and power distribution units/transformers are connected downstream of the UPS, a utility outage or DR event has no effect on this equipment unless the UPS fails. Most of the UPSs use double conversion circuitry without any bypass because of fear of voltage fluctuations within equipment. Studies have indicated that using this bypass, shown in Figure 32, for shorter durations causes no impact to equipment (The Green Grid 2008).

Subcomponents with conversion losses are shown in a darker shade. Use of bypass technology and avoiding double conversion for a DR event can increase the UPS efficiency by 5\% (LBNL 2005).

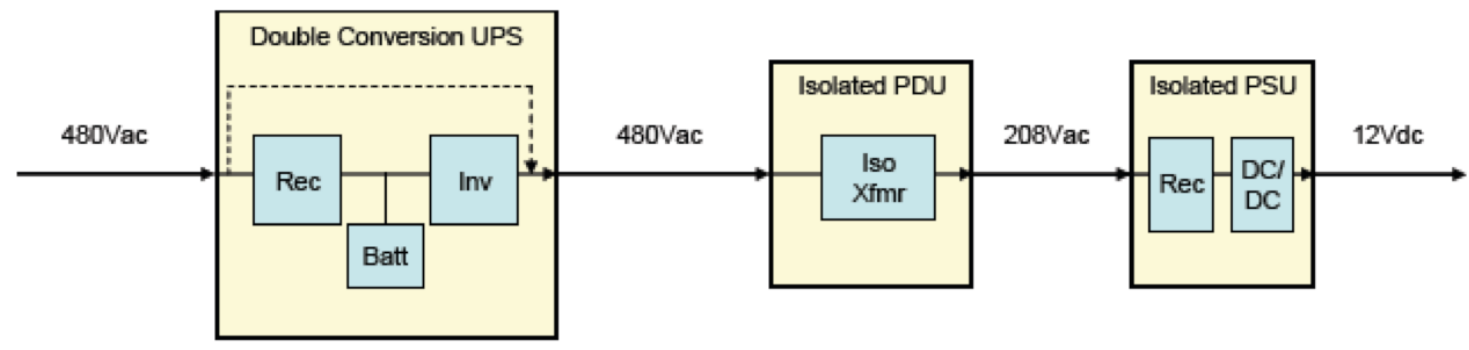

Figure 35. Typical UPS Bypass Configuration and Conversion Components

\section{Back-Up Generators}

Nearly all sizable data centers employ generators to power UPS, lighting and HVAC equipment during power outages. Back-up generators are usually configured to start following a utility outage or voltage fluctuation two to four seconds in duration or greater than a $10 \%$ swing in voltage or frequency. They are usually able to serve load within 15 seconds, often 12 seconds and even as little as two seconds for some combined flywheel-UPS units. In nearly all cases, the utility breaker is opened before back-up generators provide power (open transition) so that back-up power is not sent to the utility grid, and utility grid instability and phase issues do not 
affect them. Nearly all back-up generators are fueled by diesel, which means that, in California, most air districts will not allow them to run for more than 50 hours per year or for DR activities. Most data center operators are comfortable with having some reserve time on their 50-hour limit to participate in DR events but risk a penalty or loss of their permit if they run their backup generators for DR. This is an area where significant political, legislative, and technical changes would be needed for data centers to completely disconnect from the utility for DR events. For example:

- Reducing air emissions from back-up generators would require technology advancements.

- For air districts to allow diesel back-up generators for DR events would require legislative changes.

- A small number of data centers use natural gas as an alternate or primary fuel for reciprocating or for turbine generators, and use fuel stock for hydrogen fuel cells for back-up power. These data centers might have air permits and/or meet emissions codes to allow them to operate these alternate sources of energy during DR events.

- In areas where diesel generators are allowed to run and grid security and higher energy prices are of concern, they could be used as a DR strategy and also, when possible, they could schedule regular mandatory tests with DR events.

Facilities with back-up power storage and generation, such as fuel cells, photovoltaics, or diesel generators, could participate in a DR event by temporarily switching to their back-up power source. While facilities may be apprehensive about running down their back-up power supply, it should be noted that helping to reduce demand on the electricity grid for even a few hours may significantly reduce the chance of a power shortage.

One disincentive to the use of back-up power sources during a DR event is that these power sources can be considerably more expensive than electricity prices. However, a DR event provides an ideal opportunity to conduct necessary periodic testing of back-up power to ensure that during a real emergency or blackout, everything is in working order.

\section{Summary of DR Strategies and EPA Scenarios}

Table 16 summarizes key DR strategies that may apply to Open Auto-DR. These conceptual strategies are based on EPA's three operating scenarios for data center energy efficiency: "improved operation," "best practice," and "state-of-the art." This includes strategies for IT and site infrastructure and load characterization. 
Table 16. Demand Response and Open Auto-DR Opportunities and Strategies Summary

\begin{tabular}{|c|c|c|c|}
\hline $\begin{array}{l}\text { All Data } \\
\text { Center Load } \\
\text { Types }\end{array}$ & $\begin{array}{l}\text { Operating at EPA } \\
\text { "Current Operation" Scenario }\end{array}$ & $\begin{array}{l}\text { Operating at EPA } \\
\text { "Best Practice Operation" } \\
\text { Scenario }\end{array}$ & $\begin{array}{l}\text { Operating at EPA } \\
\text { "State-of-the-Art Operation" } \\
\text { Scenario }\end{array}$ \\
\hline \multirow{5}{*}{ Site } & $\begin{array}{l}\text { Raise temperature setpoints } \\
\text { minimally up to industry or OEM } \\
\text { recommended range, whichever is } \\
\text { higher. }\end{array}$ & $\begin{array}{l}\text { Raise temperature setpoints } \\
\text { moderately close to industry or } \\
\text { OEM recommended range, } \\
\text { whichever is higher }\end{array}$ & $\begin{array}{l}\text { Raise temperature setpoints } \\
\text { aggressively to industry or OEM } \\
\text { recommended range, whichever is } \\
\text { higher, for short duration. } \\
\end{array}$ \\
\hline & $\begin{array}{l}\text { Use bi-level switching and dimming } \\
\text { lighting controls to lower light-levels }\end{array}$ & & \\
\hline & $\begin{array}{l}\text { Use back-up storage (chilled water, } \\
\text { flow-battery, etc.) for short duration. }\end{array}$ & & \\
\hline & $\begin{array}{l}\text { Efficiently use UPS and transformers } \\
\text { and bypass technologies. }\end{array}$ & \multicolumn{2}{|c|}{$\frac{1}{u}$} \\
\hline & $\begin{array}{l}\text { Eliminate or lower humidification } \\
\text { controls. }\end{array}$ & & \\
\hline \multirow{6}{*}{$\begin{array}{c}\text { IT } \\
\text { Infrastructure }\end{array}$} & $\begin{array}{l}\text { Use virtualization for moderate server } \\
\text { consolidation as applicable. }\end{array}$ & $\begin{array}{l}\text { Use virtualization for aggressive } \\
\text { server consolidation, likely for } \\
\text { shorter duration. }\end{array}$ & \multirow{2}{*}{ r } \\
\hline & $\begin{array}{l}\text { Use virtualization for moderate storage } \\
\text { consolidation for increased storage } \\
\text { density for short duration. }\end{array}$ & $\begin{array}{l}\text { Use virtualization for aggressive } \\
\text { storage consolidation for } \\
\text { increased storage density for short } \\
\text { duration. }\end{array}$ & \\
\hline & $\begin{array}{l}\text { Use network virtualization minimally } \\
\text { for networked data centers. }\end{array}$ & $\begin{array}{l}\text { Use network virtualization } \\
\text { moderately for networked data } \\
\text { centers. }\end{array}$ & $\begin{array}{l}\text { Use network virtualization } \\
\text { aggressively for networked data } \\
\text { centers for short duration. }\end{array}$ \\
\hline & $\begin{array}{l}\text { Where applicable, shift data center } \\
\text { loads to less-constrained location. }\end{array}$ & & \\
\hline & $\begin{array}{l}\text { Where applicable, shift data center } \\
\text { IT/back-up job processing queue to } \\
\text { non-peak. }\end{array}$ & & \\
\hline & $\begin{array}{l}\text { Enable power management for } \\
\text { applications, operational IT } \\
\text { infrastructure (servers, networking and } \\
\text { storage). }\end{array}$ & & \\
\hline Office-Space† & $\begin{array}{l}\text { Raise office-space HVAC setpoints } \\
\text { moderately during office hours and } \\
\text { aggressively outside office hours. }\end{array}$ & & \\
\hline & $\begin{array}{l}\text { Lower light levels aggressively } \\
\text { outside office hours. }\end{array}$ & & \\
\hline
\end{tabular}

† Mixed-use data centers should consider all strategies in "Flat and Incremental Load" data centers, plus office space 
Below are examples of DR opportunities for data centers in each of these scenarios:

- A data center operating at the EPA “improved operation" level is unlikely to be employing server consolidation strategies. Thus, this data center could likely benefit from a wide range of possible DR strategies using virtualization technologies.

- A "best practice" data center may already be implementing practices such as server consolidation, so, to achieve noticeable energy savings during a DR event, this data center would look to other strategies, such as raising temperature setpoints and aggressively consolidating servers, storage, and networks.

- A state-of-the-art data center is likely to be energy efficient, employing a number of energy-saving strategies, so, to meaningfully reduce energy use during a DR event, this data center would need to look to more aggressive and innovative strategies such as raising temperature setpoints, using network virtualization, and eliminating humidification controls for short durations.

- For any of the operational scenarios, synergistic strategies enabling site HVAC systems to quickly respond to reduced IT infrastructure energy use and employing intelligent airflow management could amplify energy reduction. 
